\title{
Categorization and Level of Appropriateness of Waray-waray Music as Mother Tongue-Based Teaching Materials for Grades One to Three Pupils of Tacloban City
}

\author{
Marisol Conde-Abanilla \\ marisol.abanilla@lnu.edu.ph \\ Leyte Normal University, Paterno St., Tacloban City, 6500. Philippines
}

\begin{abstract}
The dearth of MTB-MLE materials for classroom use is widely felt by lower primary teachers. It is for this reason that this study produced teaching materials, by collecting and categorizing local printed songs in the vernacular to be included as MTB-MLE instructional materials for Grades 1, 2 and 3 Waray-waray speaking pupils in the DepEd, Division of Tacloban City, Philippines. The Grades One to Three teachers categorized the Winaray folk songs in terms of level of appropriateness, using a survey instrument designed for this particular study. Descriptive and correlation statistics were used to analyze and interpret the data.

Based on the results of this study it is recommended that male teachers in the academe should be given equal chances to be assigned in the primary levels. Lack of gender diversity in elementary education has a negative impact on young children.

Age should not be a prime criterion for assigning teachers to a particular grade level. For many adults, as they age, they accumulate life experiences which allow them to be confident in the teachinglearning situation.

Attendance in music related-seminar trainings and workshops is recommended as well, to lift teacher's morale and boost their confidence to teach music. Recruiting and assigning a music specialist in every district of the DepEd Tacloban City is highly recommended.

This study echoes the suggestion that since Universities that offer a music degree are limited and the tuition fee is expensive, perhaps more scholarships should be provided to those individuals who cannot afford the cost but have the music talent and skills that are perfect for a music educator.

One of the salient features and objective of the $\mathrm{K}$ to 12 program is to preserve and promote cultural identity and heritage. This is the best time for music educators to do more research on production of materials that fit the Philippine setting especially the ones which are culture-based, up-to-date and state-of-the-art educational instruction.

Hence, it is highly recommended that further studies of this kind be conducted. For one, this study can be replicated by collecting other untapped songs that are pricedly kept by musicians found somewhere else in the region. The potential to collect mother tongue-based compositions from contemporary songwriters should also be considered in future research investigation along this line.
\end{abstract}




\section{Introduction}

Government and education leaders from all over the world aspired for universal education, focusing specifically on education for children in the minority or non-dominant language communities after a series of "world conferences of Education For All (EFA)." This is based on the realization that "Education For All" will not truly be "for all" until every child from every language community has access to schooling. One of the main reasons why the EFA emphasized the ethnic minority children is because these children are often taught in a language they struggle to understand (UNESCO, 2016), (Trudel \& Young, 2016).

The United Nations Educational, Scientific and Cultural Organization (UNESCO) set in motion the program to educate children in their mother tongue. MTB-MLE refers to the use of students' mother tongue and two or more additional languages as Languages of Instruction (Lol) in schools. It is also bilingual education across multiple language communities, using their own mother tongue aside from the official language instruction of the school. In south Asia, multilingual education usually follows the first definition, learning and using multiple languages in school. In some countries, MTB-MLE includes four languages-the students' mother tongue or first language, a regional language, the national language and an international language (Lartec, 2015).

The reports of UNESCO, on the implementation of the MTB-MLE, indicate that some countries were able to efficiently accomplish the MTB-MLE program while others did not (Wa-Mbaleka, 2014). In East, South and South-east Asia, the Philippines was found to be one of the least successful countries in the implementation of MTB-MLE (UNESCO, 2005).

Music education in the Philippine context has been geared toward the acquisition of musical knowledge, skills, and values. Its purpose may variably mean an area for the transfer of a culture or tradition, a curricular component in elementary and secondary education and a prescribed sequence of study in preparation for professional careers in music.

By the year 2012, a mandate from the Philippine Government was passed to refurbish the educational system of the Philippines, which is now known as the K to 12 programs. One of the salient features of the K to 12 program is DepEd Order no. 16, series of 2012 under the Republic Act No. 10533, also known as Mother Tongue-Based Multi-Lingual Education (MTB-MLE) for grades 1 to 3. The curriculum before the MTB-MLE covered by the "bilingual education" policy used Tagalog (Filipino) and English as medium of instruction. In reality, however, there are more than 180 dialects all over the country, and Tagalog is not the only dialect spoken in the Philippines. The non-Tagalog speaking children had to learn English and Tagalog in school as their second and third language. This language policy created some instructional predicaments in the past (Okabe, 2013).

The music program envisioned by the $\mathrm{K}$ to 12 curricula for every Filipino individual learner is something that will cultivate the natural creative skill, acquire competence and knowledge in one's culture, and above all honor one's Filipino cultural heritage (DepEd curriculum guide 2013). Hackett (1997) stresses that studying music contributes significantly to a child's complete education. It helps students understand their own culture and the culture of others. Language specialists, on the other hand, assert that the use of the mother tongue in the classroom is much more comfortable for pupils to use when they study a second language (Ocbian, 2015). UNESCO (2003), reported that children who are active second language learners, and fast learners compared to their peers, are those who started first to learn how to read and write in their mother tongue.

The Philippines has finally embraced the trend of MTB-MLE. It is already an approved national law in the country. Therefore, educators and curriculum designers have to face and address the challenges that the MTB-MLE will create during its implementation. The reality of teaching the mother tongue-based program showed that it demands an immense variety of skills set, many of which are not available at present. Producing contextually sensitive teaching and reading local/native materials, and how to establish a considerable amount of fluency in their language are just some of the many significant concerns of teachers 
(Cruz, 2015). Therefore, it is deemed necessary to produce new instructional materials using the local dialect since the production of instructional materials for MTB-MLE instruction is supported by DepEd Order No. 90 series of 2011 (Ocbian, Suod, Garduque, and Arimado, 2015).

In Hungary, a method for teaching music called "Kodaly method" was developed. The music subject in Hungary is taught daily, given equal importance as with mathematics, science, and language. The Kodaly method is now being used all over the four corners of the world. The target of this educational program is universal musical literacy--love of music supported by knowledge of music. One of the principal goals of the Kodaly method is to make music belong to everyone, not just the educated upper classes. This pedagogy uses a very child-centered developmental approach. It emphasizes that the musical material should be the mothertongue folksong---meaning a child's native music, the folk songs of his/her country. Before a child learns other foreign languages, a child naturally learns his mother tongue. Zoltan Kodaly believes that a child must learn first his musical mother tongue - that is the purest of the authentic folk music of his own countrybefore other music (Choksy, 1999).

Ward (2003), claims that knowing children's folk songs of one's musical heritage, is an opportunity for one to richly experience one's cultural heritage, and get to know one's ancestors entirely. Villodre (2014), likewise opined that music education in early childhood helps nurture the child's motor skills and communicative abilities, and their socio-affective relationships. The singing of songs is also another way of actual application and experience of one's culture of origin. For collected folklores and traditions to be preserved, they have to remain in daily use. Better yet, they have to be integrated for use in the classroom. The concept of folk music for pedagogical purposes is widely used all over the world. It has also served as a basis for making music syllabi (Kons, Stienback, Kivestu, 2016).

DepEd order no. 90. series of 2011 recommends the production of indigenized teaching and learning materials for the MTB-MLE. These are homegrown instructional materials using the local language to facilitate the teaching and learning process (Ocbian, 2005). The primary purpose of this study is to collect and sort out or categorize printed Waray-waray songs to be used as MTB-MLE music materials for Grades 1 to 3. This is virtually attuned to the implementation of the music curriculum of the $\mathrm{K}$ to 12 program. The Waray-waray songs utilized in this study are traditional Waray-waray songs, which means that the traditional language was used one hundred years ago (Oyzon, 2010).

\subsection{Statement of the Problem}

The Mother Tongue-Based Multi-lingual Education (MTB-MLE) music modules for Grades 1, 2 and 3 are found wanting of teaching materials or songs in the vernacular. Thus, this study has culled out materials from various sources for instructional purposes particularly for grades one, two and three learners. This research sought the help of the teachers in the Division of Tacloban City to categorize Waray-waray songs appropriate to the primary grades. Moreover, this study tried to examine how the categorization done by music teachers differs from the categorization done by the readability instrument developed for the National Network of Normal Schools (3NS) Corpora Project. It was discontinued because the 3ns readability's evaluation of the songs was different from the survey instrument developed for this particular study. Hence, this study focuses on discussing the results of the 3ns corpora readability software (see supplementary table in Appendix E). The meanings or messages carried by these songs from the perspective of the teachers were likewise determined to explain their level of appropriateness to certain grade levels.

A repertoire of some 30 songs can help pupils sing well, show high and low sounds, correctly clap and step to the beat and rhythm, and finally apply dynamics and tempo to the songs (Choksy, 1999). Along with this vein, the study also subjected at least 30 songs to a new transcription or musical scoring using Sibelius 7; then to the highly developed software for notating music that is hardly available yet in the cyber market at the time of this study. 
Specifically, the study investigated the following research questions:

- Is there a significant relationship between the demographic profile of the respondents and their categorization of Waray-waray songs in terms of level of appropriateness to a particular grade level?

- Is there a significant relationship between the education profile of the respondents and their categorization of Waray-waray songs in terms of level of appropriateness to a particular grade level?

\subsection{Theoretical Framework}

Zoltan Kodaly once said, "Teach music and singing in school in such a way that it is not a torture, but a joy to the pupil" (Choksy, 1999). The main purpose of this present study is to collect teacher- and pupilfriendly music materials appropriate for Grades 1,2 and 3 learners. This collection of songs can serve as a repertoire of local music for the MTB MLE music classes fitted to the lower primary Leyteño pupils and at the same time aligned to the $\mathrm{K}$ to 12 music curriculum. The cornerstone of this study is anchored on the following theoretical and conceptual underpinnings that serve as guide and direction.

This study makes use of the instructional theory of Meaningful Reception by David Ausubel, which holds that when teachers package lessons well and prepare students through advance organizers, students acquire information most efficiently. To facilitate a student's acquisition of new knowledge, Ausubel (1960) introduced the concept of advance organizers--explanations which organize information already stored in mind and prepare the learner to receive the data. The following process details the contention of Ausubel's theory of meaningful reception: The teacher is the subject matter expert. First, the teacher assesses the domain and chooses from it a portion appropriate for the lesson. Second, he identifies the concepts implicit in the preferred material. Third, he analyzes the student (ideally, each one individually) to determine what each knows about the subject. If the student already grasps the concepts of the lesson, the teacher merely alerts him/her as to the set of ideas needed to profit from the experience. If the student does not know the concepts, the teacher has two choices: (1.) To create comparative advance organizer, comparing the new idea to something already known, and (2.) To create an expository organizer, a verbal explanation of the main features of the concept. Its purpose is to establish the new idea as a category in the student's structure. Not until the teacher is assured that the student understands the concept in the same way as the teacher does and that they both have the same idea in focus, can the lesson proceed (Davis, 2014).

Another theory that serves as a springboard for this study is the "Child Developmental Approach" as used in the Kodaly method (1945). In Hungary, a very child-friendly approach for teaching music was developed. It emphasizes that the musical material that is best used is the mother-tongue folksong--meaning a child's native music, the folk songs of his/her country. Before a child learns other foreign languages, a child naturally learns his mother tongue, seeing that Zoltan Kodaly believes a child must learn his musical mother tongue - that is the purest of the authentic folk music of his own country - before other music (Choksy, 1999).

The child development approach does not use the typical subject logic approach, which starts with a whole note, followed by halves, then quarters - fundamentally similar to mathematical progression which is a complicated way for a new student who has no background and experience in feeling the underlying beat of a song. Using the subject logic approach to teach music to young children is similar to making them think of something that in reality does not exist. This is not easy for the children. Instead, the child development approach uses patterns that are easy for children to cope with, especially when we are talking about the arrangement of subject matter. This approach takes into consideration the abilities of the child while he/she is growing up (Choksy, 1999).

Among others, one of the philosophies held by the Kodaly method is that everybody is capable of music literacy. Therefore, music belongs to everyone, not just to the upper classes. Choksy (1999) considers 
this approach easy and fun to use by educators and students. This perspective can be equated with B.F. Skinner's theory of operant conditioning, which holds that reinforcements strengthen response; lack of reinforcements weakens the reaction. Skinner believes that students should have fun, and must love to learn at different paces of instruction (Taetle \& Cutietta, 2002). Skinner's theory is an excellent guide for producing instructional materials for the MTB-MLE, which is the first intention of this research.

The Kodaly method claims that since a child naturally learns his mother tongue, hence a child must learn his musical mother tongue - that is the purest of the authentic folk music of his own country-before other music (Choksy, 1999). Ludke (2009) claims that theorist's; researchers, and educators deem the use of songs and music as another form of a positive emotional and quality language instruction that can be provided to students of different ages and stages of learning. Researchers from psychology and neuroscience also revealed that musical presentation methods could also support language learning. Therefore, music has shown support for verbal education in Language 1 and Language 2.

Through the use of the Waray-waray songs as instructional materials as produced in this research, can be tools to facilitate in learning the proper grammar for L1, which is Waray-waray and to build a vocabulary at an appropriate grade level. This is supported by Jim Cummins (2008) work on the theory of language development and literacy development of learners. According to Cummins', there is a difference between social and academic language acquisition. He called it the BICS and CALP, which refers to the processes that help a teacher to qualify a student's language ability.

The Basic Interpersonal Communication Skills (BICS) refer to the day-to-day language needed to socially interact with others; in other words, these are language skills needed in social situations. The BICS occur in a meaningful social context. Therefore, they are not very demanding cognitively (Cummins, 2008; Oyzon, 2012; Mozayan, 2015; Castelo, 2015).

\subsection{Conceptual framework}

The K to 12 curriculum aims to develop cultural literacy, cultural identity, or cultural awareness. However, this study contends that this objective is not being attained due to the insufficient and inadequate materials available for classroom use. It is argued that the current teachers of MBT-MLE do not even know how to teach Waray grammar and have "no best practices" on how to produce and design instructional materials in Waray-waray (Oyzon, 2012).

It is along this line that the researcher envisions to help improve the adequacy of MTB-MLE classroom materials for music instruction by means of collecting and classifying appropriate MTB-MLE songs (Winaray) culled from sources at large with a view to categorize and determine their level of appropriateness for classroom use in the primary grades (Grade 1, Grade 2, and Grade 3). Hence these collected songs were sorted out and, an attempt was made to analyze the statistical difference using the results of the songs categorized based on the evaluation of the 3ns Corpora Project instrument (software), and the Primary Teacher-respondents--Grades 1, 2, \& 3 (see Appendix G). It was discontinued however, because the categories of measurement were not complementing; as a result, it was deleted. This study makes do with discussing the results of the categorization of songs via $3 \mathrm{~ns}$ and by the teachers. The study also considered the demographic as well as education profile of the teacher-respondents as factors that may influence or have some bearing on the categorization of the songs.

As an offshoot of this study, 36 pieces of MTB-MLE songs were compiled (see Appendix K) as instructional materials appropriate for Grades 1, 2, and 3 and made available for classroom use. And finally, a seminar-workshop for teaching music in the lower primary as a strategy was conducted as a means to expedite the collection of data (copy of the program of activities documentation/pictorial in Appendix H \& L). Figure 1 shows the conceptual model of this study. 


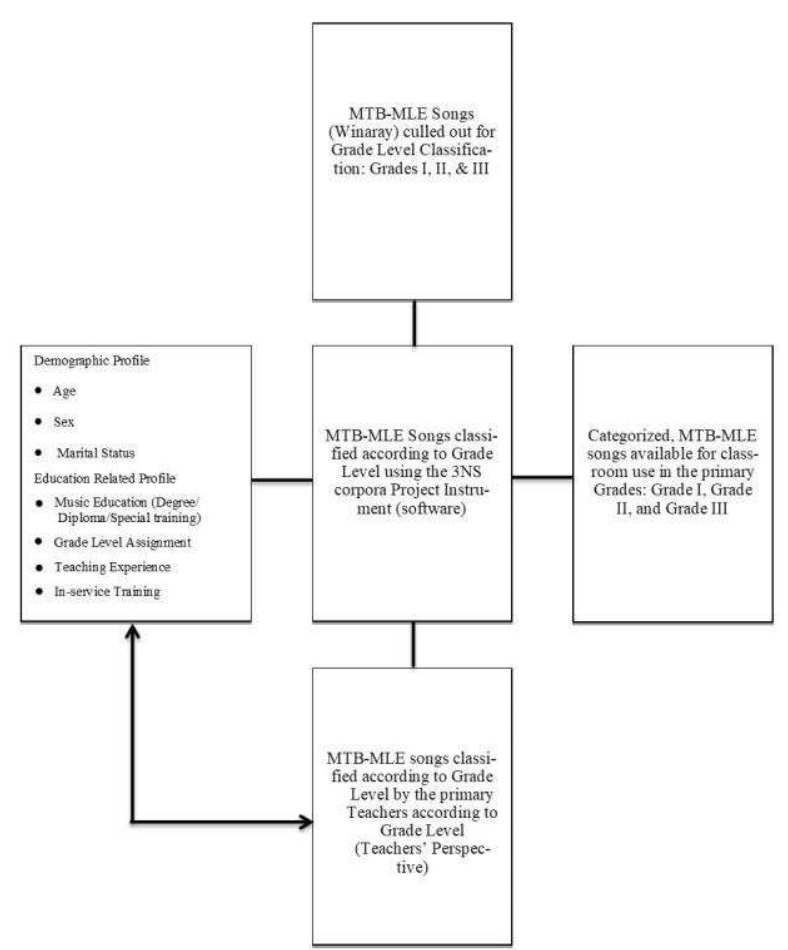

FIGURE 1. Conceptual Model

\section{Methodology}

\subsection{Research Design}

The method of implementation most appropriate for this particular study is the in-person or face-toface format because it is structured to permit the data collector to solicit information directly from a respondent. On account of the variables covered in this study and the statistical treatment of data needed, the empirical research method used in this study is the descriptive-correlational survey. Descriptive research is described as collecting data in order to test hypothesis or answers data concerning the current status of the subject of investigation. A questionnaire survey, an interview, and observation are the means of collecting data in this type of research. The instruments of the descriptive analysis usually have to be developed for specific studies; the devices developed require time and skill (Gay 1990).

Correlational research, on the other hand, is sometimes treated as a type of descriptive study, primarily because it does describe a condition. The correlational research involves collecting data to determine whether and to what degree a relationship exists between two or more quantifiable variables (Gay, 1990).

\subsection{Research Environment}

This study was conducted in the primary education schools of the Department of Education, Division of Tacloban City. There are 46 elementary schools in the whole division.

The songs used for this study are Waray-waray songs only. There are three Waray dialects namely: Samar-Leyte Winaray, spoken in Central Samar and the northern half of Leyte, Waray spoken in southern and eastern Samar, and the Northern Samar dialect. In western Leyte, people speak the Cebuano dialect while, the 
northeast is dominated by the Waray-waray speaking people (Nolasco, 2008). There are 3,265,000 Waraywaray speakers in Samar, the north-eastern part of Leyte, and some parts of Billiran (Lewis, Fennig \& Simmons 2013). NSCB Population Census (2000) reports fifty-six-point six percent (56.6\%) are Waray speakers in the total population of the Eastern Visayan Region.

\subsection{Respondents and Sampling Procedure}

The respondents of the study were Grades One, and Two, Three teachers. These teachers were either handling self-contained classes or were assigned as individual subject teachers (SST). The study covered the six-district learning centers (DLC) of the Division of Tacloban City. In particular, the study involved a sample of primary school teachers drawn from the population of Grades One, Two, and Three classroom teachers.

The respondents in this study are geographically spread out and quite large in population. This could result in the considerable expenditure of time, money and effort. Hence, the stratified random-sampling technique was employed to draw a representative sample that comprised $30 \%$ of the Grade One, Grade Two, and Grade Three teachers in the Division of Tacloban City. (See Appendix A for details.)

The matrix below shows the schools and number of Grades One to Three teachers in the six DLC's in the DepEd-Division of Tac. City. (See Appendix A for details)

\begin{tabular}{|c|c|c|c|c|c|c|c|c|c|c|c|c|c|c|c|c|c|c|}
\hline DLC & & 1 & & & 2 & & & 3 & & & 4 & & & 5 & & & 6 & \\
\hline $\begin{array}{l}\text { No. of teachers } \\
\text { by grade level }\end{array}$ & & II & & & III & & & II & II & & & II & & & III & & II & II \\
\hline Sch. A & 8 & 8 & 8 & 8 & 6 & 8 & 9 & 7 & 7 & 3 & 3 & 3 & 11 & 11 & 11 & 4 & 4 & 4 \\
\hline Sch. B & 3 & 3 & 4 & 3 & 3 & 3 & 4 & 4 & 3 & 7 & 7 & 7 & 4 & 4 & 3 & 4 & 4 & \\
\hline Sch. C & 2 & 2 & 2 & 2 & 22 & 2 & 2 & 2 & 2 & 2 & 5 & 3 & 3 & 3 & 3 & 5 & 4 & 5 \\
\hline Sch. D & 2 & 2 & 2 & 1 & 1 & 1 & 1 & 1 & 1 & & 2 & 2 & 2 & 2 & 2 & 3 & 2 & 2 \\
\hline Sch. E & 4 & 4 & 4 & 2 & 2 & 2 & 2 & 2 & 2 & 2 & 2 & 2 & 1 & 1 & 1 & 2 & 2 & 2 \\
\hline Sch. F & 1 & 1 & 1 & 4 & 4 & 3 & 1 & 1 & 1 & 0 & 0 & 0 & 1 & 1 & 1 & 1 & 1 & \\
\hline Sch. G & 1 & 1 & 1 & 2 & 2 & 2 & 3 & 3 & 3 & 0 & 0 & 0 & 1 & 1 & 1 & 3 & 3 & 3 \\
\hline Sch. H & 1 & 1 & 1 & 0 & 0 & 0 & 1 & 1 & 1 & 0 & 0 & 0 & 2 & 2 & 2 & 0 & 0 & 0 \\
\hline Sch. I & & 0 & 0 & 0 & 0 & 0 & 3 & 3 & 3 & 0 & 0 & 0 & 1 & 1 & 1 & 0 & 0 & 0 \\
\hline Sch. J & 0 & 0 & 0 & 0 & 0 & 0 & 0 & 0 & 0 & 0 & 0 & 0 & 2 & 2 & 2 & 0 & 0 & 0 \\
\hline TOTAL & & 22 & 23 & 22 & $20 \quad 22$ & 22 & 26 & 24 & 23 & 16 & 20 & 14 & 28 & 28 & 27 & 22 & 20 & 22 \\
\hline $30 \%$ & 7 & 76 & 6.9 & 6.6 & $\begin{array}{ll}6 & 6.6 \\
\end{array}$ & 5.6 & 7.8 & 7.2 & 6.9 & $4.8 \mathrm{G}$ & 64 & 4.2 & 8.4 & 8.4 & 8.1 & 6.6 & 6 & 6.6 \\
\hline Sample size & 7 & 7 & 7 & 7 & $7 \quad 7$ & 7 & 8 & 8 & 8 & 5 & 5 & 5 & 8 & 8 & 8 & 5 & 5 & 5 \\
\hline $\begin{array}{l}\text { Total no. of } \\
\text { teachers by grade } \\
\text { level }\end{array}$ & & $\begin{array}{l}\text { I: } 136 \\
\text { III: } 134 \\
\text { IIII: } 131\end{array}$ & & & & & & & & & & & & & & & & \\
\hline $\begin{array}{l}\text { Sample size by } \\
\text { grade level }\end{array}$ & & $\begin{array}{l}\text { I: } 40 \\
\text { II: } 40 \\
\text { III: } 40\end{array}$ & & & & & & & & & & & & & & & & \\
\hline
\end{tabular}

There are 136 Grade One teachers, 134 Grade Two teachers, and 131 Grade Three teachers with a combined total of 401. Thirty percent from each grade level (or stratum) was drawn as a sample. Hence, from the 136 Grade I teachers, 30 were drawn as the sample; from the 134 Grade II teachers, 30; and from the 131 Grade III teachers, 30 were drawn as samples for a total sample size of 120 teachers.

To draw the suggested sample size for each stratum, random sampling was used. A master list of all the names of 401 Grade one to three teachers was made; they were grouped according to their school and grade level assignment. For example, in School A of DLC I, there were 24 teachers, eight teachers in Grade one, eight teachers in Grade two and, eight teachers in Grade three. In order to get the sample size using a scientific calculator, the following procedure was done; (1) press shift sign, (2) then click RAN\#, (3) press the $\mathrm{X}$ button, (4) then press the number of teachers/population size, (5) finally press the equals sign, to get the random number. The same procedure was done to draw the representative sample for the Grade One, Two and Three teachers respectively.

\subsection{Research Instrument}

Survey Questionnaires for the Grades One, Two and Three music teachers. This was a researcher-made instrument. A pilot testing was done before it was used in the actual data gathering. The pilot test was held on a Saturday last January 13, 2018, in Palo I, Central School DepEd Division of Leyte. 
Palo is one of the nearby towns of Tacloban City.

During the conduct of the Pilot test, ten songs for each grade level were used; there was a total of 30 Winaray songs. All of the songs used for Grade One level came out as reliable. But one song for Grades Two and Three came out as not reliable. In the actual data collection, the researcher decided to use 36 songs-12 songs for each grade level. So that, if a song will result as not reliable, this study will still be able to complete the ten songs for each grade level.

After the pilot testing, the actual data gathering was held on February 16, 2018, at the Audio-Visual Studio, Leyte Normal University. The survey instrument was used by the respondent participants (teachers in the primary grades) to evaluate the level of appropriateness of the thirty songs that the researcher collected as instructional materials for Grades 1, 2 and 3 MTB MLE music classes.

Part I of the instrument collects data on the profile characteristics of the respondents (e.g., age, sex, marital status, music teaching experience, music education, etc.). Part II contains the criteria or standard characteristics of songs appropriate for Grades I, II, III that were rated by the respondents using a 5-point Likert scale (see Appendix C).

\subsection{Data Gathering Procedure}

This study collected 36 Waray-waray instructional materials for MTB-MLE music in the primary grades (i.e., Grades I, II, and III). The songs were evaluated based on the standards used for classifying songs concerning level of appropriateness to a particular grade level.

In the case of this particular study, the respondents were gathered in one venue where they participated in a seminar-workshop designed primarily for this study. The participants were given the research instruments in the form of a survey questionnaire where they filled in the information asked for in Part I (Respondent's Profile), and Part II (Categorizing/classifying the songs as to Grade Level---Grade I, Grade II, and Grade III). (See Appendix C for the instrument).

The accomplished survey instruments were collected by or submitted to the seminar-facilitators as soon as the respondent-participants were done evaluating the songs. The questionnaire responses obtained were then subjected to analysis.

The songs that were analyzed were collected from various sources like the old files or personal collection of local songs kept by an individual for cultural preservation. One such source came from a faculty member in the MAPEH/Humanities Unit of Leyte Normal University. Samples of the songs were sung by the said faculty member and recorded by the researcher using an application in her mobile phone.

The songs were likewise subjected to a new transcription by the researcher using Sibelius 7 software. Other songs were taken from the following theses, dissertations, and books; (1) An Analysis and Adaptation of Leyte-Samar Folk Songs for Use in Music Education Classes by Jesusita L. Arteche (1982). (3) A Manual on Rhythmic Development for Grade One Children In the Leyte-Samar Region by Aurora Oliva Lumen (1976). Some of the books were; (1) Kandabao: Essays on Waray Language, Literature, and Culture by Gregorio C. Luangco (1982). (2) Waray Literature An Anthology of Leyte-Samar Writings by Gregorio C. Luangco (1982) and, (3) Koro Leyteño, by Stephen Lagarde (2004). The songs were copied and notated by the researcher using the Sibelius 7. An English version of each of the Waray-waray songs was made by Firie Jill T. Ramos. The English versions were not literal translations of the songs; however, the real meanings of the songs in the vernacular were maintained.

Some of the keys of the songs were purposely adjusted to fit with the singing range of Grades One to Three pupils. By the same token, chords were added for accompaniment purposes using musical instruments like the keyboard, guitar, and ukulele so that the singing of songs will be more lively, exciting and enjoyable.

About 85 songs were collected and subjected to filtering. Songs containing lyrics not suitable for Grades One to Three were discarded. The songs that were considered, included a minimum of 20 measures only since songs should be short: eight to 16 measures in length owing to that fact that lung capacity and breath control are limited at a young age. Hence song phrases should be that short. 
Moreover, the songs were mostly within the range of the Grade One pupils, which is $\mathrm{C}$ to $\mathrm{A}$ and $\mathrm{C}$ to $\mathrm{C}$ for grades two and three pupils (Hackett 1997). The songs were validated using the 3 Ns corpora project for categorizing level appropriateness of each song. The total number of songs was 30 , that is, ten songs for each grade level.

The plan supposedly was to evaluate and classify the songs through the use of the 3NS Corpora Project software to determine the level of language text difficulty (e.g. easy, moderately difficult, and difficult). The intention was to classify the songs as to grade placement based on the instrument for text readability developed by the 3NS corpora project with Leyte Normal University as lead institution.

The collected songs were sorted out and an attempt to analyze the statistical difference using the results of the songs categorized based on the evaluation of the $3 \mathrm{~ns}$ Corpora Project instrument (software), and the Primary Teacher-respondents--Grades 1, 2, \& 3 (see Appendix G). It was discontinued however, because the categories of measurement were not complementing; as a result, it was removed. This study makes do with discussing the results of the categorization of songs via $3 \mathrm{~ns}$ and by the teachers. The study also considered the demographic as well as education profile of the teacher-respondents as factors that may influence or have some bearing on the categorization of the songs.

Part of the pre-survey data were the Waray-waray songs culled out from various sources. Before the data gathering started, the researcher collected at least thirty Winaray songs. The research data were gathered from teachers identified as respondent-participants of the study. They were invited to attend a one-day seminar workshop (free registration) conducted by the researcher with the assistance of some identified MAPEH major students who did the live performance of the songs, colleagues--faculty members from the MAPEH and Humanities Unit of Leyte Normal University.

The venue of the seminar-workshop was the Human Resource Development Center (HRDC), AudioVisual Hall of the university. Using the survey instruments, the participants were requested to evaluate the songs based on the criteria or standards for classifying the appropriateness of the song according to grade level (i.e., for Grade I, II, and III) as provided for in the instrument. The completed survey forms were gathered from the participants for statistical data analysis.

\subsection{Data Analysis Procedure}

For this study, the data on profile variables: demographic and education-related were analyzed with the use of descriptive statistics such as frequency counts and percentages. The same was true for MTB-MLE songs classified according to grade level using the instrument for classifying songs based on the given set of standards or criteria for categorizing songs.

Means and standard deviations were likewise used to analyze the data gathered from the survey instrument rated by the respondents relative to the measures for classifying songs according to grade level (Grade I, II and III). (See Appendix C for the instrument)

Spearman Rank-Order correlation or Spearman rho, and the Chi-square statistics were applied to analyze the significance of relationship between the demographic profile and education-related variates and the ratings of the respondents of the songs they classified according to grade level.

\subsection{Ethical Considerations}

At the outset, the topic addressed by this study is neither sensitive nor involves a sensitive population. While it may require the use of incentives to encourage individuals to participate in the survey, these incentives need not be expensive in such a way that they became unethical for individual participation. Good ethical practices dictate that survey researchers do not overstate the benefits of participating and deliver on what benefits are guaranteed (Fowler, $2009 \mathrm{cf}$. Creswell, 2012). In the case of this study, the seminarparticipants who were invited to evaluate the songs were given reimbursement of their transportation expenses only and were treated with free lunch and snacks.

It is unlikely that this study would involve the use of interviews to go out in the field to gather 
information. Should there be a need for interviews the proponent had ensured that sensible procedures would be put in place so that interviewees will not be put at risk for their safety or put the interviewer in a position of being deceptive, misleading, or inaccurate. In this particular study, the need to interview some school administrators took place only during the collection of the pre-survey documents as for a master list of teachers and the need to arrive at an acceptable schedule as to when the teachers could be gathered for the pilot-testing and the seminar-workshop.

Moreover, the safety of the respondent-participants was priority in this study. Confidentiality of their responses was assured and protected by minimizing identification of answers and specific participants. Hence, indicating the name of the respondent on the research questionnaire was made optional.

\section{Data Presentation and Analysis}

Demographic Profile of the Respondents

As shown in Table 1, 120 Grades One to Three teacher-respondents completed the survey instrument: 119 females (99\%) and, one male (1\%). The respondents' ages ranged from 19 to 56 years old, with a mean age of 37 years. The majority of respondents were within the 36-55 age bracket $(50.42 \%)$, followed by the $19-35$ group $(47.06 \%)$ and the 56 and above age bracket $(2.52 \%)$. One respondent, however, did not declare her age. Concerning marital status, a majority of the respondents were married $(44.17 \%)$, followed by the single or never been married respondents $(2.50 \%)$, and the widowed (1.67\%). Two of the respondents $(1.67 \%)$, did not indicate their marital status.

The respondents' ages ranged from 19 to 56 years old, meaning their ages are within the category of adulthood, which is composed of three major developmental stages - the young adult stage, the middle-aged adult stage, and the older adult stage. Adulthood is also known as the peak of physical, cognitive capacities. Early adulthood is between 20-24 years of age and belong to the so-called millennial or net generation; the 25-40 years of age are known as Generation X. This stage is a period for adjusting to a chosen lifestyle, choosing an occupation, creating long-term, intimate relationships with other people, and managing a home and family. All these decisions can be a potential source of stress. At this stage, the physical attributes of the young adult are at their peak, or at their best functioning capacity. The cognitive function on the other hand of a young adult is fully matured; they, however, continue to gather new skills and learning from various formal and non-formal experiences (Bastable, 2007).

The 41-64 years of age group also referred to as the baby boomers or middle age adulthood, is a period of transition between young adulthood and older adulthood. This is the time supposedly when individuals have found their identity, most probably are successful in their careers, their children are grown, and they have time to share their talents, serve as mentors for others. This is also the stage when physiological attributes diminish, such as hormonal changes which cause a variety of symptoms: hearing and visual complications, skin and muscle tone decreases, metabolism slows down, body weight tends to increase, endurance and energy levels lessen (Bastable, 2007).

All these physical changes and others affect the middle-aged adult's self-image. The cognitive attributes of a middle-aged person remain at a steady state, meaning the adult's thought processes during this stage go beyond the capability to search for complex and changing minds to find solutions to any given situation or problem. In other words, adults can see the bigger picture. For many adults, as they age, they accumulate life experiences which allow them to be confident in the teaching-learning situation (Bastable, 2007).

Looking into the music preferences of each, it may vary according to age. The age of 20-25 years is the time for building a fixed music preference. However, when individuals get older, the choice of music of a person also develops to a more complex type of music. This is attributed to the increase of musical knowledge over the lifespan. Moreover, people with a higher degree of artistic ability or musical training 
tend to like complex music (Schäfer, 2008).

Regarding sex, it is apparent that all participants, save one, were females. Sex (gender) was factored out in the correlation of the categorization of the Waray-waray songs, because only one male teacher against 119 female teacher-respondents participated in the survey. Wood (2012) notes that women outnumber men in the teaching profession in a ratio that is approximately three to one. This is attributed to the fact that female teachers have a unique ability to make moral decisions about personal and caring aspects of development. In other words, female teachers are more nurturing. Male teachers, especially in the elementary are stereotyped and recognized negatively on account of the fact that they are more laid back, dominant and commanding with students.

Regardless, men are considered good possible role models, even though providing male teachers cannot solve the schools' diverse educational problems. Unfortunately, it is believed that poor male role models could do a lot of damage in the classroom. That is why schools need more male teachers who can serve as good role models for a balanced educational environment for students. Although there are variations of reports on teachers' effectiveness, what matters is that a teacher can promote significant learning of students in the whole educational process (Wood, 2012).

As regards marital status, several types of research have reported that marital condition does not have significant influence on the teacher's performance and or effectiveness (e.g., Islahi, 2013, and Odanga, 2015). Research in India by Islahi (2013) has a very intriguing report. Male, married teachers, and female, unmarried teachers were found to be more effective teachers than the male, unmarried and female married teachers. The probable reason for this is the existing social setup and cultural demands of a traditional country like India wherein the responsibilities, priorities, and the routine of life change drastically after marriage. Such differences are more pronounced in females than their male counterparts especially if they belong to traditional families. Even in the modern nuclear families, it is the responsibility of the women to take care and manage almost all household chores either independently on their own or utilizing domestic help.

Another research in Africa that investigated the influence of marital status on teachers' self-efficacy in public secondary schools of Kisumu County, Kenya, bears some unique findings likewise. The quantitative results showed that marital status had no statistically significant influence on the teacher's self-efficacy, while the qualitative findings manifested that marital status influences teacher's self-efficacy (Odanga, 2015). There may be variations in research findings about the relationship of demographic factors that affect a teacher per se. Effective teachers, nevertheless, may come from diverse backgrounds (Islahi, 2013)

This research focused on how the respondents categorize the Winaray songs intended for Grades One to Three. Regarding the influence of gender, research findings are still inconclusive. However, there seems to be a tendency for females to like softer musical styles such as pop, and males prefer harder styles such as rock or rap. Researches on the association of music preference and socioeconomic status or lifestyle are very rare. Nevertheless, it was shown that a person who likes sophisticated music such as classical/art music had higher income and a higher level of education, while individuals who prefer rap or electronic music tend to have lower socio-economic status (Schäfer, 2008).

Table 1 Demographic Profile of the Respondents

\begin{tabular}{|c|c|c|}
\hline Profile & Frequency & Percentage \\
\hline Demographic: & & \\
\hline Age (in years) & & 47.67 \\
\hline $19-35$ & 56 & 50.00 \\
\hline $36-55$ & 60 & 2.50 \\
\hline 56 and above & 3 & 0.83 \\
\hline NI (not indicated) & 1 & 100.00 \\
\hline Total & 120 & \\
\hline Mean Age=37 years & & 99.17 \\
\hline *Sex & 119 & 0.83 \\
\hline Female & 1 & 100.00 \\
\hline Male & 120 & 74.17 \\
\hline Total & & 21.67 \\
\hline Marital Status & 89 & 2.50 \\
\hline Married & 26 & 1.67 \\
\hline Single & 3 & 100.00 \\
\hline Widow & 2 & \\
\hline NI (not indicated) & 120 & \\
\hline Total & & \\
\hline
\end{tabular}

*Note: Only 1 male respondent 
Education-related Profile of the Respondents

Table 2 shows the education-related profile of the teacher-respondents. Music education-defined in this study as highest degree, diploma or specialized training music in was factored out in the correlation because none of the respondents signified having earned any music education degree or specialized training in music.

Regarding grade level assignment, the Grade One to Three teacher-participants represented almost the same proportion of the sample $(n=43$ and $n=42$, respectively), and 35 or $29.17 \%$ were Grade Two teachers.

The data indicated that none of the respondents had earned a music education degree. This means that all of the teachers who participated in the survey graduated from a bachelor's degree program in elementary education. This is an indication of the fact that there is no music educator specialist employed or hired in the DepEd. Elementary schools of Tacloban City.

Forty-three (35.83\%) Grade One Teachers, thirty-five (29.17) Grade Two teachers and, forty-two (35\%) Grade Three teachers from DLC 1 to 6 of Tacloban City Division participated in the survey. All the $120(100 \%)$ respondents reported not having earned any music education degree or specialized training to their credit. The studies of Gravis (2013), Holden (2006) \&, de Vries (2017) suggest that generalist teachers feel incapable of teaching music in the classroom aside from the fact that they have very low confidence in teaching music. The absence of a music specialist is a common situation in many countries of the world. The DepEd, Division of Tacloban City is not an exception.

The most appropriate instructional setup, nonetheless, is one with music specialists who can collaborate closely with classroom teachers on how to make music a part of the daily life of the students and integrate music with the whole curriculum. In the absence of a music specialist, however, music instruction is then the task of a generalist classroom teacher (Hacket, 1997).

Most participants have a teaching experience between $0-5$ years $(45.83 \%$; $=55)$; followed by those with $6-10$ years to their credit $(27.50 \%$; $n=33)$; others have between $11-15$ years $(7.50 \% ; n=9)$ and $16-20$ years $(7.50 \%$; $n=9)$; still others have between $21-25$ years $(4.17 \%$; $n=5)$; between $26-30$ years $(2.50 \% ; n=3)$; and between $31-35$ years $(1.67 \% ; n=3)$. However, four or $3.33 \%$ did not indicate their number of years in the teaching service.

For number of in-service training attended in line with music, majority of the respondents reported have not a single training attended $(65.83 \% ; \mathrm{n}=79)$; while some reported having attended at least one inservice training $(31.67 \% ; \mathrm{n}=38)$, and a small proportion of the sample $(2.50 \% ; \mathrm{n}=3)$ have attended at least two in-service training.

Forty-three (35.83\%) Grade Teachers, thirty-five (29.17) Grade Two teachers and, forty-two (35\%) Grade Three teachers from DLC 1 to 6 of Tacloban City Division participated in the survey.

Rice (2010) argues that the years of experience of an employee are considered as appropriate elements for human resource policies in recognizing compensation systems \& promotion decisions. Apparently, this is due to the fact the knowledge; skills and productivity of workers are gained over time through experience. In the case of the teachers, the underlying assumption is that experience promotes effectiveness. Therefore, the teacher's teaching experience is a critical factor in personnel policies such as transfer and promotion policies that prioritize seniority. Unfortunately, however, this becomes a significant source of unfair practices across schools.

Rice (2010) contends that experience matters, but more is not always better. Moreover, some researchers showed that less experienced teachers tend to be less effective than more experienced teachers. However, many less experienced teachers may have plus points that equal to or exceed those of the more experienced teachers. Research has shown further that other policy-relevant factors-such as teacher's academic training and program preparation - may equal or even outweigh the impact of the early-career experience. In some cases, veteran teachers may be less effective than the less-experienced teachers (Rice, 2010). 
The profile on attendance to in-service training provides a dismal picture. This is an unfortunate reality that our educators have very minimal or much worse, no involvement in seminar-trainings and workshops on enhancing learning and teaching music. In many countries around the world, when a music specialist is not available, the generalist teachers are responsible for the delivery of music instruction. This scenario supports the notion of Zoltan Kodaly, which states that "Music is for everybody" and as such, all teachers should teach it. (Gravis, 2013). This idea is tantamount to saying that all teachers are music teachers.

It is likewise argued that the quality of the music instruction provided by the generalist teachers hinges on their knowledge of music, as well as on their understanding of what it is to be a musician. To teach music, and to learn music for that matter, should be derived from personal experiences in learning music like doing private study in a studio or joining community singing such as choir singing. These teachers had no experience in formal music education - also known as formal training to study the music elements and the ways they interact to produce musical works (Wiggins, 2008)

Table 2 Education-related Profiles of the Respondents

\begin{tabular}{|c|c|c|}
\hline Profile & Frequency & Percentage \\
\hline Education-Related: & & \\
\hline $\begin{array}{l}\text { Music education* } \\
\text { (Degree/Diploma/Special Training) }\end{array}$ & & \\
\hline Grade Level Assignment & & \\
\hline Grade I & 43 & 35.83 \\
\hline Grade II & 35 & 29.17 \\
\hline Grade III & 42 & 35.00 \\
\hline Total & 120 & 100.00 \\
\hline Teaching Experience & & 45.83 \\
\hline $0-5$ & 55 & 27.50 \\
\hline $6-10$ & 33 & 7.50 \\
\hline $11-15$ & 9 & 7.50 \\
\hline $16-20$ & 9 & 4.17 \\
\hline $21-25$ & 5 & 2.50 \\
\hline $26-30$ & 3 & 1.67 \\
\hline $31-35$ & 2 & 3.33 \\
\hline NI (not indicated) & 4 & 100.00 \\
\hline Total & 116 & 31.67 \\
\hline No. of In-service Training attended & & 2.50 \\
\hline 1 & 38 & 65.83 \\
\hline 2 & 3 & 100.00 \\
\hline None & 79 & \\
\hline Total & 120 & \\
\hline
\end{tabular}

*for music education, respondents signified having no special training.

Relationships between Demographic and Education Profile and the Categorization of Songs

Tables 3, 4 \& 5 presents the relationships between the demographic and education profile characteristics of the Grade One respondents and their categorization of Waray-waray songs in terms of the level appropriateness to a particular grade level.

In this particular study, three demographic and four education variates namely age, sex, marital status, music education, grade level assignment, teaching experience, and in-service training were correlated with the categorization of Winaray songs. Music education was factored out in the correlation because all of the respondents signified not having attended any specialized training in music. Sex was factored out in the correlation as well, because there was only one male teacher who participated in the survey, the rest of the 119 teachers were females.

Relationships between the Demographic and Education Profile and the Categorization of Songs by the Grade One teachers

The bivariate analysis of data using the Spearman rank-order correlation (Spearman rho or $r_{\mathrm{s}}$ ) shows 
that, as hypothesized, there were significant correlations between the, categorization of songs, and such demographic variate as age: $r_{\mathrm{s}}(118)=0.26$, p 0.005 for Grade I respondents; and the education variableteaching experience; rs $(114)=0.26$, p 0.005 for the Grade I respondents.

On the other hand, results revealed there were no correlations in the data set between marital status $\left(\chi^{2}=0.59,3.52\right.$, and 0.172 , respectively, $\left.\mathrm{n}=2, \mathrm{~ns}\right)$; and in-service training $(\mathrm{rpb}=-0.05$ and, 0.590 , respectively, $\mathrm{n}=118, \mathrm{~ns})$.

Table 3 Relationships between the Demographic and Education Profile Characteristics and the Categorization of Songs by the Grade One teachers

\begin{tabular}{|l|c|r|r|l|}
\hline \multicolumn{1}{|c|}{ Variable per } & Relationship & $d f$ & P value & Remarks \\
\hline \multicolumn{1}{|c|}{ Grade I } & & & & \\
\hline Demographic Profile: & & & & \\
\hline Age & $\mathrm{r}_{\mathrm{s}}=0.26$ & 118 & 0.005 & Significant \\
\hline Marital Status & $\chi^{2}=0.59$ & 2 & 0.745 & Not significant \\
\hline Education Profile: & & & & \\
\hline Grade Level Assignment & $\chi^{2}=3.52$ & 2 & 0.172 & Not Significant \\
\hline Teaching Experience & $\mathrm{r}_{\mathrm{s}}=-0.26$ & 114 & 0.005 & Significant \\
\hline In-service Training & $\mathrm{rpb}=0.05$ & 118 & 0.590 & Not Significant \\
\hline
\end{tabular}

Relationships between the Demographic and Education Profile and the Categorization of Songs by the Grade Two teachers

As hypothesized, there were significant correlations between the, categorization of songs, and such demographic variate as age: $\mathrm{r}_{\mathrm{s}}(118)=0.180$, $\mathrm{p} 0.049$ for Grade II respondents; and education variableteaching experience; $r_{\mathrm{s}}(114)=0.232$, p 0.012 for the Grade II teacher-respondents.

On the other hand, results indicated there were no correlations in the data set between marital status $\left(\chi^{2}=3.58\right.$, and 1.72, 0.423, respectively, $\mathrm{n}=2$, $\left.\mathrm{ns}\right)$; and in-service training $(\mathrm{rpb}=-0.12$, and 0.207 , respectively, $\mathrm{n}=118, \mathrm{~ns})$.

Table 4 Relationships between the Demographic and Education Profile and the
Categorization of Songs by the Grade Two teachers
\begin{tabular}{|c|c|r|r|l|}
\hline & Relationship & $d f$ & P value & Remarks \\
\hline Variable per & & & & \\
\hline Grade II & & & & \\
\hline Demographic Profile: & $\mathrm{r}_{\mathrm{s}}=0.180$ & 118 & 0.049 & Significant \\
\hline Age & $\chi^{2}=3.58$ & 2 & 0.167 & Not significant \\
\hline Marital Status & & & & \\
\hline Education Profile: & $\chi^{2}=1.72$ & 2 & 0.423 & Not significant \\
\hline Grade Level Assignment & $\mathrm{r}_{\mathrm{s}}=0.232$ & 114 & 0.012 & Significant \\
\hline Teaching Experience & $\mathrm{rpb}=-0.12$ & 118 & 0.207 & Not significant \\
\hline In-service Training & & & &
\end{tabular}

Relationships between the Demographic and Education Profile Characteristics and the Categorization of Songs by the Grade Three teachers

The education variable - teaching experience $r_{s}(114)=0.253, p 0.006$, for Grade 3 respondents, respectively, showed a significant correlation to categorization of songs. Moreover, the chi-square test indicated that the relationship between the education variate: grade level assignment and categorization was also significant, $\chi^{2}(2, \mathrm{n}=114)=7.83, \mathrm{p} 0.019$. This significant relationship though registered only for the Grade III teachers. 
On the other hand, there were no correlations in the data set between age, $r_{s}(118)=0.163, p 0.078$ for the Grade Three respondents and the categorization of songs. The same is true for marital status $\left(\chi^{2}=\right.$ $4.00,0.135, \mathrm{n}=2, \mathrm{~ns})$; and in service training ( $\mathrm{rpb}=-0.05,-0.12$, and $0.11, \mathrm{n}=118, \mathrm{~ns}$ ).

Concerning age, the literature provides that age is a vital indicator of one's physical, cognitive and psychosocial stage of development. The uniqueness of each developmental style is said to be a healthy milestone of the progression of the life cycle. Moreover, age is likewise meant to be an influential factor in dealing with the teaching-learning process. Age is synonymous with growth and development. Together, age, growth, and development work with experiences in life, physical and emotional status, and personal motivation, as well as various environmental factors such as stress, the surrounding conditions, available support systems, to affect an individual's ability to function (Bastable, 2007).

The ages of the respondents in this study range from 19 to 56 years old. This range of ages is categorized in the developmental stages of a person as the "adulthood period" which is composed of three major developmental stages - the young adult stage, the middle-aged adult's stage, and the older adult stage. Adulthood stage is also known as the peak stage of physical, cognitive capacities. The various tasks of social roles concerning family, employment, and other activities beyond the responsibilities of home and career are the primary emphasis of the teaching and learning process. And also, past experiences for adults are sources of information on which to build further understanding of relationships between ideas and concepts (Bastable, 2007).

Since adults are already accustomed to their attitudes, values and, ideas, they tend to resist change. The challenges in life are also important factors for an average adult's teaching-learning process like when there are difficulties with work, social responsibilities, family related burdens, and health-related issues. The life experiences of many adults are elements that are the basis of their confidence in the teaching-learning situation. However, if their past experiences with a teaching-learning situation were minimal and difficult, their enthusiasm would be at a low level for facilitating the teaching-learning situation (Bastable, 2007).

The significant findings in this study relative to age and teaching experience find support from the aforecited literature. As Bastable (2007) remarked, age is an influential factor in dealing with the teachinglearning process. Age is synonymous with growth and development; they work together with experiences in life.

Rice (2010), likewise argues that knowledge, skills, and productivity of workers are gained over time through experience. In the case of teachers, the underlying assumption is that experience promotes effectiveness.

Moreover, results of the chi-square test indicated a significant correlation between grade level assignment and song categorization. When the teachers are assigned to a particular grade level for their teaching assignment, typically the ones assigned in the lower level like Grade One, usually considered are the less experienced teachers or most likely, younger teachers. The ones assigned to the upper levels like Grade II or Grade III are the older or senior teachers.

The underlying assumption here is that experience promotes effectiveness. Hence, the teacher's teaching experience is considered a critical factor in personnel policies such as transfer and promotion policies that prioritize seniority. This practice becomes a major source of unfair practices across schools (Rice, 2010).

In the case of this study, the Grade Three teachers who took part in the survey were virtually the more experienced or the more senior teachers. The teachers who have had several or longer years of teaching experience are believed to be more likely in a best position to know the suitable and convenient activities and especially as to what materials to use for their pupils.

Table 5 Relationships between the Demographic and Education Profile Characteristics and the Categorization of Songs by the Grade Three teachers

\begin{tabular}{|l|c|r|r|l|}
\hline \multicolumn{1}{|c|}{ Variable per } & Relationship & Df & P value & Remarks \\
\hline \multicolumn{1}{|c|}{ Grade III } & & & & \\
\hline Demographic Profile: & & & & \\
\hline Age & $\mathrm{r}_{\mathrm{s}}=0.163$ & 118 & 0.078 & Not significant \\
\hline Marital Status & $\chi^{2}=4.00$ & 2 & 0.135 & Not significant \\
\hline Education Profile: & & & & \\
\hline Grade Level Assignment & $\chi^{2}=7.83$ & 2 & 0.019 & Significant \\
\hline Teaching Experience & $\mathrm{r}_{\mathrm{s}}=0.253$ & 114 & 0.006 & Significant \\
\hline In-service Training & $\mathrm{rpb}=0.11$ & 118 & 0.229 & Not significant \\
\hline
\end{tabular}


Teachers Categorization of Waray-waray Songs in terms of their level of appropriateness for Grades 1, 2 and, 3 MTB-MLE music

Table 4 presents the teacher-respondents categorization of Winaray songs in terms of level of appropriateness for Grades One, Two \&, Three MTB-MLE music. For this study, four song characteristics namely: melodic structure, rhythmic structure, length of the song and syllabication were used to describe the level of appropriateness of the Winaray songs evaluated by the Grades 1, $2 \&, 3$ teachers. As shown in Table 4, a total of twelve songs for each grade level was used and rated by the teachers in terms of categorization and level of appropriateness. The five Point Likert scale 5-very much appropriate, 4-very appropriate, 3-appropriate, 2-less appropriate and, 1-not appropriate, was used to rate the four song characteristics that describes the level of appropriateness of the Winaray songs (see Appendix $\mathrm{H}$ for the survey instrument).

The most significant materials in a music program of instruction are singing and moving. These two activities can motivate young children to participate in musical activities. In order to come up with an enjoyable, child friendly, appropriate and definite materials, songs and singing games should be selected carefully so as to provide both pleasant and happy immediate experience as well as suitable materials for later, more specific music learning. Songs should be within the comfortable singing range of the children, and the best materials are heritage type such as "folk songs" (Hacket, 1997).

If there is a repertory of some such thirty (30) songs, then the pupils can sing well, show high and low sounds, clap and step to the beat and rhythm correctly, then apply dynamics and tempo to the songs. Subsequently, the symbolic learning of music reading and writing will be a success in the years to come (Choksy, 1999).

During the conduct of the survey, in the form of a seminar-workshop, the teacher respondents watched live musicians or performers as they sang the collected songs and at the same time played musical instruments, as accompaniment. As the group of musicians performed, the invited participants categorized the level of appropriateness of the songs for the three grade levels: Grades, One, Two, and Three. As we all know, watching a live performance is entirely different from viewing it through the multi-media means.

Research in music therapy used live music performance to treat patients who are diagnosed with dementia. The live musical performance showed a highly significant level of positive engagement compared with prerecorded music. It is apparent that visual experience of watching live musicians sing and play musical instruments has a different and unique effect on people (Holmes, C, Knights, et al., 2006).

Researches by Jola, \& Grosbras, (2013); Maja \& Marković (2017) investigated how the audience would react to viewing a live dance performance compared to watching recorded versions or video presentation. It was found out that the audience was more sensitive to live performance. Hence, the audience judged the live performance higher on all dimensions of aesthetic experience compared to the video presentation. As a result, live performances were found to be more enjoyable compared to merely watching the recorded video. Considering this, in the present study, the teacher respondents' categorization of the songs could be considered consistently very much appropriate in all levels of the parameters.

\section{Grade One MTB-MLE Categorized Waray-waray Songs in terms of level of appropriateness as rated by} the Grades 1, 2 \& 3 Teachers

Table 6 highlights the categorized Winaray songs for the Grade One MTB-MLE music classes. The following are the total means of the teachers ratings in the parameters melodic structure $(\mathrm{M}=4.67)$, rhythmic structure $(M=4.67$, length of song $(M=4.81)$, syllabication $(M=74)$. Consistently the Grade One teacherrespondents ratings across parameters and by parameter are very much appropriate $(\mathrm{M}=4.72)$.

The six-year-olds or the Grade One pupils are said to be imaginative, eager to know, curious, and very enthusiastic learners. These pupils enjoy singing and they would want to shout at first in light and highpitched voices. However, they must be advised to sing pleasantly and tunefully. These children are already 
capable of distinguishing between beat and rhythm. They can create simple accompaniments through playing rhythm and melody instruments (Rozmajzl, 2006).

The Grade One songs selected for this study are mostly within the C to A pitch, which is the Grade One singing range in terms of melodic pattern. Moreover, the Waray-waray songs for the Grade One are easy to learn and remember particularly for Grade One pupils when they contain repeated words and pitches while the rhythmic pattern is short, eight to sixteen measures in length. By the same token, singers should breathe at every end of phrases because at this age, lung capacity and breath control are limited. Therefore, song phrases should be short (Hacket 1997).

Choksy (1999), on the other hand, contends that genuine children's singing games and folk music must be the initial material used for teaching children to sing in tune. But most importantly, it should be of proper range, that is within the range of five or six notes centering $\mathrm{F}$ or F\#. Children can sing independently with $\mathrm{F}$ or F\# center tone since this is the most comfortable range for children. Research has shown that fa and mi are arduous for young children to sing.

It is advised that teaching materials should take out the half steps fa and ti. But it does not mean that songs with half steps and songs of wider range must not be taught to children. As argued, it is through experiencing that children will acquire singing some songs with half steps, and some notes beyond their comfortable tessitura along with complicated melodic patterns like minor seconds. Grade One pupils must be able to acquire numerous rote songs of wider range. Some of these songs will be used to expand the child's musical learning experience and also for future learning in the higher-grade levels. Children must never be given the feeling that music is difficult and mechanical. They must be given the chance to enjoy singing with dynamics, phrasing and with proper tempo (Choksy, 1999).

Table 6 Categorized Waray-waray Songs in terms of appropriateness for the Grade One MTB-MLE music classes by the Grades $1,2 \&, 3$ Teachers

\begin{tabular}{|c|c|c|c|c|c|}
\hline Grade Level and Songs & $\begin{array}{l}\text { Melodic } \\
\text { Structure }\end{array}$ & $\begin{array}{l}\text { Rhythmic } \\
\text { Structure }\end{array}$ & $\begin{array}{l}\text { Length } \\
\text { of Song }\end{array}$ & Syllabication & Mean \\
\hline \multicolumn{6}{|l|}{ Grade 1} \\
\hline 1. Hardin & 5.00 & 5.00 & 5.00 & 4.60 & 4.90 \\
\hline 2. Langoy & 4.74 & 4.77 & 4.84 & 4.74 & 4.77 \\
\hline 3. Syomoy & 4.80 & 4.79 & 4.86 & 4.81 & 4.82 \\
\hline 4. Lubi-lubi & 4.45 & 4.49 & 4.60 & 4.63 & 4.54 \\
\hline 5. Burongkahay & 4.88 & 4.87 & 4.91 & 4.93 & 4.90 \\
\hline 6. Lukso & 4.77 & 4.71 & 4.77 & 4.79 & 4.76 \\
\hline 7. Maupay nga Aga & 4.17 & 4.16 & 4.65 & 4.58 & 4.39 \\
\hline 8. Pagbakingking & 4.90 & 4.84 & 4.95 & 4.98 & 4.92 \\
\hline 9. Paghugas & 4.57 & 4.57 & 4.63 & 4.67 & 4.61 \\
\hline 10. Pagsayaw Kita & 4.74 & 4.71 & 4.81 & 4.74 & 4.75 \\
\hline 11. Pagtanum & 4.69 & 4.71 & 4.91 & 4.77 & 4.77 \\
\hline 12. Iklopon & 4.27 & 4.37 & 4.74 & 4.67 & 4.51 \\
\hline Mean & 4.67 & 4.67 & 4.81 & 4.74 & 4.72 \\
\hline $\begin{array}{l}\text { Legend: } \\
1.00-1.79=\text { Not appropriate } \\
2.60-3.39=\text { Appropriate }\end{array}$ & $\begin{array}{l}1.80-2.59=L \\
3.40-4.19==V\end{array}$ & $\begin{array}{l}\text { s appropria } \\
\text { y appropric }\end{array}$ & & & \\
\hline
\end{tabular}

Grade Two MTB-MLE Categorized Waray-waray Songs in terms of level of appropriateness by Grades 1,2 \& 3 Teachers

Table 7 shows the results of the categorized Winaray songs by the teachers for Grade Two MTBMLE music. The Table shows that the teachers consistently rated the songs in all levels of parameters, both vertical and horizontal as very much appropriate with the following mean scores by parameter with respect to the level of appropriateness in terms of melodic structure $(\mathrm{M}=4.73)$, rhythmic structure (4.80), length of song (4.85), and syllabication (M4.92), revealing very much appropriate results. With a total mean average for 
both vertical and horizontal parameters of $\mathrm{M}=4.83$ or very much appropriate in terms of level of appropriateness.

The repertoire of songs must be categorized, i.e., there should be songs for just listening, singing games, dance songs, and songs for plain singing. The songs should be simple duple and duple compound meter only (Choksy, 1999). The singing voice is one of the most powerful and natural ways to make music. Thus, when children are taught to sing, it is like teaching them to use their musical instrument, which they can expressively use to make music. Once the joy of singing is established, it can remain throughout a lifetime. Therefore, children need frequent opportunities to continue singing during their school years as they mature physically, emotionally, and socially (Hackett, 1997).

The second graders or the seven-year-old's singing has a pleasant tone and can produce the exact tone. They can as well hold a pitch and perform simple rounds while the teacher plays or sing a different part. This age group is ready to write and read music (Rozmajl, 2006).

Once the first graders have achieved and completed the outlined musical activities, they are ready to experience selected advance or complex music. Rote singing songs with ties, fermatas, intricate melodies and rhythmic patterns can already be taught. All songs taught during this grade level must be performed creatively and beautifully (Choksy, 1999). Expectedly, Grade Two children can sing familiar, simple songs in tune, and their voices remain light and relatively thin. They can sing with more expression than the First Graders. This is attributed to the fact that they have higher physical control of dynamics and longer pitches. Grade two pupils, for instance, can hold words for four beats (Hackett, 1997).

Beyond enjoying more complex singing games, second-grade pupils can likewise sing simple ostinato parts that add harmony to familiar songs. For grades two and three learners, the vocal range expands, extending from middle $\mathrm{C}$ to high $\mathrm{C}$. While short songs with repetition are still easier to learn and memorize, phrases can be longer (Hackett, 1997).

Table 7 Categorized Waray-waray Songs in terms of level appropriateness for Grade Two MTB-MLE music classes by the Grades $1,2 \&, 3$ Teachers

\begin{tabular}{|l|c|c|c|c|c|}
\hline \multicolumn{1}{|c|}{ Grade Level and Songs } & $\begin{array}{c}\text { Melodic } \\
\text { Structure }\end{array}$ & $\begin{array}{c}\text { Rhythmic } \\
\text { Structure }\end{array}$ & $\begin{array}{c}\text { Length of } \\
\text { Song }\end{array}$ & Syllabication & Mean \\
\hline Grade 2 & & & & & \\
\hline 1. An Bato & 5.00 & 5.00 & 5.00 & 4.80 & 4.95 \\
\hline 2. Ay ay Alibangbang & 4.86 & 4.90 & 4.94 & 4.83 & 4.88 \\
\hline 3. An Tugon ni Nanay ngan Tatay & 4.80 & 4.83 & 4.97 & 5.00 & 4.90 \\
\hline 4. An Ngaran nga Nanay & 4.61 & 4.70 & 4.80 & 4.86 & 4.74 \\
\hline 5. An Tamsi nga Tikbubulan & 4.91 & 4.94 & 4.94 & 4.94 & 4.93 \\
\hline 6. Hi Mano Palabyo & 4.73 & 4.79 & 4.94 & 4.89 & 4.84 \\
\hline 7. Dandansoy & 4.21 & 4.36 & 4.60 & 4.57 & 4.44 \\
\hline 8. Ayaw Pagtinangis & 4.73 & 4.86 & 4.94 & 4.94 & 4.87 \\
\hline 9. Hi Tokmo & 4.86 & 4.89 & 4.83 & 5.91 & 5.12 \\
\hline 10. Ringindingginding & 4.79 & 4.79 & 4.60 & 4.83 & 4.75 \\
\hline 11. Inday Inday & 4.81 & 4.93 & 4.89 & 4.91 & 4.89 \\
\hline 12. Mahamot nga Marol & 4.44 & 4.61 & 4.77 & 4.60 & 4.61 \\
\hline
\end{tabular}

Legend:

1.00-1.79= Not appropriate $\quad 1.80-2.59=$ Less appropriate

2.60-3.39=Appropriate

3.40-4.19=Very appropriate

4.20-5.00=Very much appropriate

Grade Three MTB-MLE Categorized Waray-waray Songs in terms of the level of appropriateness by the Grades 1,2 \& 3 Teachers

Table 3 shows the teacher's categorized Waray-waray songs in terms of the level of appropriateness 
for Grade three MTB-MLE music classes. Indicated are the statistical means by parameter with respect to: melodic structure ( $M=4.54)$, rhythmic structure $(M=4.48)$, length of song (4.76), and syllabication (4.70), with a total mean score by parameter and across parameters of $\mathrm{M}=67$ resulting in a rating of a very much appropriate in terms of categorized songs for the Grade 3 MTB-MLE music classes.

The third graders or the eight-year-olds' attention span is continually growing. They can enjoy small-muscle movements so they can be more coordinated. As to the quality and range of their singing voice, they are more enhanced, and they have greater control over it. Through guided and active participation, eightyear-olds are capable of mastering symbolic systems since they can organize and categorize abstract concepts. This age group is capable of understanding the idea of music notation. They are ready to do music reading and writing through games and performances. Eight-year-olds are likewise capable of learning to play musical instruments because at this age they can progress rapidly regarding physical aspects. Plays, dances, and folk songs are suitable materials for this age group and even choral and instrumental songs (Rozmajzl, 2006).

Third-graders are ready to sing in parts (harmony) when they can sing unison songs accurately and confidently. That is, begin with a type of harmony that can be improvised or created from a song fragment. Ostinatos can be produced from parts of many rounds. Children in this age group can sing familiar songs in two parts, such as rounds or "partner songs" (two different songs that share the same sequence of chords, with the same key and tempo) (Hackett, 1997).

Regarding rhythmic learning for third graders, song materials should include duple simple, duple quadruple and compound meters as well. The rhythmic patterns should include a combination of the quarter, eighth note, and eighth rest patterns and even dotted notes/rests. Regarding melodic learning, this can be the right time to introduce uncommon and unsingable intervals for the children's intervallic vocabulary to increase. In all of the grade levels, it is important that children are taught to sing correctly by singing in tune and with good tone quality. All music classes must end with enjoyable singing rather than a mechanical and arduous reading and writing in music skill teaching. It is because the foundation of a good music program must be singing (Choksy, 1999).

The literature provides useful guidelines for teaching children to sing. These are: (1.) Select songs that are within the vocal range of a child (2.) Choose age-appropriate songs to motivate the singer (3.) Encourage proper posture and breath support, and (4.) Sing accurately and on a pitch to provide explicit model for singers. It pays to keep in mind that every child with normal hearing and vocal physiology can learn to sing. It is because singing is said to be a developmental skill that improves with practice. Therefore, frequent opportunities for singing in the classroom is imperative. And because music is a temporal art, each model experience facilitates perception and conceptualization simultaneously. Hence, great care to be taken to suggest how this may be accomplished without reducing the aesthetic impact of the art (Hackett, 1997).

Table 8 Categorizated Waray-waray Songs in terms of the level of appropriateness for Grade 3 MTB-MLE music classes by the Grades One, Two \&, Three Teachers

\begin{tabular}{|l|c|c|c|c|c|}
\hline \multicolumn{1}{|c|}{ Grade Level and Songs } & $\begin{array}{c}\text { Melodic } \\
\text { Structure }\end{array}$ & $\begin{array}{c}\text { Rhythmic } \\
\text { Structure }\end{array}$ & $\begin{array}{c}\text { Length of } \\
\text { Song }\end{array}$ & Syllabication & Mean \\
\hline Grade 3 & & & & & \\
\hline 1. An Kahoy nga Lawaan & 4.00 & 5.00 & 5.00 & 4.69 & 4.67 \\
\hline 2. An Labasero & 4.86 & 4.90 & 4.95 & 4.90 & 4.90 \\
\hline 3. an Lemon & 4.80 & 4.75 & 4.93 & 4.79 & 4.82 \\
\hline 4. An Mananggiti & 4.61 & 4.71 & 4.67 & 4.52 & 4.63 \\
\hline 5. An mga Isda & 4.89 & 4.88 & 4.88 & 4.88 & 4.88 \\
\hline 6. Hira Nanay Tatay & 4.61 & 4.69 & 4.83 & 4.76 & 4.72 \\
\hline 7. Ha Kan Inday & 4.12 & 4.20 & 4.50 & 4.45 & 4.32 \\
\hline 8. Kamote Ragayray & 4.70 & 4.62 & 4.83 & 4.76 & 4.73 \\
\hline 9. Kuradang & 4.69 & 4.76 & 4.64 & 4.79 & 4.72 \\
\hline 10. Pinalangga Ko Ikaw & 4.39 & 4.63 & 4.64 & 4.63 & 4.57 \\
\hline 11. Lubi Lubi & 4.70 & 4.73 & 4.74 & 4.79 & 4.74 \\
\hline 12. Maupay Nga Pasko & 4.06 & 4.31 & 4.52 & 4.40 & 4.32 \\
\hline
\end{tabular}

Legend:

1.00-1.79= Not appropriate $\quad 1.80-2.59=$ Less appropriate

2.60-3.39=Appropriate $\quad 3.40-4.19=$ Very appropriate

4.20-5.00=Very much appropriate 
Categorization of the Waray-waray songs via the National Network for Normal Schools or the 3ns Corpora Project software

During the conduct of the research, an attempt was made to use the National Network for Normal Schools or the $3 \mathrm{~ns}$ Corpora Project software relative to the significant difference between the teachers categorization of songs and the 3ns (see Appendix E). This software is a database of various texts in ten (10) Filipino languages. The database has a variety of purposes, namely; to create an archive language text, analyze the structure of these languages, and specify word repetition rank texts according to comprehension level. These texts are designed for teaching and research. Instruction in the mother tongue (L1) is part of the new (2012) K to 12 education curriculum, so teachers need texts that are appropriate for their students' reading level.

This computer software was developed by Leyte Normal University. It was modelled after the Spache Readability Formula (1953) made for English) made to help rank texts that are used by teachers or research grounded on selecting appropriate reading materials to support the DepEd's MTB-MLE program in Region VIII, in the Philippines (Oyzon, 2015)

This software uses readability algorithms to help rank the texts. The corpus is a simple list of language texts. It identifies the following things about each entry: word count, sentence count, words per sentence, syllable count, average number of syllables, a percentage of words from the most frequent words used, readability metrics (Flesh-Kincaid, Coleman-Liau, Smog, Gunning-fog, Flesch Grade Level). It can also find the following things about the language as a whole: most frequent words, usage patterns of individual words (such as "an" vs. "it" in Winaray) conjugation patterns (for example, when to use affixes "um", "in", and "nag" forms), rules for standard spelling (orthography).

The plan was to use this software as an instrument to evaluate the wordings of the Winaray songs used in this study. Songs with easy wordings as identified by the device were considered appropriate for Grade One. Songs containing moderately tricky words were considered for Grade Two use. Those that included language texts that were difficult were considered for Grade Three level. But it was discontinued because the categories of measurement between the $3 \mathrm{~ns}$ and the survey instrument used in this study to evaluate the level of appropriateness of the Winaray songs for the Grades 1 to 3 were not complementing.

With respect to the results of the $3 \mathrm{~ns}$, none of the repertoire of songs for the Grade One level was classified by the $3 \mathrm{~ns}$ as belonging to the Grade One category in terms of the level of difficulty of the wordings of the song. The outcome of twelve Grade Two repertoire of songs categorized via 3 ns showed that the songs: Ay, ay Alibang-bang, Inday-Inday and, Mahamot nga Marot, as songs appropriate for the Grade Two level. The rest of the nine songs were not appropriate for the Grade Two level in terms of language text difficulty. The data of the 3 ns categorization of the Grade Three songs language text difficulty revealed that four out of twelve songs were appropriate for the Grade Three level, namely: An Kahoy nga Lawaan, An Mananggiti, Hira Nanay-Tatay, and Maupay Nga Pasko (see Appendix E).

The songs used in this study are mostly traditional Waray-waray songs. There were several words that the 3 ns categorized as difficult words and many words not occurring frequently. Some of the language and vocabulary of the songs used in this study are old fashioned and are no longer in everyday use. Nonetheless using songs can enable learners to acquire better understanding of culture. Songs communicate cultural reality in a very unique way. Although cultural songs are more applicable to older learners, young learners must be given the opportunity to learn about seasonal or historical events in the target language through songs. There may be several reasons why songs can be valuable to teaching but there are some issues to consider. Most importantly, the teacher needs to take care in selecting a suitable song for his or her class. The language, vocabulary, and sentence structure of songs can be quite different from that used in the spoken dialect (Milington, 2011).

Concerning the readability instrument that was developed by Oyzon and Fullmer (2015), the software is designed or programmed to rank Winaray texts that can be used by the elementary grades teachers for research and for selecting appropriate reading materials. This is in support of the DepEd's MTB-MLE 
program in Region VIII, in the Philippines. The software functions to provide among others, the following: word count, sentence count, words per sentence, syllable count, average number of syllables, and percentage of words from the most frequent words.

By and large, computer software is limited based on how they are programmed. In the case of this study, when the software categorized the Winaray songs, it was not able to discern the aesthetic attributes of the songs when live musicians performed them live. And also, the software did not recognize many Winaray wordings of the songs. Pool of words, which are very important aspects of life like: domestic work, games, food, emotions, family, religion, occupation, etc. were not recognized by the software. Hence, the ratings provided by the software were based solely on how it was programmed.

\section{Summary of Findings, Conclusions, and Recommendations}

\subsection{Summary}

The Mother Tongue-Based Multi-lingual Education (MTB-MLE) music modules for Grades 1, 2 and 3 are found wanting of teaching materials or songs in the vernacular. Thus, this study has culled out materials from various sources for instructional purposes particularly for grades one, two and three learners. This research sought the help of the teachers in the Division of Tacloban City to categorize Waray-waray songs appropriate to the primary grades.

Moreover, this study attempted to examine how the categorization done by music teachers differs from the categorization done by the readability instrument developed for the National Network of Normal Schools (3NS) Corpora Project. However, this was discontinued because the 3ns software and the survey instrument made for this particular study had different ways of categorizing the level of appropriateness of the songs for Grades One, Two and, Three. This study makes do with discussing the results of the categorized songs via $3 \mathrm{~ns}$ and by the teachers. The study also considered the demographic as well as education profile of the teacher-respondents as factors that may influence or have some bearing on the categorization of the songs.

A repertoire of some 30 songs can help pupils sing well, show high and low sounds, correctly clap and step to the beat and rhythm, and finally apply dynamics and tempo to the songs (Choksy, 1999). Along this vein, the study also transcribed the Winaray songs to musical scoring using Sibelius 7, seeing that most of the collected songs were handwritten.

Three demographic and four education variates namely age: sex, marital status, music education, grade level assignment, teaching experience, and in-service training were correlated with the categorization of Winaray songs. Music education — defined as the degree, diploma, or specialized training in music — was factored out in the correlation analysis because not one of the respondents signified having earned a degree or diploma, or attended any specialized training in music. Sex - a demographic profile was also factored out in the correlation because only one male teacher-respondent participated in the survey.

The bivariate analysis of data using the Spearman rank-order correlation (Spearman rho or $\mathrm{r}_{\mathrm{s}}$ ) shows that, as hypothesized, there exists a significant correlation between age and categorization of songs. Moreover, the chi-square test indicated that there exists a significant relationship between grade level assignment, an education variable, and categorization of Winaray songs. Teaching experience, another education variate, consistently posted a strong association with the classification of the songs for the three groups.

On the other hand, between sex (gender), marital status, and in-service training registered no significant correlation with the categorization of the Winaray songs.

\subsection{Conclusions}

From among the demographic variates, age stood out as a significant correlate of the categorization variable together with two education variates: grade level assignment and teaching experience. 
These results find support from literature, which holds that many individuals accumulate life experiences, which allow them to be confident in the teaching-learning situations as they age. Moreover, if the past teaching-learning experiences were minimal and difficult, the learners' enthusiasm will be at a low level that hinders facilitation in the teaching-learning situation (Bastable, 2007).

The knowledge, skills, and productivity of workers are gained over time through experience. In the case of teachers, the underlying assumption is that experience promotes effectiveness (Rice, 2010).

In actual practice, when the teachers are given their Grade level assignments, the ones assigned in the lower level such as Grade One are usually those with less experience, most likely the younger ones. Those assigned to the higher levels like Grade II or Grade III are more or less old or senior teachers. For teachers, the underlying assumption is that experience promotes effectiveness. It is argued, therefore, that the teachers' teaching experience is a critical factor in personnel policies such as transfer and promotion policies that prioritize seniority which, on the other hand could be, a significant source of unfair practices across schools (Rice, 2010).

Such was the case in this study; the Grade III teachers who took part in the survey were the experienced or senior teachers. The teachers who have had several or longer years of teaching experience are more likely to know the suitable and convenient activities, especially materials appropriate to use for their pupils. Other studies, however, say that veteran teachers may be less effective compared to new teachers. Apparently, these experienced teachers do not keep up with the latest curricular and pedagogical advances or the decline in their performance is a result of teacher burn out. On that account, policymakers and stakeholder's ought to equip educators with seminar-trainings and workshops for professional development to encourage the ongoing development of teaching skills that will enable teachers to deliver up-to-date and stateof-the-art educational instruction (Rice, 2010).

In the data collection a seminar-workshop was held where teacher-participants watched the actual singing of songs by musicians who simultaneously played musical instruments for accompaniment. At the same time, the participants evaluated the appropriateness of the songs with the use a rating instrument made for this purpose. The whole experience was very entertaining and exciting for the teacher-respondents. To experience watching a live performance is entirely different from watching a pre-recorded performance viewing via multi-media. This is due mainly to the fact that the visual experience of watching live musicians sing and play musical instruments provides a different and unique effect on people. As a result, live performances are found to be more enjoyable compared to merely watching recorded video. (Vukadinović, \& Marković, 2017, Holmes, C, Knights et al.,2006, Jola, \& Grosbras, 2013).

Concerning the readability instrument that was developed by Oyzon and Fullmer (2015), the software is designed or programmed to rank Winaray texts that can be used by the elementary grades teachers for research and for selecting appropriate reading materials. This is in support of the DepEd's MTB-MLE program in Region VIII and in the entire Philippines. The software functions to provide among others, the following: word count, sentence count, words per sentence, syllable count, average number of syllables, and percentage of words in the most frequently used words.

The plan supposedly was to evaluate and classify the songs through the use of the 3NS Corpora Project software to determine the level of language text difficulty (e.g. easy, moderately difficult, and difficult). The intention was to classify the songs as to grade placement based on the instrument for text readability developed by the 3NS corpora project with Leyte Normal University as lead institution.

The collected songs were sorted out and an attempt was made to analyze the statistical difference using the results of the songs categorized based on the evaluation of the 3 ns Corpora Project instrument (software), and the Primary Teacher-respondents--Grades 1, 2, \& 3 (see Appendix E). It was discontinued however, because the categories of measurement were not complementing. As a result, it was taken out. This study makes do with discussing the results of the categorization of songs via 3 ns by the teachers.

By and large, computer software is limited based on how they are programmed. In the case of this study, when the software was used to categorize the Winaray songs, it was not able to discern the aesthetic 
attributes of the songs as when live musicians performed them. Hence, the ratings provided by the software were based solely on how it was programmed.

This study has its limitations. So, for those who would be interested to conduct future studies of this kind, other factors could be explored such as insufficient facilities as equipment, classrooms, etc., content, ICT knowledge, pedagogical knowledge, teacher career satisfaction, professional commitment, teacher collaboration, salary grade, extra working hours, teaching and learning style, family and personal factors, and student behavior (Coe, R., Aloisi, C., Higgins, S., \& Major, L.E., 2014).

\subsection{Recommendations}

In the light of the findings of this study, the following recommendations may be considered:

Based on the results of this study of the 120 teacher-respondents, only one male teacher attended versus 119 female teachers. This indicates that the teaching profession is a female-dominated field. Maybe it is about time that this scenario changes and our talented male teachers be given the chance to be assigned to the lower primary levels.

The lack of gender diversity in elementary education has a negative impact on young children. The absence of talented male teachers may cause negative gender stereotype formation and future career aspirations. Although there have been many attempts to educate everybody on gender diversity and sensitivity, the education world remains to be a female-dominated field. In our very modern world, maybe it is time to give the male teachers in the academe equal chances to be assigned to the primary grade levels. A balanced number of male and female teachers is suitable for a balanced educational experience for students.

Regarding age as a prime criterion for assigning teachers to a particular grade level, the 20-40 years old - the young adult stage is the point where physical attributes of an individual are at its peak, or it is at its best functioning capacity. The cognitive function, on the other hand, of a young adult is fully matured. They, however, continue to gather new skills and learning from various formal and non-formal experiences.

The 40-64 years - the middle age adulthood, the period when it is believed the physiological attributes of an individual diminish. The cognitive attributes, however, of a middle-aged individual remains at a steady state. The adult's thought processes during this stage go beyond the ability to search for complex and changing understandings to find a variety of solutions to any given situation or problem. In other words, adults are more able see the bigger picture. For many adults, as they age, they accumulate life experiences which allow them to be confident in the teaching-learning situation. Age and experience are like salt and pepper of life. As people's age increase, life experiences increase as well. As the saying goes, education is a lifelong process.

The study found that most, if not, all respondents have not been sent to a seminar-workshop. Hence, attendance in music-related seminar-trainings and workshops is highly recommended for lower primary teachers. Policy makers and stakeholders ought to equip educators with music-related seminar-trainings and workshops for professional development to encourage the ongoing development of teaching skills that will enable them to deliver up to date and state-of-the-art educational instruction. This will, in turn, lift teacher morale and boost confidence to teach music.

This study also reveals that there is no music specialist in the DepEd Division schools of Tacloban City. The school administrators have the discretion to allocate resources to attract teachers to teach music and promote music in the school. Therefore, if a music specialist is present in a school, it is a sign that music is valued in that school.

Hence, recruiting and assigning a music specialist in every district is highly recommended. As stressed in the literature, music education is one of the avenues for culture and arts. The quality of arts and music education depends on the expertise of a teacher.

Filipinos are known to have this great love for music because whichever part of the Philippines one goes to, it is very typical to see Filipinos play a musical instrument excellently or to see those with exceptional singing skills singing their hearts out at all times of the day in the karaoke bars. In other words, 
for the whole lifetime, music is part of the Filipino way of life.

The Philippines, just like any other country in the world, is facing a scarcity of music educator specialists in schools. This research has shown that music education is not given sufficient value as evidenced by the fact that the teacher-respondents seldom or have never at all been sent to music related seminartrainings and workshops. Moreover, there is no specialist music educator in the schools of the Division of Tacloban City, Department of Education.

The scarcity of music specialist educators in the entire Philippines could be attributed to a variety of factors like lack of Universities, which offer the course; another reason is that obtaining a degree in music is expensive. Hence, sending DepEd scholars to specialize in music education is in order and highly recommended.

The study of Ninwanit, Ngamsuttit, Wisuttitpat (2012) on "Development of Administration of Music Education Conservatory of Music, National University Philippines, "reports that, in 1946 administrators who were competing with each other, established administrative policies which contributed adversely to the development of music schools and the sustainable development of music education in the Philippines". The lack of clearly defined administrative policy resulted to limitations in the curriculum which would produce academics and future generations of teachers for colleges and for the country and the students that graduated during that period were not accredited which limited opportunities for their professional careers.

This study echoes suggestion that since Universities that offer music degrees are limited, and the music study is expensive, perhaps more scholarships should be provided to those individuals who cannot afford but have the musical talent and skills for a music educator. Maybe it would not be difficult to allocate a budget for Music seminar-workshops for teachers to be facilitated by some music specialists at least two times every five months.

While these music training and workshops are quite expensive due to the fact that there are only a few music specialists; the registration of the participants can be funded from the Maintenance and Operating Expenses (MOE) of the sending school. It is recommended further that, if possible, music specialist should be required to give a series of community service (meaning no professional fee), free music training and workshops twice in a semester in the DepEd. The free seminar-workshop could be supported financially (purchase of the plane/bus/boat ticket of the music educator facilitator, accommodation, and food) by the DepEd administration.

This study just culled out materials from various sources of Winaray local music for instructional purposes particularly for Grades 1, 2 and 3 only. Only a minimum of 30 Winaray folk songs has been collected and categorized for this study. These songs will be taught to children through "rote method". By popular request of the teacher-participants, it is recommended that the collected songs be transformed into music video/karaoke/tutorial form whereby the teachers in the classroom will merely play the video so that teachers and students can sing and play along with the video in their classrooms. To be included in the music video will be a tutorial on how to play the accompaniment part on the ukulele and/or guitar along with homemade percussion instruments. This idea of using a rote-method approach is intended for non-music specialists like the participants in this study who do not have confidence to sing and play music.

The culture of the Philippines is unique and diverse; it changes from one island to another. The study of Perez, M.J.V., \& Templanza, M. R. (2012), holds that the Spanish friars who started writing the local history, descriptions of religions, domestic and social lives, as well as industries of arts and music of the early Filipinos, could have reflections of biases or prejudices in the narratives of the Spanish friars historians.

One of the salient features of the $\mathrm{K}$ to 12 program is to preserve and promote cultural identity and heritage. This is the best time for music educators to do more research on the production of materials that are fit to the Philippine setting especially the ones which are culture-based, for up to date and state-of-the-art educational instruction, and most especially student and teacher friendly music materials so as to develop the teachers' confidence to teach music properly.

Hence, it is highly recommended that further studies of this kind be conducted. For one, this study 
can be replicated by collecting other untapped songs that are priced and kept by musicians found somewhere else in the region. The potential to obtain mother tongue-based compositions from contemporary songwriters should also be considered in future research investigations.

\section{References}

Abril, J.E., is Epep(2017). The State of Music Education in Basic General Public Schools of Ecuador: The Administrators' Perspective. (Doctoral dissertation, University of Miami)

Arteche, J. (1983). An Analysis And Adaptation of Leyte-Samar Folk Songs For Use in College of Music Education (Doctoral Dissertation, Leyte State College, Tacloban City)

Bastable, S. B., \& Dart, M. A. (2008). Developmental stages of the learner. Nurse as educator: Principles of teaching and learning practice, 147-198.

Beall, G. (1991). Learning Sequences and Music Learning. The Quarterly Journal of Music Teaching and Learning II, 1, 87-96.

Balmer, F. (2007). Phonetic, Phonological and Prosodic Triggers for Mondegreens.Borromeo, M. (2015). Philippine Music Education http://ncca.gov.ph/subcommissions/subcommission-on-the-arts-sca/music/philippine-music-education/ (Retrieved as of: July 3, 2017, 8am)

Buhl-Wiggers, J., Kerwin, J., Smith, J., \& Thornton, R. (2017, April). The impact of teacher effectiveness on student learning in Africa. In Centre for the Study of African Economies Conference.

Castello, D. (2015). First Language Acquisition and Classroom Language Learning: Similarities and Differences.

Choksy, L., (1999) Kodaly method 1 (Vol. 1). Prentice Hall.

Coe, R., Aloisi, C., Higgins, S., \& Major, L.E., (2014). What makes a great teaching? Review of the underpinning research.

Corrigall, K. A., \& Schellenberg, E. G. (2015). Liking music: Genres, contextual factors, and individual differences. Art, aesthetics, and the brain, 263.

Creswell, J. W. (2012). Educational Research: Planning Conducting, and Evaluationg Quantitative and Qualitative Research. Boston, MA: Pearson Education, Inc.

Cruz, N. (2015). The Implementation of the Mother Tongue-Based Multilingual Education in Grade I in the Public Elementary Schools in Pangasinan I. DLSU Research Congress

Cummins, J. (2008). BICS and CALP: Empirical and theoretical status of the distinction. In Encyclopedia of language and education (pp. 487-499). Springer US.

DepEd curriculum guide 2013

Davis, P.M. (2014). Cognition and Learning: A review of the literature with reference to ethnolinguistic minorities. Sil International

Dalby, B. (2005). Toward an Effective Pedagogy for Teaching Rhythm: Gordon and Beyond. Music Educators Journal 92(1), 54-60.

Elliot, D. (2009). Praxial Music Education; Reflections and Dialogues. Oxford University Press.

Espina, M. (1987). A Proposed Supplementary Repertoire (Doctoral Dissertation, Leyte State College, Tacloban City)

Failoni, J. W. (1993). Music as Means To Enhance Cultural Awareness and Literacy in the Foreign Language Classroom. Mid-Atlantic Journal of Foreign Language Pedagogy, 1, 97-108.

Garvis, S. (2013). Beginning generalist teacher self-efficacy for music compared with maths and English. British Journal of Music Education, 30(1), 85-101.

Gouyon, F., Dixon, S., Pampalk, E., \& Widmer, G. (2004, June). Evaluating rhythmic descriptors for musical genre classification. In Proceedings of the AES 25th International Conference (pp. 196-204).Hacket, P., Lindeman C. (1997), The Musical Classroom, Backgrounds, Models, and Skills for Elementary Teaching. Prentice Hall, New Jersey 07458

Hargreaves, D. J., Miell, D., \& MacDonald, R. A. (2002). What are musical identities, and why are they important. Musical identities, 120.

Holden, H., \& Button, S. (2006). The teaching of music in the primary school by the non-music specialist. British Journal of Music Education, 23(01), 23-38.

Holmes, C., Knights, A., Dean, C., Hodkinson, S., \& Hopkins, V. (2006). Keep music live: music and the alleviation of apathy in dementia subjects. International Psychogeriatrics, 18(4), 623-630.

Houlahan, M., \& Tacka, P. (2015). Kodaly Today: A Cognitive Approach to Elementary Music Education. Oxford University Press.

Kim, Y., \& Weseley, A. J. (2017). The Effect of Teacher Gender and Gendered Traits on Perceptions of Elementary School Teachers. Journal of Research in Education, 27(1), 114-133.

Islahi, F., \& Nasreen, N. (2013). Who Make Effective Teachers, Men or Women? An Indian Perspective. Universal Journal of Educational Research, 1(4), 285-293.

Jola, C., \& Grosbras, M. H. (2013). In the here and now: Enhanced motor corticospinal excitability in novices when watching live compared to video recorded dance. Cognitive Neuroscience, 4(2), 90-98.

Kons, M., Steinbach, K., \& Kivestu, T. (2016). Local Cultural Heritage Usage in Music Studies in South-eastern Estonian Schools. Procedia-Social and Behavioral Sciences, 217, 531-536.

Kramer, L. (2015). Song as a phrase. New Literary History, 573, Vol. 46, No, 4 pp 573-594 
Lagarde, S. (2004), Koro Leyteño, Choral Arrangements of Selected Traditional Songs of Leyte. APO Production Unit, Inc. Diliman Quezon City, Philippines

Lewis, M. P., \& Gary, F. (2015). Simmons, and Charles D. Fennig (eds.). 2013. Ethnologue: Languages of the world., 233-62

Luanco, G., (1982) Kandabao: Essays On Waray Language, Literature, and Culture. Divine Word University Publications, Tac. City Phils.

Luangco, G., (1982) Waray Literature Literature An Anthology Of Leyte-Samar Writings. Divine Word Univ. Publications, Tacloban City

Ludke, K. M. (2009). Teaching foreign languages through songs. Edinburgh: The University of Edinburgh.

Lumen, A., (1968). A Manual On Rhythmic Development For Grade I Children in Leyte-Samar Region (Doctoral Dissertation, Divine Word University, Tacloban City)

Maricel (2012). Filipinos Undying love for music. https://basangsisiw.wordpress.com/2012/04/22/filipinos-undying-love-for-music/

(Retrieved as of: August 25, 2016, 3:35 PM)

Ninwanit, K., Ngamsuttit, C., Wisuttitpat, M. (2012), Development and Administration of Music Education Conservatory of Music, National University Philippines. European Journal of Business \& Social Sciences, Vol. 1, No. 8, pp 33-37

Nolasco, R. M. (2008). The prospects of multilingual education and literacy in the Philippines. The paradox of Philippine education and education reform: Social science perspectives, 133-145

Trudel, B., \& Young, C., (2016) Good Answers to Tough Questions in Mother Tongue-Based Multi Lingual Education. SIL International

McClellan, R. (2015). https://notes.noteflight.com/noteflight-behind-the-notation-lyrics/ (Retrieved as of: November 30, 2015, 2:30 AM)

McCrae, R. R., \& Costa, P. T. (1987). Validation of the five-factor model of personality across instruments and observers. Journal of personality and social psychology, 52(1), 81

Mozayan, M. R., (2015) (BICS \& CALP Revisited: A Critical Appraisal.

Nadeem, M., \& Rahman, A. (2013). Stress out of stress: stressing unaccented syllables’ Dilemma. STRESS, 2(2).

Ocbian, M. M, Suod, M. A. F., Garduque Jr, J. G., \& Arimado, I B.. (2005). "Big Books" as Mother Tongue-Based Instructional Materials in Bicol for Grade One Pupils. Asia Pacific Journal of Multi-Disciplinary Research, 3(4)

Odanga, S. J., Aloka, P. J., \& Raburu, P. (2015). Influence of Marital Status on Teachers' Self-Efficacy in Secondary Schools of Kisumu County, Kenya. Academic Journal of Interdisciplinary Studies, 4(3), 115.

Okabe, M., \& 岡部正義. (2013). Where does Philippine education go?: the" K to 12" program and reform of Philippine basic education.

Oyzon, V. Q (2010). Taking Another Woman as My Mother: The State of Waray Language as Used by Today's Waray Children.

Oyzon, V. Q., Corrales, J. B., \& Estardo Jr, W. M. (2015). Validation Study of Waray Text Readability Instrument. International Journal of Evaluation and Research in Education, 4(2), 45-53.

Oyzon, V. Q., Lubio, C. C., Salamia, J. I., \& Ripalda, L. M. (2014). Teaching Geometrical Figures in Waray: The LNU-ILS Experience. Journal of Education and Learning (EduLearn), 8(2), 115-121.

Oyzon, V., \& Fullmer, J. M. (2012). MTBMLE initiatives In Region 8. Viewed on April, 24, 2012.Perez, M. J. V., \& Templanza, M. R. (2012). Local studies centers: Transforming history, culture and heritage in the Philippines. IFLA journal, 38(4), $297-309$.

Rea, L. and Parker, R., (2005). Designing and conducting survey research. A comprehensive guide. San Francisco, CA: John Wiley \& Sons, Inc.

Rentfrow, P. J., \& Gosling, S. D. (2007). The content and validity of music-genre stereotypes among college students. Psychology of Music, 35(2), 306-326.

Rice, J. K. (2010). The Impact of Teacher Experience: Examining the Evidence and Policy Implications. Brief No. 11. National center for analysis of longitudinal data in education research.

Rozmajzl, M., \& Boyer-White, R. (2006). Music Fundamentals, Methods, and Materials for the Elementary Classroom Teacher. Longman, Inc., 95 Church Street, White Plains, NY, 10601.

Sanchez, A. S. Q. (2013). Literacy Instruction In The Mother Tongue: The Case Of Pupils Using Mixed Vocabularies. Journal of International Education Research, 9(3), 235.

Taetle, L. A. U. R. I. E., \& Cutietta, R. O. B. E. R. T. (2002). Learning theories as roots of current musical practice and research. The new handbook of research on music teaching and learning, 279-298.UNESCO (2005) Education for All, The Quality Imperative

UNESCO (2003) Multiculturalisn and Political Integration in Modern Nation-States 2012.

UNESCO (2016) Including the Excluded: Promoting Multi-lingual Education

Valerio, M.T., (2015). Current Perspectives On Mother-Tongue Based Instruction In The Newly Implemented K to 12 Curriculum of The Philippines. British Journal of Education. British Journal of Education, Vol. 3, No, 9 pp, 51-56

Vukadinović, M. S., \& Marković, S. (2017). The relationship between the dancers' and the audience's aesthetic experience.

Wa-Mbaleka, S. (2015). Switching to Mother Tongue-Based Education: The New Trend and Its Challenges. US-China Foreign Language, 257.

Wa-Mbaleka, S. (2014). Two proposed perspectives on mother tongue-based education in the Philippines. International Journal of Academic Research in Progressive Education and Development, 3(4), 302-312.

Ward, M. (2003). The extent to which American children's folk songs are taught by general music teachers throughout the United States (Doctoral dissertation, University of Florida).

Wiggins, R. A., \& Wiggins, J. (2008). Primary music education in the absence of specialists. International Journal of Education \& the Arts, 9(12), 1-27

Wood, T. D. (2012). Teacher perceptions of gender-based differences among elementary school teachers. Saint Louis University. 
Valerio, M.T., (2015). Current Perspectives On Mother-Tongue Based Instruction In The Newly Implemented K to 12 Curriculum of The Philippines. British Journal of Education. British Journal of Education, Vol. 3, No, 9 pp, 51-56

Basilio, F., et.al., (2003), Fundamental Statistics. Trinitas Publishing, Inc. Bulacan, Philippines.

\section{Appendix A.}

\section{APPENDIX A}

The Schools and Number of Grades One to Three Teachers in the Six DLC's in the DepEd-Division of Tacloban City.

\begin{tabular}{|c|c|c|c|c|c|}
\hline DLC 1 & DLC 2 & DLC 3 & DLC 4 & DLC 5 & DLC 6 \\
\hline $\begin{array}{l}\text { 1. Name of Central School: Rizal } \\
\text { Central School } \\
\text { No. of Teachers: } \\
\text { Grade I: } 8 \\
\text { Grade II: } 8 \\
\text { Grade III: } 8 \\
\text { 2. RTR Elem. School } \\
\text { Grade I: } 3 \\
\text { Grade II: } \\
\text { Grade III: } 4 \\
\text { 3. Bliss Elem. School } \\
\text { Grade I: } 2 \\
\text { Grade II: } 2 \\
\text { Grade III: } 2 \\
\text { 4. Salvacion Elem School } \\
\text { Grade II } 2 \\
\text { Grade II: } 2 \\
\text { Grade III: } 2 \\
\text { 5. Caibaan Elem School } \\
\text { Grade I: } 4 \\
\text { Grade II: } 4 \\
\text { Grade III: } 4 \\
\text { 6. Tagpuro Elem. School } \\
\text { Grade I: } 1 \\
\text { Grade II: } 1 \\
\text { Grade III: } 1 \\
\text { 7. Lorenzo Daa Memorial Schl } \\
\text { Grade I: } 1 \\
\text { Grade II: } 1 \\
\text { Grade III: } 1 \\
\text { 8. Greendale Residences } \\
\text { Integrated Schol } \\
\text { Grade I: } 1 \\
\text { Grade II: } 1 \\
\text { Grade III: } 1\end{array}$ & $\begin{array}{l}\text { 1. Name of Central School: San } \\
\text { Fernando Central School } \\
\text { No. of Teachers: } \\
\text { Grade I: } 8 \\
\text { Grade II: } 6 \\
\text { Grade III: } 8 \\
\text { 2. Bãez Memorial School } \\
\text { Grade I: } 3 \\
\text { Grade II: } 3 \\
\text { Grade III: } 3 \\
\text { 3. Bayanihan Elementary School } \\
\text { Grade I: } 2 \\
\text { Grade II: } 2 \\
\text { Grade III: } 2 \\
\text { 4. San Roque Elementary School } \\
\text { Grade I: } 1 \\
\text { Grade II: } 1 \\
\text { Grade III: } 1 \\
\text { 5. Palanog Resettlement } \\
\text { Grade I: } 2 \\
\text { Grade II: } 2 \\
\text { Grade III: } 2 \\
\text { 6. JARMS } \\
\text { Grade I: } 4 \\
\text { Grade II: } 4 \\
\text { Grade III: } 3 \\
\text { 7. UTAP Elem. School } \\
\text { Grade I: } 2 \\
\text { Grade II: } 2 \\
\text { Grade III: } 2\end{array}$ & $\begin{array}{l}\text { 1. Name of Central School: } \\
\text { Kapangian Central School } \\
\text { No. of Teachers: } \\
\text { Grade I: } 9 \\
\text { Grade II: } 7 \\
\text { Grade III: } 7 \\
\text { 2. Sto, Niño SPED Center } \\
\text { Grade I: } 4 \\
\text { Grade II: } 3 \\
\text { Grade III: } 3 \\
\text { 3. Bulante Elem. School } \\
\text { Grade I: } 2 \\
\text { Grade II: } 2 \\
\text { Grade III: } 2 \\
\text { 4. Sta. Elena Elem. School } \\
\text { Grade I: } 1 \\
\text { Grade II: } 1 \\
\text { Grade III: } 1 \\
\text { 5. Cabalawan Elem School } \\
\text { Grade I: } 2 \\
\text { Grade II: } 2 \\
\text { Grade III: } 2 \\
\text { 6. Basper Elem. School } \\
\text { Grade I: } 1 \\
\text { Grade II: } 1 \\
\text { Grade III: } 1 \\
\text { 7. Palanog Elem School } \\
\text { Grade I: } 3 \\
\text { Grade II: } 3 \\
\text { Grade III: } 3 \\
\text { 8. New Hope Elem. Schl } \\
\text { Grade I: 1 } \\
\text { Grade II: } 1 \\
\text { Grade III: } 1 \\
\text { 9. Ridgeview Integrated Schl. } \\
\text { Grade I: } 3 \\
\text { Grade II: } 3 \\
\text { Grade III: } 3\end{array}$ & $\begin{array}{l}\text { 1. Name of Central School: } \\
\text { Panalaron Central School } \\
\text { No. of Teachers: } \\
\text { Grade I: } 3 \\
\text { Grade II: } 3 \\
\text { Grade III: } 3 \\
\text { 2. Sagkahan Elem. School } \\
\text { Grade I: } 7 \\
\text { Grade II: } 8 \\
\text { Grade III: } 7 \\
\text { 3. Tigbao Diit Elem School } \\
\text { Grade I: } 2 \\
\text { Grade II: } 5 \\
\text { Grade III: } 3 \\
\text { 4. Bagacay Elem. School } \\
\text { Grade I : } 2 \\
\text { Grade II: } 2 \\
\text { Grade III: } 2 \\
\text { 5. Mercyville Elem. School } \\
\text { Grade I: } 2 \\
\text { Grade II: } 2 \\
\text { Grade III: } 2\end{array}$ & $\begin{array}{l}\text { 1. Name of Central School: San } \\
\text { Jose Elem School } \\
\text { No. of Teachers: } \\
\text { Grade I: } 11 \\
\text { Grade II: } 11 \\
\text { Grade III: } 11 \\
\text { 2. Marasbaras Elem School } \\
\text { Grade I: } 4 \\
\text { Grade II: } 4 \\
\text { Grade III: } 3 \\
\text { 3. DVQ Elementary School } \\
\text { Grade I: } 3 \\
\text { Grade II: } 3 \\
\text { Grade III: } 3 \\
\text { 4. Nula-tula Elem. School } \\
\text { Grade I: } 2 \\
\text { Grade II: } 2 \\
\text { Grade III: } 2 \\
\text { 5. Camansihay Elem School } \\
\text { Grade I: } 1 \\
\text { Grade II: } 1 \\
\text { Grade III: } 1 \\
\text { 6. Sto. Niño Elem. School } \\
\text { Grade I: } 1 \\
\text { Grade II: } 1 \\
\text { Grade III: } 1 \\
\text { 7. Fishermen's Village Elem. } \\
\text { School } \\
\text { Grade I: } 1 \\
\text { Grade II: } 1 \\
\text { Grade III: } 1 \\
\text { 8. Manlurip Elem. School } \\
\text { Grade I: } 2 \\
\text { Grade II: } 2 \\
\text { Grade III: } 2 \\
\text { 9. North Hill Arbours } \\
\text { Integrated School } \\
\text { Grade I: } 1 \\
\text { Grade II: } 1 \\
\text { Grade III: } 1 \\
\text { 10. Guadalupe Heights } \\
\text { Integrated School } \\
\text { Grade I: } 2 \\
\text { Grade II: } 2 \\
\text { Grade III: } 2 \\
\end{array}$ & $\begin{array}{l}\text { 1. Name of Central } \\
\text { School: City Central } \\
\text { School } \\
\text { No of Teachers: } \\
\text { Grade I: } 4 \\
\text { Grade II: } 4 \\
\text { Grade III: } 4 \\
\text { 2. Anibong Elem } \\
\text { School } \\
\text { Grade I: } 4 \\
\text { Grade II: } 4 \\
\text { Grade III: } 5 \\
\text { 3. V\&G Elem. School } \\
\text { Grade I: } 5 \\
\text { Grade II: } 4 \\
\text { Grade III: } 5 \\
\text { 4. Lucio Elem School } \\
\text { Grade I: } 3 \\
\text { Grade II: } 2 \\
\text { Grade III: } 2 \\
\text { 5. Scandinavian Elem } \\
\text { School } \\
\text { Grade I: } 2 \\
\text { Grade II: } 2 \\
\text { Grade III: } 2 \\
\text { 6. Old Kawayan Elem. } \\
\text { Schl } \\
\text { Grade I: } 1 \\
\text { Grade II: } 1 \\
\text { Grade III: } 1 \\
\text { 7. Kapuso Integrated } \\
\text { Schl. } \\
\text { Grade I: } 3 \\
\text { Grade II: } 3 \\
\text { GradeIII: } 3 \\
\end{array}$ \\
\hline TOTAL: & 63 & 72 & 53 & 83 & 64 \\
\hline 30\% Sample: & 18.9 & 21.6 & 15.9 & 24.9 & 19.2 \\
\hline $\begin{array}{l}\text { Total no. of } \\
\text { sample: }\end{array}$ & 19 & 22 & 15 & 25 & 19 \\
\hline Total Sample; & 120 & & & & \\
\hline
\end{tabular}




\section{APPENDIX B \\ PROGRAM OF THE SEMINAR-WORKSHOP ON}

\section{Categorizing local Waray-waray Songs as MTB-MLE music instructional materials for Grades One, Two, and Three. \\ February 17, 2018}

Objectives:

1. Showcase the selected 30 Winaray songs to the grades 1 to 3 teachers of DepEd, Division of Tacloban City so that they will be able to see how to:

1.1. perform the songs using home-made classroom musical instruments (e.g., drums, rhythm sticks, shakers, triangle, tambourine) and simple musical instruments such as guitar and or ukulele for accompaniment.

1.2. sing the songs properly (e.g. in-tune singing, correct tempo, accent, and phrasing)

2. Evaluate the songs according to their grade level appropriateness using a given set of criteria.

3. Come up with a compilation of Waray-waray songs that can be used in addition to the existing MTBMLE materials for music instruction in the primary grades (Grades I, II, III).

Schedule of seminar-workshop activities

\begin{tabular}{|l|l|}
\hline \multicolumn{1}{|c|}{$\begin{array}{l}\text { Categorizing Local Waray-waray Songs as MTB-MLE Music Instructional Materials } \\
\text { for Grades One, Two, and Three. } \\
\text { February 17, 2018 }\end{array}$} \\
\multicolumn{1}{|c|}{ LEYTE NORMAL UNIVERSITY, AV Studio } \\
\hline \multicolumn{1}{|c|}{ TIME } & \multicolumn{1}{c|}{ Activities } \\
\hline $8: 00-8: 30$ & Registration \\
\hline $8: 30-8: 40$ & Opening Program \\
\hline $8: 40-9: 10$ & Discussion on how to answer the survey instrument. \\
\hline $9: 10-9: 40$ & $\begin{array}{l}\text { First set of performance (10 songs) and evaluation of songs using the } \\
\text { rating scale }\end{array}$ \\
\hline $9: 40-10: 00$ & Snack break/coffee break \\
\hline $10: 00-10: 30$ & $\begin{array}{l}\text { Second set of performance (10 songs) \& evaluation of the songs using } \\
\text { the rating scale. }\end{array}$ \\
\hline $10: 30-11: 00$ & $\begin{array}{l}\text { Third set of performance (10 songs) \& evaluation of the songs using } \\
\text { the rating scale. }\end{array}$ \\
\hline $11: 00-11: 30$ & $\begin{array}{l}\text { Closing activities } \\
* \text { collection of the survey instruments } \\
\text { *giving of tokens and certificates of participation/appreciation }\end{array}$ \\
\hline $12: 00$ & \begin{tabular}{l} 
Lunch \\
\hline
\end{tabular} \\
\hline
\end{tabular}

for inquiries you may email me @ marisol.abanilla@1nu.edu.ph 


\section{APPENDIX C \\ SURVEY INSTRUMENT}

\section{PART I - PROFILE OF TEACHER-RESPONDENTS}

Demographic profile refers to the profile variables of Grade I, Grade II, and Grade III Teachers relative to such personal factors as age, sex, and marital status.

Education Profile. refers to the completed course or highest educational attainment of the teacher, whether he/she has a bachelor's, master's, or doctoral degree. In addition, teaching experience in the grade level, and number of trainings, seminar-workshops and/or conferences attended related to music education are also covered.

Directions: Please provide/fill in the needed information asked for in the following:

Name of Respondent (optional):

Grade Level Assignment:

Age (as of last birthday): Sex:

Marital Status:

Music Education (refers to the highest degree or diploma in music, whether the teacher earned a formal degree in music or had only completed special training in music as basis for teaching assignment):

Music teaching experience (refers to the number of years the respondent has been teaching in the grade level he/she is assigned to teach):

In-service training (refers to the number of courses, trainings, workshops and seminars in music teaching attended by the teacher for the past five years): 
Directions: As you listen to each of the songs, please put a check mark in the column that corresponds to your evaluation of the characteristics of the piece of music using the following ratings.

$$
\begin{aligned}
& 5 \text { - Very much appropriate } \\
& 4 \text { - Very appropriate } \\
& 3 \text { - Appropriate } \\
& 2 \text { - Less appropriate } \\
& 1 \text { - Not appropriate }
\end{aligned}
$$

\begin{tabular}{|c|c|c|c|c|c|}
\hline Song No. 1: Title & 5 & 4 & 3 & 2 & 1 \\
\hline \multicolumn{6}{|l|}{ Characteristics for Grade One songs } \\
\hline \multicolumn{6}{|l|}{ MELODIC STRUCTURE } \\
\hline \multicolumn{6}{|l|}{$\begin{array}{l}\text { 1. The song is within the range of five or six notes centering around } \mathrm{C} \text { to } \mathrm{A} \text {, or within } \\
\text { the comfortable *tessitura of young singers. }\end{array}$} \\
\hline \multicolumn{6}{|l|}{ 2. The song has simple repeated words and pitches. ${ }^{1}$} \\
\hline \multicolumn{6}{|l|}{ RHYTHMIC STRUCTURE } \\
\hline \multicolumn{6}{|l|}{ 3. The song belongs to the duple meter of limited range and simple rhythm. ${ }^{2}$} \\
\hline \multicolumn{6}{|l|}{$\begin{array}{l}\text { 4. The meter of the song belongs to the simple meters (two-two, or four-four) of } \\
\text { children's songs. }{ }^{2}\end{array}$} \\
\hline \multicolumn{6}{|l|}{ 5. The song is in the six-eight meter. ${ }^{3}$} \\
\hline \multicolumn{6}{|l|}{ LENGTH OF THE SONG } \\
\hline \multicolumn{6}{|l|}{ 6. The songs is short with at least eight (8) to sixteen (16) measures in length. ${ }^{4}$} \\
\hline \multicolumn{6}{|l|}{ SYLLABICATION } \\
\hline $\begin{array}{l}\text { 7. The song takes into account the basics of lyric notation such as proper set up of the } \\
\text { musical markings. }\end{array}$ & & & & & \\
\hline
\end{tabular}

(*tessitura: the range within which most notes of a vocal part fall.)

\section{Endnotes:}

${ }^{1}$ Songs are easy to learn and remember for Grade one pupils when they have repeated words and pitches. Melodic pattern should be simple.

${ }^{2}$ This is not to say that only the duple meter songs should be taught in Grade One. It is still essential to teach some songs in four-four and six-eight meter.

${ }^{3}$ It does not mean that songs with three four or six-eight shall not be taught, other meters can also be taught in preparation for the next grade level. Grade one pupils are already capable of distinguishing between beat and rhythm. They can create simple accompaniments through playing rhythm instruments.

${ }^{4}$ At this age, the lung capacity and breath control are limited; therefore song phrases should be short.

${ }^{5}$ Music and singing is a form of language, singing is an enhanced speech or a refigured speech. The meaning of an entire word will possibly change, if syllabic stress is misplaced. The basics of lyrics notation, such as proper set up of the music markings (e.g. accelerating the tempo or prolonging the note, beam, slur, dots, staccato, dynamic markings, phrase marks, stress marks etc..) is a way of how a musician shapes a sequence of notes in a passage of music to express emotion or impression. If lyric notations are not done properly, mondegreens (mondegreens are usually sang, singers make use of a rather altered and modified type of pronunciation) are likely to happen. 
Directions: As you listen to each of the songs, please put a check mark in the column that corresponds to your evaluation of the characteristics of the piece of music using the following ratings.

$$
\begin{aligned}
& 5 \text { - Very much appropriate } \\
& 4 \text { - Very appropriate } \\
& 3 \text { - Appropriate } \\
& 2 \text { - Less appropriate } \\
& 1 \text { - Not appropriate }
\end{aligned}
$$

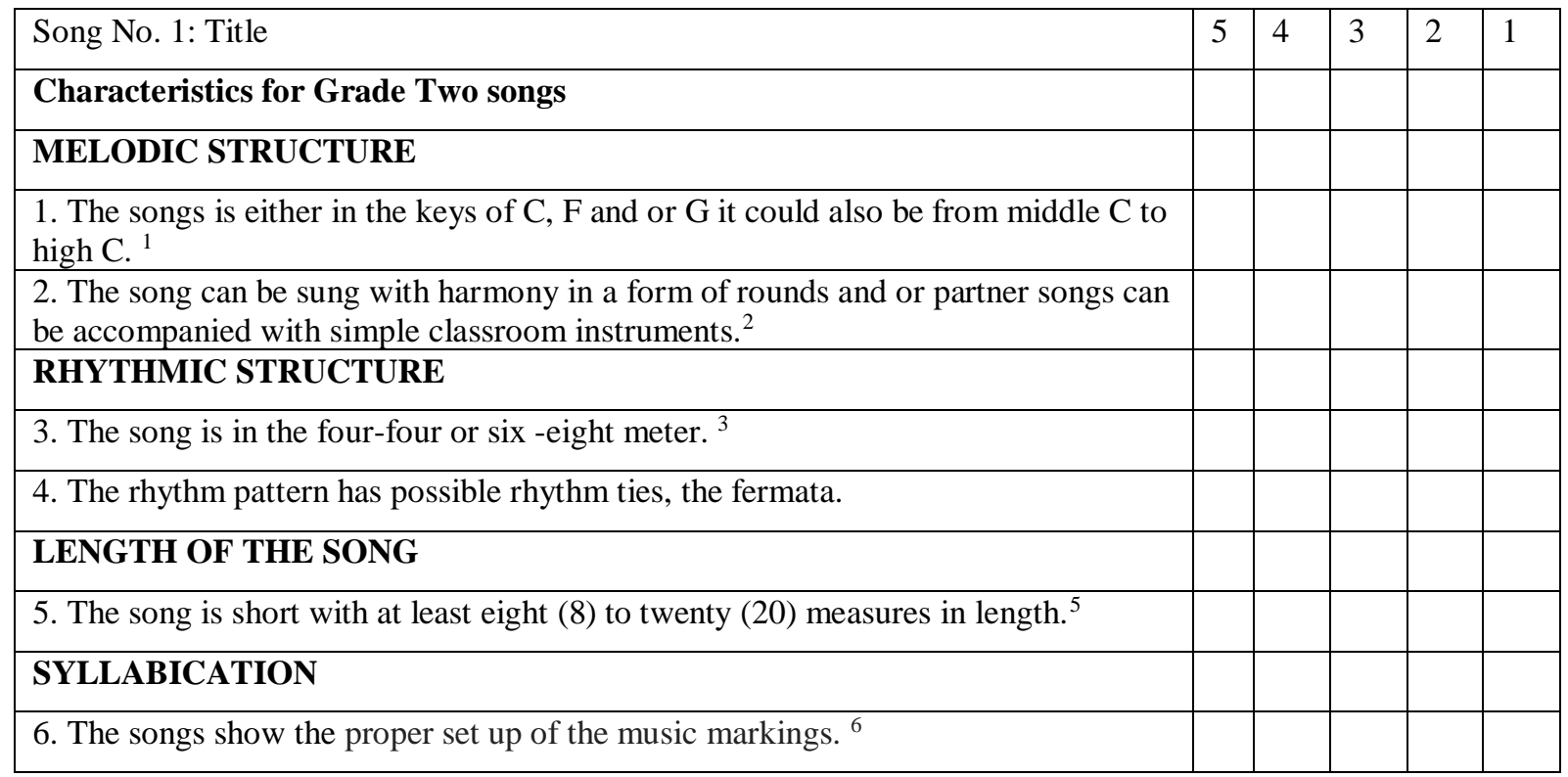

\section{Endnotes:}

${ }^{1}$ All of the Grade Two singing exercises must be in the key of $\mathrm{C}, \mathrm{F}$ and $\mathrm{G}$ it can also be from middle $\mathrm{C}$ to high $\mathrm{C}$, because, Grades two pupils can sing advance and more complex songs. They can be more expressive than the First Graders since they have greater physical control of dynamics and of longer pitches plus their vocal range are already capable of expanding.

${ }^{2}$ Once the first grades have achieved and completed the outlines musical activities, the $2^{\text {nd }}$ graders are then ready to experience selected advance and or complex music; e.g. unsingable intervals, complicated rhythmic patterns, can perform simple harmony such as rounds and the song can be accompanied with simple classroom instruments.

${ }^{3}$ Assuming that in the Grade One of the previous school year, they have mastered duple meter.

${ }^{4}$ While short songs with repetition are still easier to learn and memorize, Grade two pupils are capable of singing longer phrases.

${ }^{5}$ Music and singing are forms of language; singing is an enhanced speech or a refigured speech. The meaning of an entire word will possibly change if syllabic stress is misplaced. The basics of lyrics notation, such as proper set up of the music markings (e.g. accelerating the tempo or prolonging the note, beam, slur, dots, staccato, dynamic markings, phrase marks, stress marks etc..) is a way of how a musician shapes a sequence of notes in a passage of music to express emotion or impression. If lyric notations are not done properly mondegreens (mondegreens are usually sang, singers make use of a rather altered and modified type of pronunciation), are likely to happen.

Directions: As you listen to each of the songs, please put a check mark in the column that corresponds to your 
evaluation of the characteristics of the piece of music using the following ratings.

5 - Very much appropriate

4 - Very appropriate

3 - Appropriate

2 - Less appropriate

1 - Not appropriate

\begin{tabular}{|c|c|c|c|c|c|}
\hline Song No. 1: Title & 5 & 4 & 3 & 2 & 1 \\
\hline \multicolumn{6}{|l|}{ Characteristics for Grade three songs } \\
\hline \multicolumn{6}{|l|}{ MELODIC STRUCTURE } \\
\hline \multicolumn{6}{|l|}{ 1. The song has uncommon and unsingable intervals. ${ }^{1}$} \\
\hline \multicolumn{6}{|c|}{$\begin{array}{l}\text { 2. The song can be sung with harmony in a form of rounds and or partner songs can } \\
\text { be accompanied with simple classroom instruments. }{ }^{2}\end{array}$} \\
\hline \multicolumn{6}{|c|}{ RHYTHMIC STRUCTURE } \\
\hline \multicolumn{6}{|c|}{ 3. The song is either duple, triple, quadruple simple and compound meter. ${ }^{3}$} \\
\hline \multicolumn{6}{|l|}{ LENGTH OF THE SONG } \\
\hline \multicolumn{6}{|c|}{ 4. The song is short with at least eight (8) to twenty (20) measures in length. ${ }^{4}$} \\
\hline \multicolumn{6}{|l|}{ SYLLABICATION } \\
\hline 5. The song has proper set up of the music markings. ${ }^{5}$ & & & & & \\
\hline
\end{tabular}

\section{Endnotes:}

${ }^{1}$ In terms of melodic learning this can be the right time to introduce uncommon and unsingable intervals in order for the children's intervallic vocabulary to increase (e.g. The song has the uncommon intervals which are the tonal extended patterns (low so, low la and high do) of the extended pentaton; s-m-l-d-r- $1_{1}, s_{1}, d^{\prime}$.) While some of these intervals are uncommon and unsingable for children, the great majority can be found in folk and composed music.

${ }^{2}$ Grade three students are ready to sing in parts (harmony) when they can sing unison songs accurately and confidently. That is, begin with a type of harmony that can be improvised or created from a song fragment. Ostinatos can be created from parts of many rounds. Children in this age-group can sing familiar songs in two parts, such as rounds or "partner songs" (two different songs that share the same sequence of chords, with the same key and tempo)

${ }^{3}$ In terms of rhythmic learning for third graders, standard numerical meter signs maybe introduced. Song materials should include duple simple, duple quadruple and compound meters as well. The rhythmic patterns should include a combination of quarter, eighth note and eighth rest patterns and even dotted notes/rests.

${ }^{4}$ Eight year olds are likewise able to progress rapidly in terms of physical aspects. Although at this age the lung capacity and breath control and limited, phrases can be longer.

${ }^{5}$ Music and singing are forms of language; singing is an enhanced speech or a refigured speech. The meaning of an entire word will possibly change if syllabic stress is misplaced. The basics of lyrics notation, such as proper set up of the music markings (e.g. accelerating the tempo or prolonging the note, beam, slur, dots, staccato, dynamic markings, phrase marks, stress marks etc..) is a way of how a musician shapes a sequence of notes in a passage of music to express emotion or impression. If lyric notations are not done properly mondegreens (mondegreens are usually sang, singers make use of a rather altered and modified type of pronunciation), are likely to happen. 
APPENDIX D

Categorized Grades One, Two \&, Three Waray-waray Songs

by the Grades One to Three Teachers

\section{GRADE ONE SONGS}

\section{Hardin}

\section{Moderato}

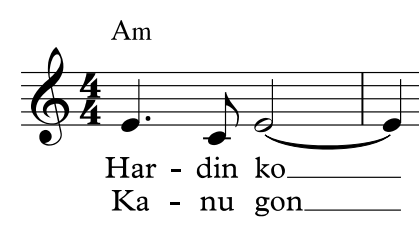

$\mathrm{Dm}$

From the thesis of Aurora Oliva Lumen (1968)

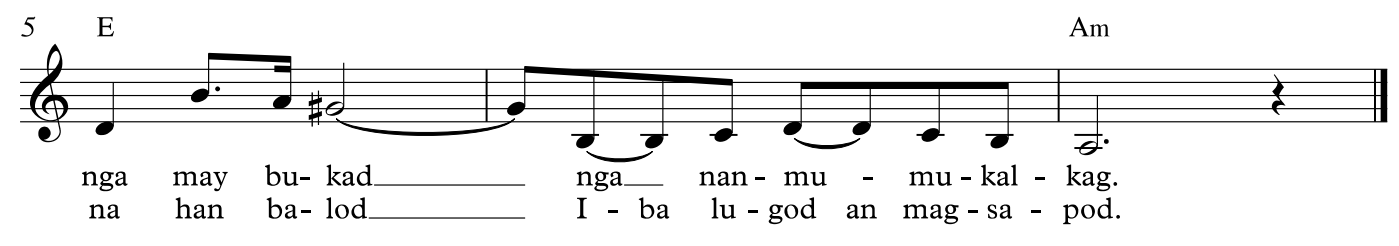

May du-ha nga tam - si lin-nu pad

Am

\section{HARDIN \\ Garden}

(Translation by Firie Jill T. Ramos)

Hardin ko, may duha nga tamsi linupad In my garden two birds fly

May dara nga sanga may bukad

Holding in their beaks a flower

$$
\begin{gathered}
\text { Nga namumukalkag } \\
\text { All a-bloom }
\end{gathered}
$$

Kanugon, kun hiya hangadto ha lawod

$\mathrm{Oh}$, what a waste if it flies to the sea

Nga magdarudagna han balod

And perchance be caught by the waves

Iba lugod an magsapod

Then it's bad destiny's gains instead 


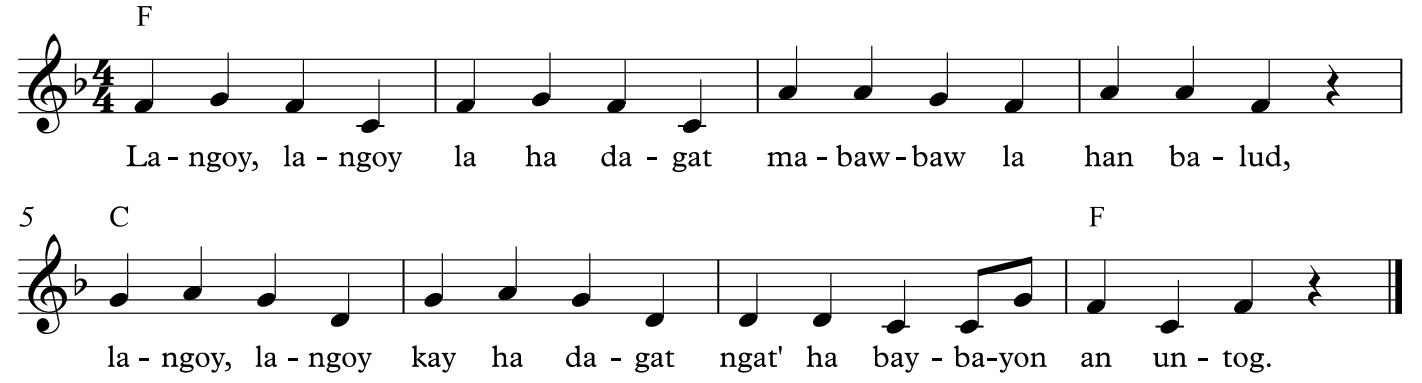

\section{LANGOY}

Swim

(Translation by Firie Jill T. Ramos)

Langoy-langoy la ha dagat, mabawbaw han balud

Swim swim in the sea, gentle are the waves

Langoy-langoy la ha dagat, ngat' ha baybayon an untog

Swim swim in the sea, till the sandy shores

\section{Syomoy}

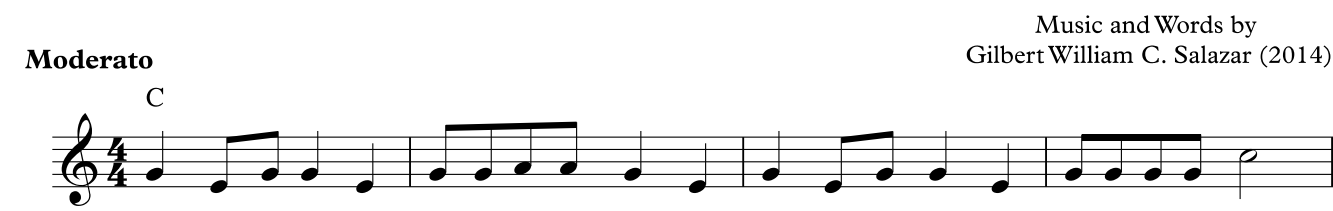

Syo-moy, ta-rat -si, ma-ris-yo nga mum-lay. Sud-sud, bu-lang-koy, tu-pa-tu-pa man.

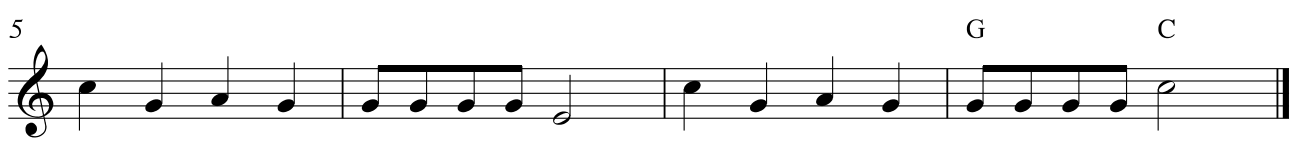

An ak sang-kay, ma-li-pay-li-pay.

$\mathrm{Bi}$ - san kat-soy ba-sta, na-en-joy.

\section{SYOMOY \\ Marbles \\ (Translation by Firie Jill T. Ramos)}

Syomoy, taratsi, marisyo nga mumlay, sud-sud, bulangkoy, tupa-tupa man Marbles, taratsi, are fun games, hopscotch, bulangkoy, tupa- tupa and more

An ak sangkay malipay-lipay, bisan katsoy, basta na-enjoy!

My friend had some fun, even if he was always it. 
Allegretto

Leyte and Samar Folk song Aurora Oliva Lumen (1968)

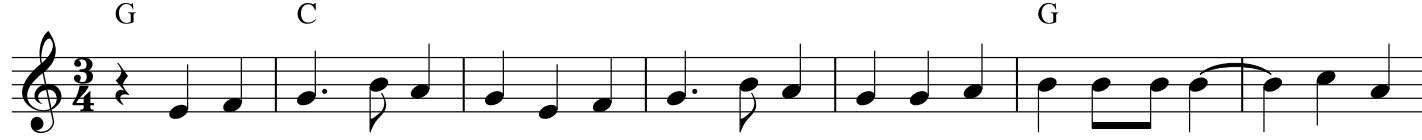

Lu-bi, lu - bi,lu - bi, lu-bi, lin - ko-ra - nay ay'gud la pag-sak-i kay hi-bu$\mathrm{G}^{7}$

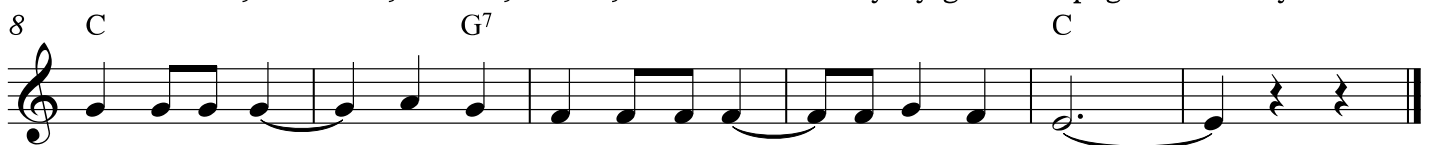

bu - a-yay, ay ay gud la pag-sak-i lu-bi, lu - bi.

\section{LUBI-LUBI (short version)}

Coconut palms

(Translation by Firie Jill T. Ramos)

Lubi, lubi, lubi, lubi linkoranany

Coconut palm, coconut palms, puny one

ay' gud la pagsak-i kay hibubuayay, ay' gud la pagsak-i lubi-lubi

Do not climb on this little one, shield the little coconut palm

\section{Burongkahay}

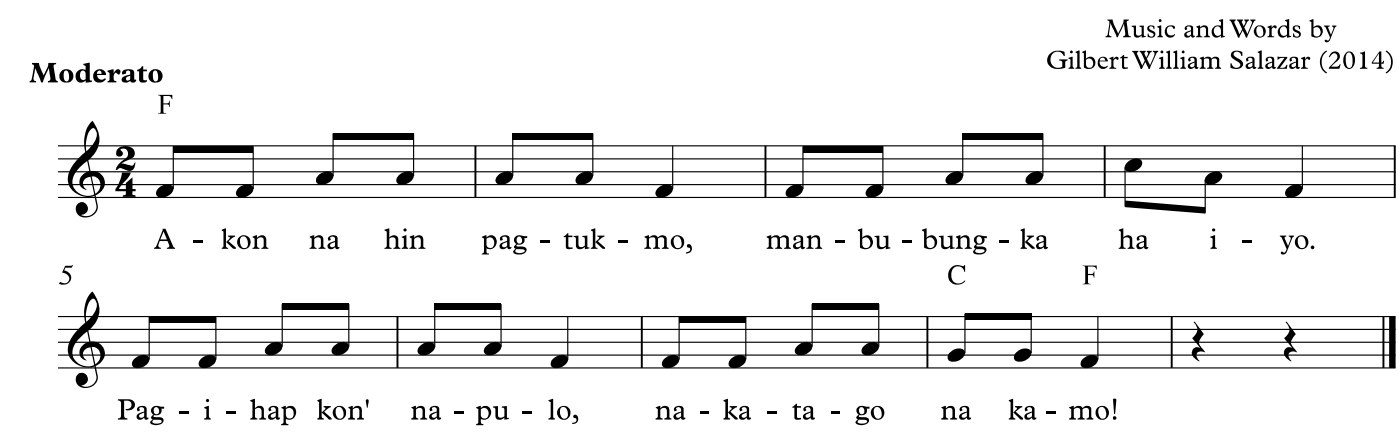

BURONGKAHAY

Hide and Seek

(Translation by Firie Jill T. Ramos)

Akon na hin pagtukmo, mabubungka ha iyo

Now it's my turn, I am it, and will seek for you

Pag-ihap kon' napulo, nakatago na kamo

When I'm done counting to ten, be off to your hiding places 


\section{Lukso}

Moderato

Aurora Oliva Lumen(1968)

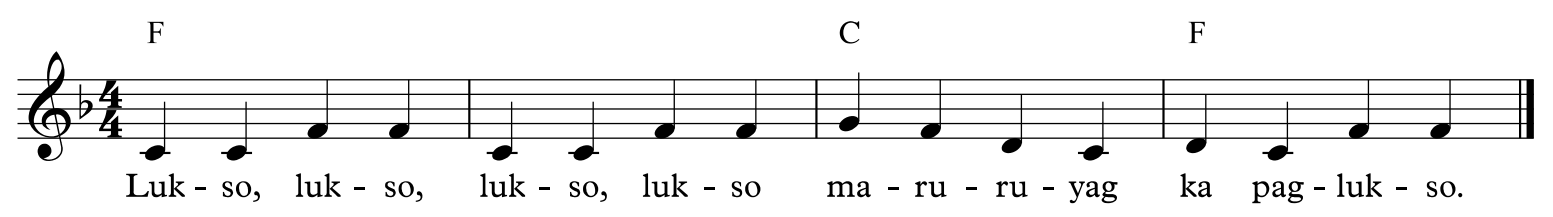

LUKSO

Jumping Game

(Translation by Firie Jill T. Ramos)

Lukso, lukso, lukso, lukso

Jump, jump, jump, jump,

Maruruyag ka paglukso

I bet you will fancy this jumping game

\section{Maupay naga Aga}

\section{Moderato}

Aurora Oliva Lumen (1968)

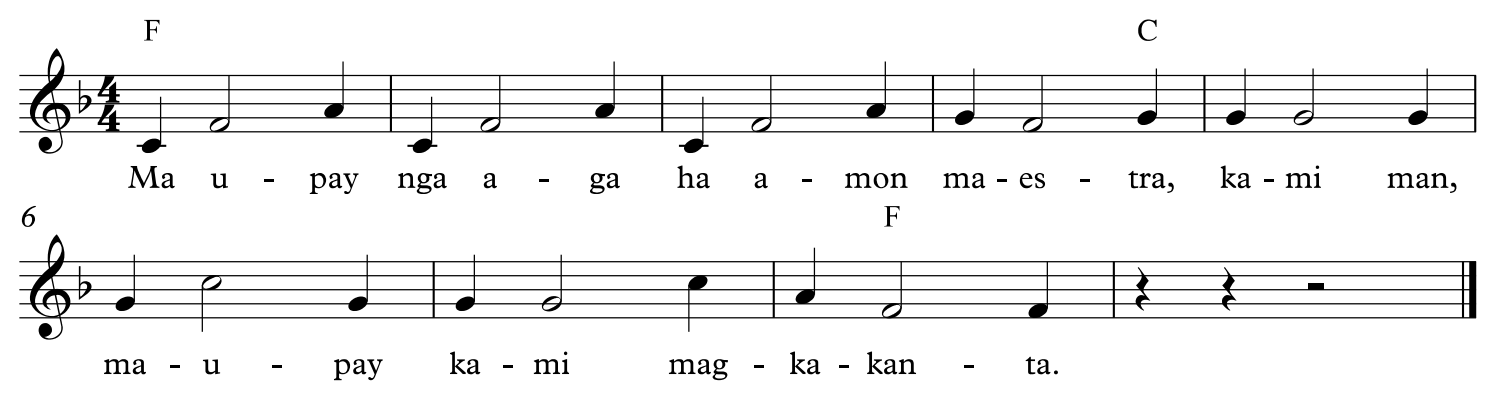

MAUPAY NGA AGA

Good Morning

(Translation by Firie Jill T. Ramos)

Maupay nga aga ha amon maestra

Teacher dear, we say good morning to you

Kami man maupay, kami magkakanta

We are well, so we will sing 


\section{Pagbakingking}

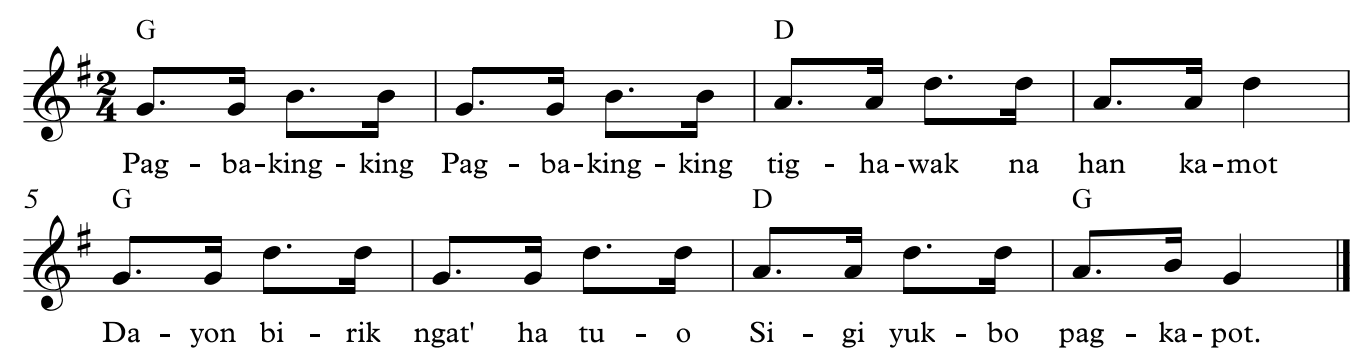

\section{PAGBAKING-KING}

Hopscotch

(Translation by Firie Jill T. Ramos)

Pagbaking-king, pagbaking-king

Hop hop hop, hop hop hop

Tighawak na han kamot, dayon birik ngat'ha tuo

Put your hands on your waist, turn to the right

Sigi yukbo pagkapot, sigi yukbo pagkapot

Bend to pick the lucky, bend to pick the lucky.

\section{Panhimsaw}

\section{Moderato}

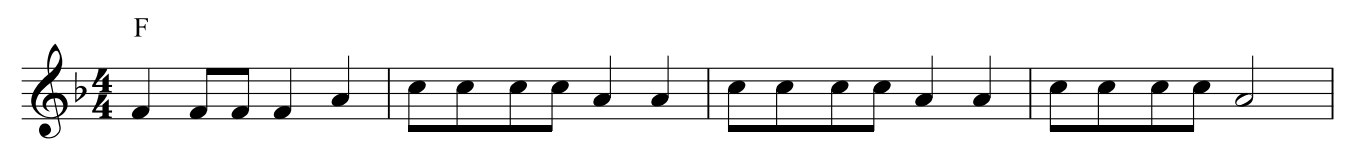

A - mo i-ni pag - hu-gas han ti-il, pag - hu-gas-han ti-il, pag - hu-gas han ti-il

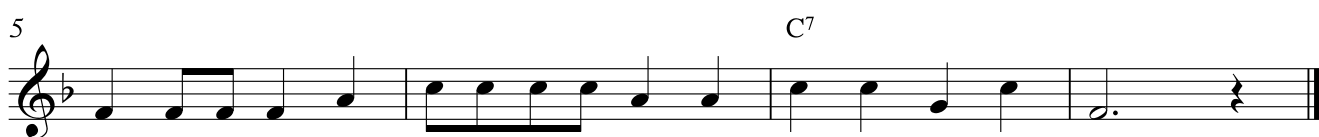

A - mo i - ni pag - hu-gas han ti - il ha a - ga pag - an - dam.

PANHIMSAW

Washing feet

(Translation by Firie Jill T. Ramos)

Amo ini paghugas han tiil, pag-hugas han tiil

This is the way I wash my feet, wash my feet

Amo ini pag-hugas han tiil ha aga pag-andam

This is the way to wash my feet and get ready in the morning 
Pagsayaw Kita

Moderato

P
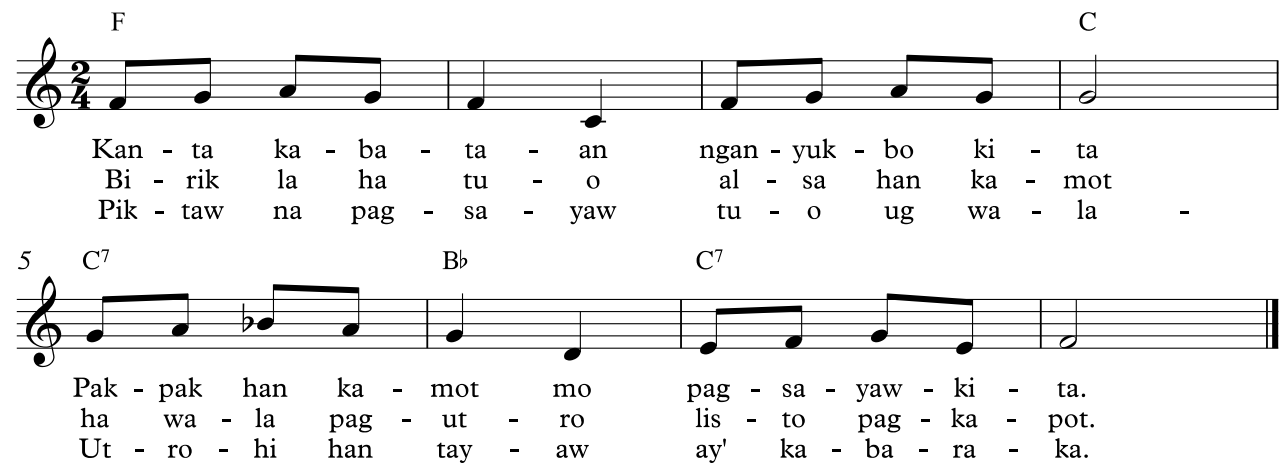

\section{PAGSAYAW KITA \\ Let's Dance}

(Translation by Firie Jill T. Ramos)

Kanta kabataan, ngan yukbo kita,

Let's sing kids! Sing, then bend,

Pakpak han kamot mo, pagsayaw kita

Clap your hands, let's dance

Birik la ha tuo, alsa han kamot,

Turn to the right and raise our hands,

Ha wala pag-utro, listo pagkapot

Then another turn to the left, be ready to hold hands

Piktaw na pagsayaw tuo ug wala, Utrohi han sayaw ay' kabaraka

Step to the left, step to the right, let's dance

Utrohi han sayaw ay' kabaraka

Just dance again, oh worry not! 
Moderato

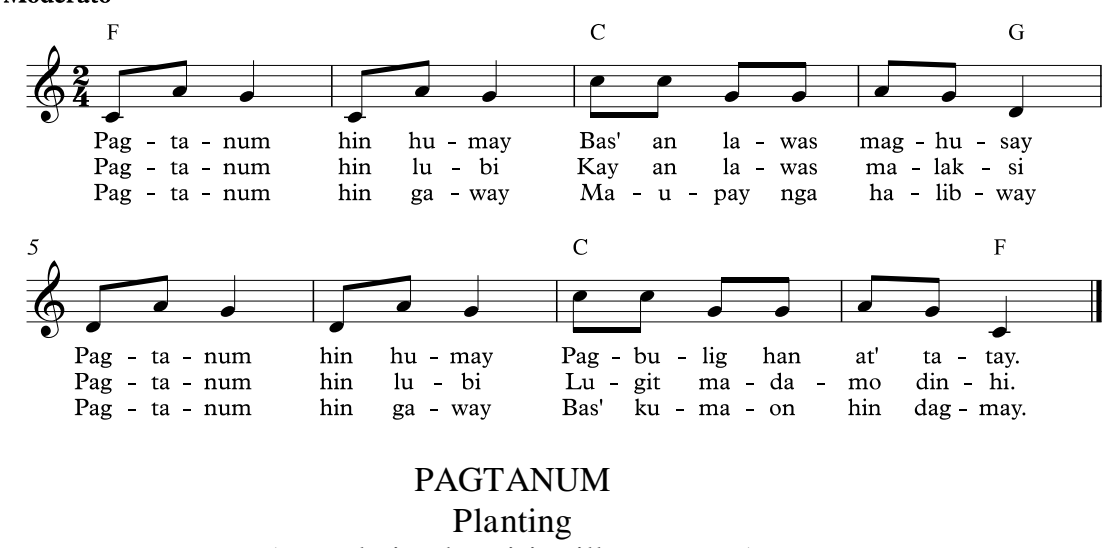

(Translation by Firie Jill T. Ramos)

Pagtanum hin humanay, bas' an lawas maghusay

Let's plant rice for good health

Pagtanum hin humay, pagbulig han at' tatay

Let's plan rice and help father

Pagtanum hin lubi kay an lawas malaksi

Let's us plant coconut palms so we'll be quick

Pagtanum hin lubi lugit madamo dinhi

Let's us plant coconut palms, so we'll have plenty of copra

Pagtanum hin gaway maupay nga halibway

Let's plant yam, it is good and easy

Pagtanum hin gaway bas' kumaon hin dagmay

Let's plant yam, then we'll eat dagmay

\section{Iklopon}

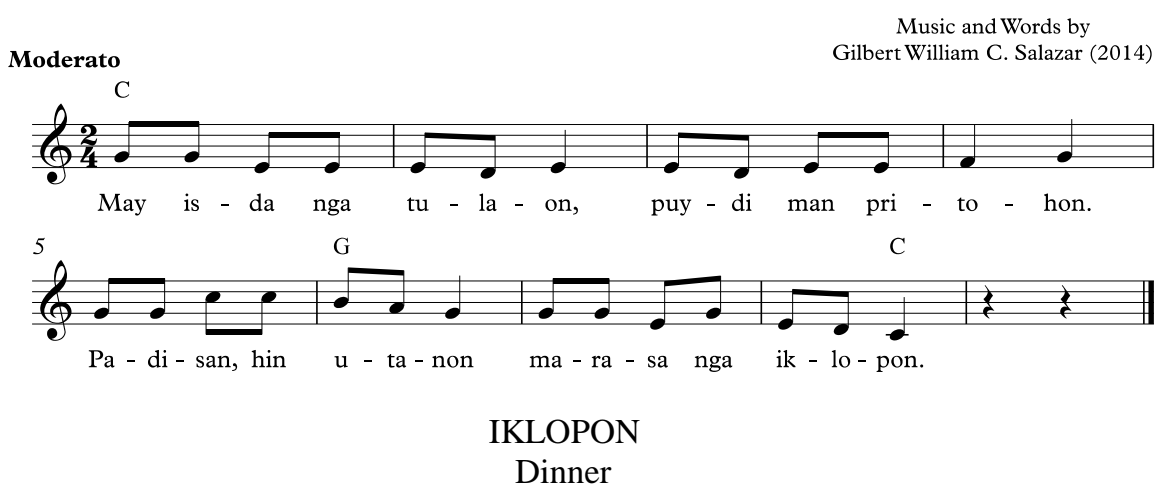

(Translation by Firie Jill T. Ramos)

May isda ng tulaon puydi man pritohon

We have fish that we can fry

Padisan hin utanon, marasa na iklopon.

To go with some greens, what a hearty dinner we hav 


\section{SONGS FOR GRADE II}

\section{An Bato}

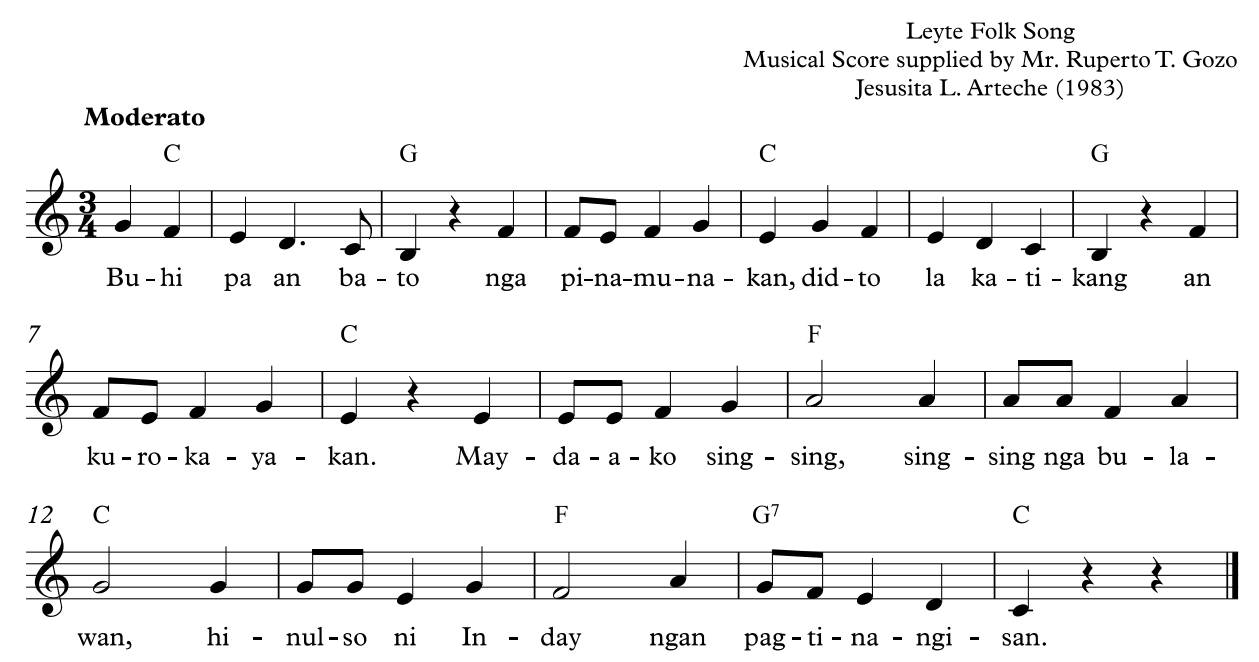

AN BATO

By the Rocks

(Translation by Firie Jill T. Ramos)

Buhi pa an bato nga pinamunakan

The rocks, where they do laundry, stands witness

Didto la katikang an kurokayakan.

This rumor started among those rocks.

Mayda ako sing-sing, sing-sing nga bulawan

I have a ring, a golden one

Hinulso ni Inday, ngan pagtinangisan

Inday, she took it off and washed it with rivers of tears 


\section{Ay, Ay Alibangbang}

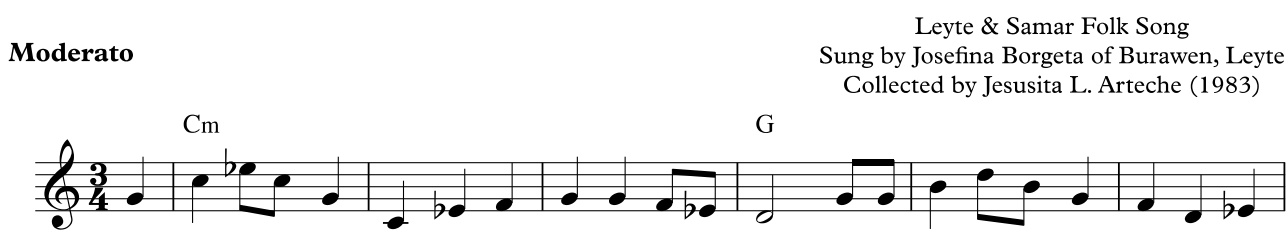

Ay, ay a-li-bang bang kon i - kaw in lu-mu-pad, pa-mi-ling hin-bu-kad nga sa-dang

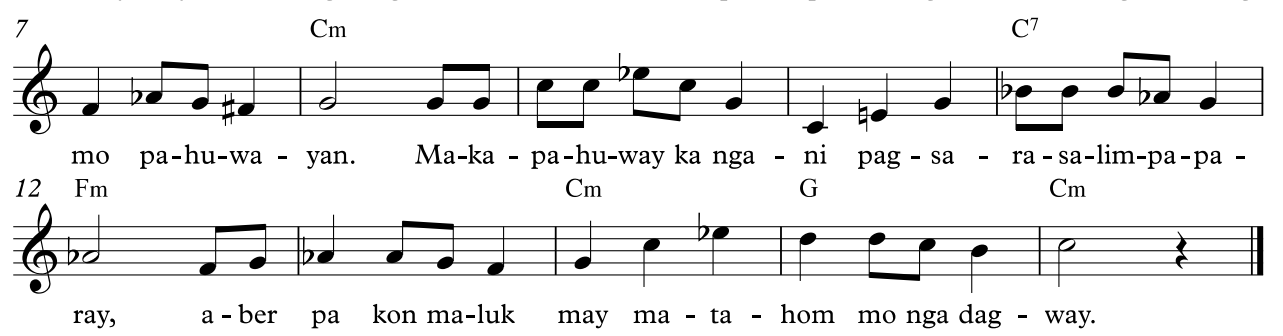

\section{AY AY ALIBANGBANG}

Ay! Ay! The Butterfly

(Translation by Firie Jill T. Ramos)

Ay, ay alibangbang kun ikaw in' lumupad Ay! Ay! butterfly should you choose to fly a way Pamiling hin bukad nga sadang mo pahuwayan

Remember to look for a flower to rest on

Makapahuway ka ngani pagsarusalimpaparay For when you've had your respite from all the frolicking

Aber pa kun malukmay matahom mo nga dagway

You'll see, no charm will work on your countenance 


\section{An Tugon Ni Nanay ngan ni Tatay}

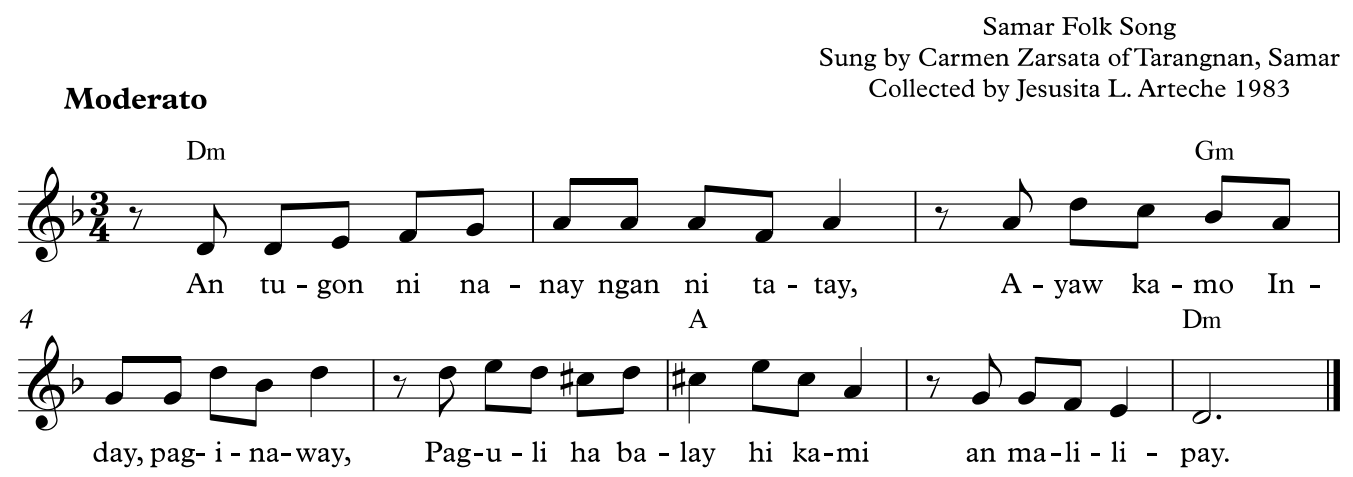

\section{AN TUGON NI NANAY NGAN TATAY \\ Mother and Father's Bidding \\ (Translation by Firie Jill T. Ramos)}

An tugon ni nanay ngan ni tatay, ayaw kamo Inday pag-inaway

Our parent's bidding goes, that we refrain from quarrelling

Pag-uli ha balay hi kami an maglilipay

for when they come home, such would please them.

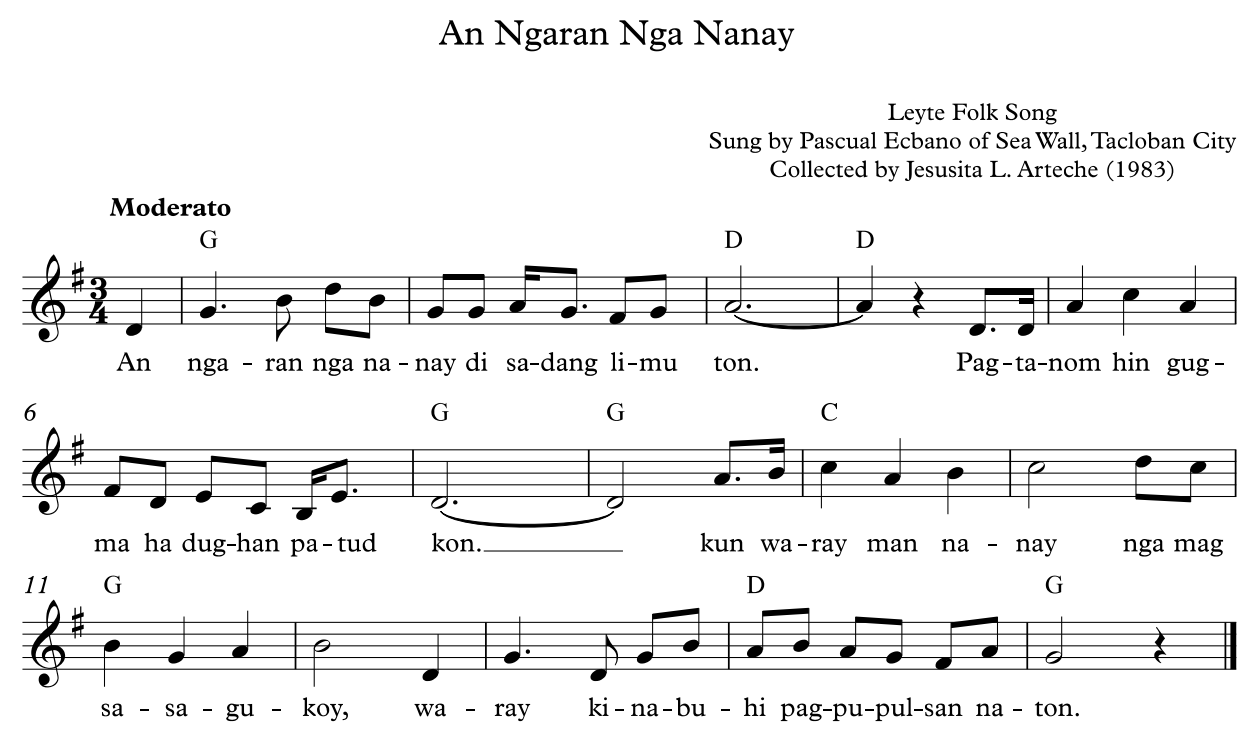




\section{AN NGARAN NGA NANAY}

The Name Mother

(Translation by Firie Jill T. Ramos)

An ngaran nga nanay di sadang limuton

The name mother should never be forgotten

Pagtanom hin gugma ha dughan patudkon.

Instead, cherish the love for her in one's heart.

Kun waray man nanay nga magsasagukoy

For if there are no mothers who shelter

Waray kinabuhi pagpulsan naton

There won't be life for us to live.

\section{An Tamsi Nga Tikbubulan}
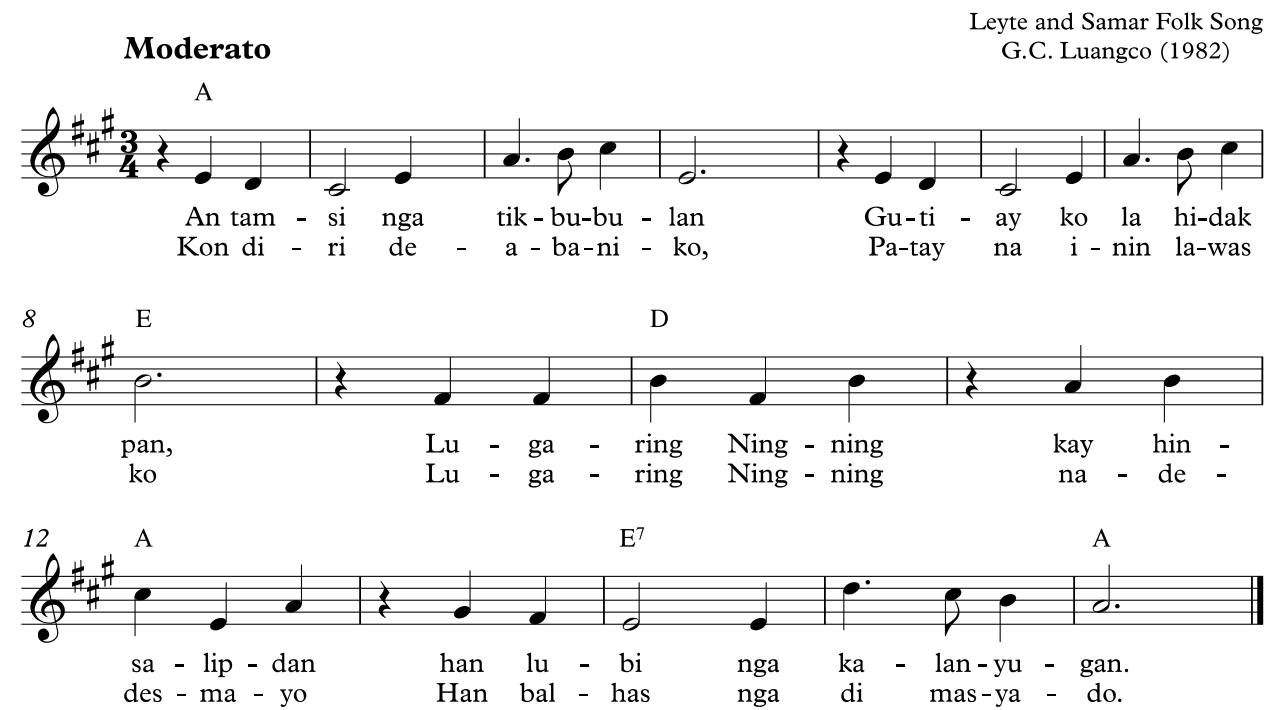

AN TAMSI NGA TIKBUBULAN

The Sparrow

(Translation by Firie Jill T. Ramos)

An tamsi nga tikbubulan, gutiay ko la hidakpan

That bird, the sparrow, I almost got him

Lugaring Ningning kay hinsalipdan, han lubi nga kalanyugan

But oh Ningning, how he took cover, behind the tallest coconut palms

Kun diri di abaniko, patay na inin lawas ko

Without these hand fans, I would have perished

Lugaring Ningning nadidismayo, han balhas nga di masyado

Because, Ningning, I feel faint, with the slightest trickling of sweat 
Hi Mano Palabyo

Leyte and Samar Folk Song Stephen Q. Lagarde (2004)

\section{Allegretto}

\section{can be fattngr song with:}

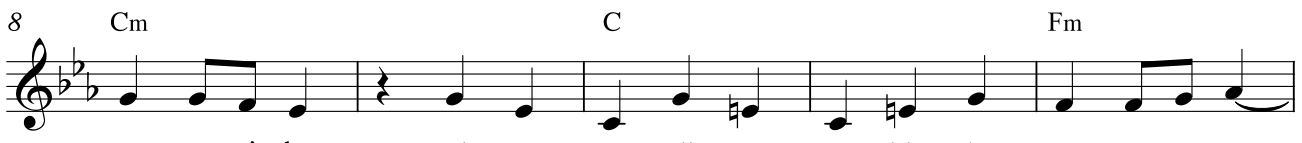

an man-ti - ka,

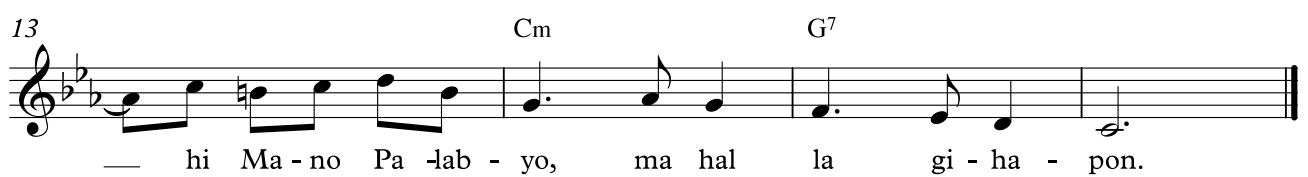

\section{HI MANO PALABYO}

Mister Palabyo

(Translation by Firie Jill T. Ramos)

Hi Mano Palabyo mahal magbaligya

Mister Palabyo's prices are outrageously high

Adobo sitsaron upod an mantika

Adobo, chicharon, and cooking oil

Pinapadisan pa hin luyat nga tarong

Along with those wretched eggplants

Hi mano palabyo, mahal la gihapon

Yet, Mister Palabyo's shop, remains expensive. 


\section{Dandansoy}

Leyte and Samar Folk Song

Musical Score supplied by Amparo M. Cinco-Tizon

Moderato
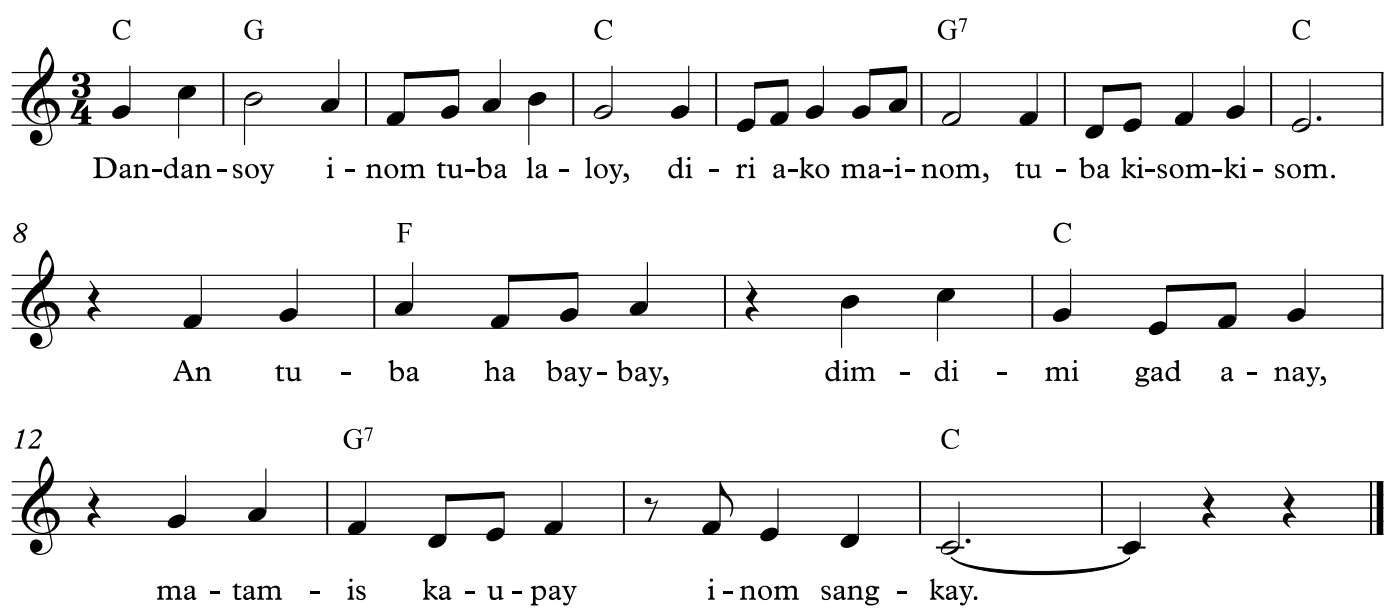

\section{DANDANSOY}

Dandansoy

(Translation by Firie Jill T. Ramos)

Dandansoy inom tuba laloy

Dandansoy, have a shot of tuba

Diri ako mainom, tuba kisom-kisom

No I wont's, lest it be sour

An tuba ha baybay dim-dimi gad anay

Oh this tuba is from Baybay, come have a sip

Matamis kaupay, inom sangkay

It's sweet and good, have a drink my friend. 
can be partner song with: Mano Palabyo
Ayaw Pagtangis

Samar Folk Song

Collected by Jesusita L. Arteche (1983)

\title{
Moderato
}

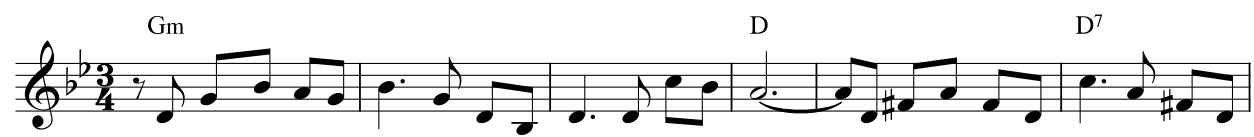

A-yaw pag-ti-na-ngis kay ka-nu-gon hit' im lu - ha

lu-ha mo ha ma - ta pa-na-lip

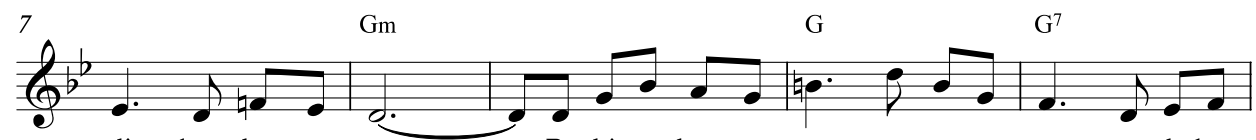

di kun daw mut - ya._ Pa-hi-ran han pan - yo, pan-yo nga may - a - da bur-

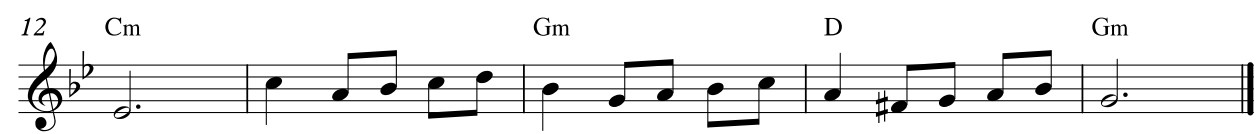

da

kay ba-si bu-ma - lik ad-ton gug-ma mo nga na-wa-wa - ra.

\author{
AYAW PAGTINANGIS \\ Cry No More \\ (Translation by Firie Jill T. Ramos)
}

Ayaw pagtinangis kay kanugon it im luha

Cry no more, don't waste your tears

Luha mo ha mata panalipdi kun daw mutya

Save your tears, as though they are treasures

Pahiran han panyo, panyo nga may ada burda

Pat them dry with this embroidered handkerchief

Kay basi bumalik adton gugma mo nga nawawara

That your lost love may find its way back to you 


\section{Hi Tokmo}

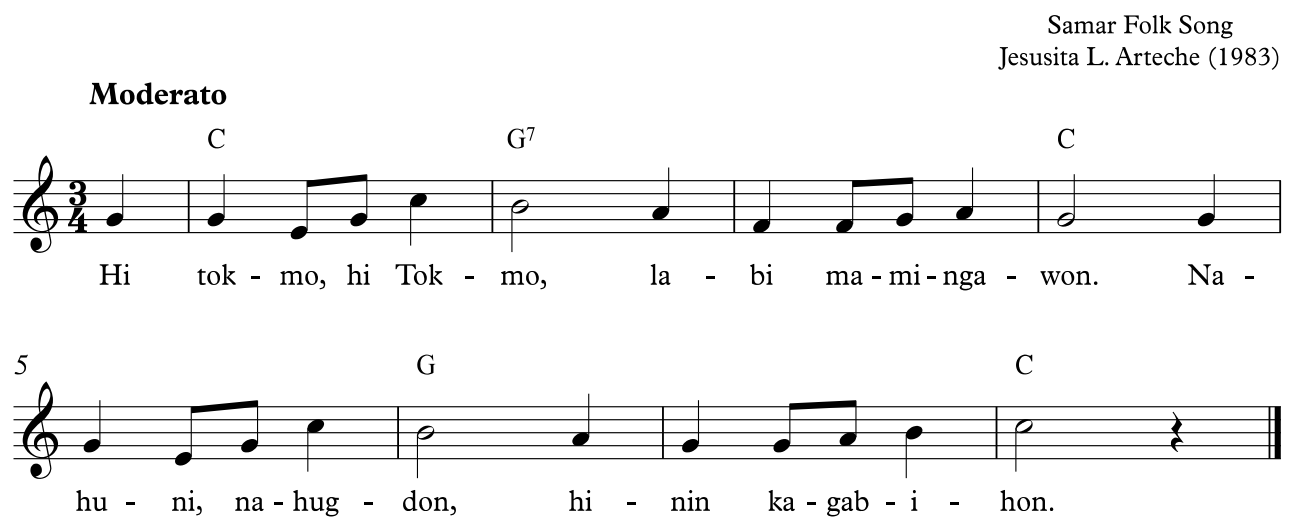

HI TOKMO

(Tokmo-a bird common in Samar)

(Translation of Jesusita L. Arteche)

Hi tokmo, hi tokmo labi mamingawon

This bird known as tokmo is quiet and tranquil

Nahuni, nahugdon, hinin kagab-ihopn

It sings every sun down and keeps flying as well

can be partner song

with: Mahamnt noa
Ring-ginding-ginding

Leyte Folk song

Aurora Oliva Lumen (1968)

Allegretto

$\mathrm{G}^{7}$
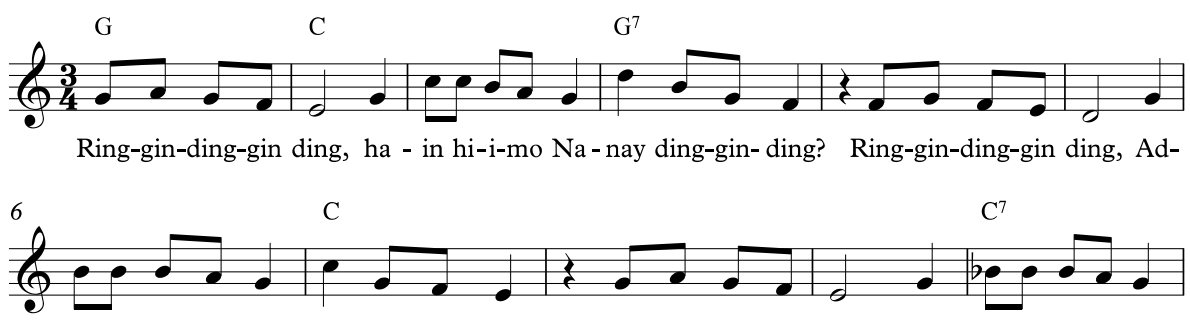

to na-nga-nga-mo - te, ring-ging-ding. Ring-gin-ding-gin ding, $\mathrm{Ha}$ - in hi-i-mo Ta -

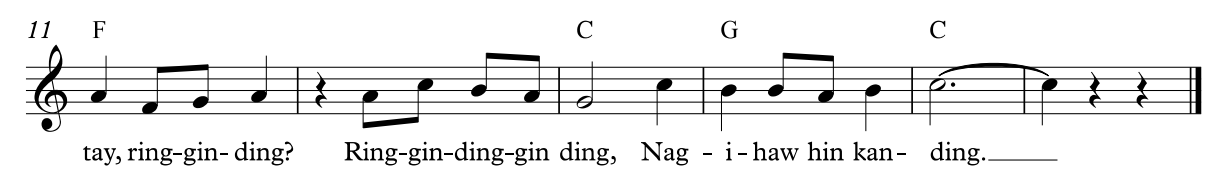




\section{RING-GINDING-GINDING \\ RING-GINDING-GINDING}

(Translation by Firie Jill T. Ramos)

Ring-ginding-ginding, hain hi imo nanay, ring-ginding

Ring-ginding-ginding where is thy mother, ring-ginding

Ring-ginding-ginding, adto nangangamote, ring-ginding

Ring-ginding-ginding, she's off to gather sweet potatoes, ring-ginding

Ring-ginding-ginding, hain hi imo tatay Ring-ginding

Ring-ginding-ginding where is thy father, ring-ginding

Ring-ginding-ginding, nag-ihaw hin kanding.

Ring-ginding-ginding, he is off to butcher a goat.

\section{Inday, Inday}

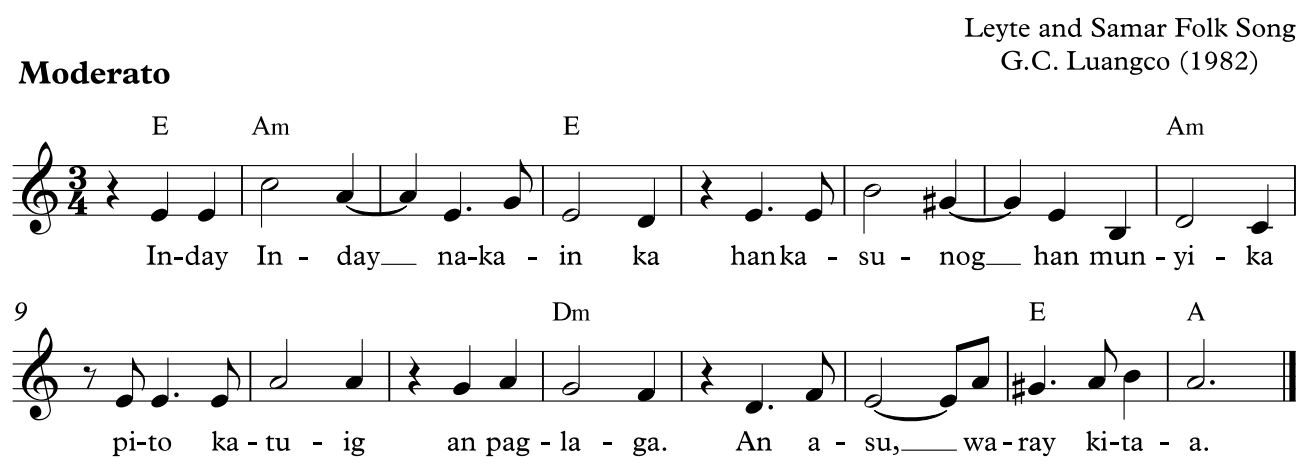

INDAY INDAY

Inday, Inday

(Translation by Firie Jill T. Ramos)

Inday, Inday nakain ka?

Inday Inday where were you?

Han kasunog han munyika

When the doll burned

Pito ka tuig an paglaga

'Twas in flames for seven years

An aso, waray kitaa

Yet, nobody saw the smokes from all the burning 
can be partner song with: Ringinding-gingding

\section{Mahamot nga Marol}

Leyte Folk Song

Sung by Rebecca Astorga of Barugo, Leyte Collected by Jesusita L. Arteche (1983)
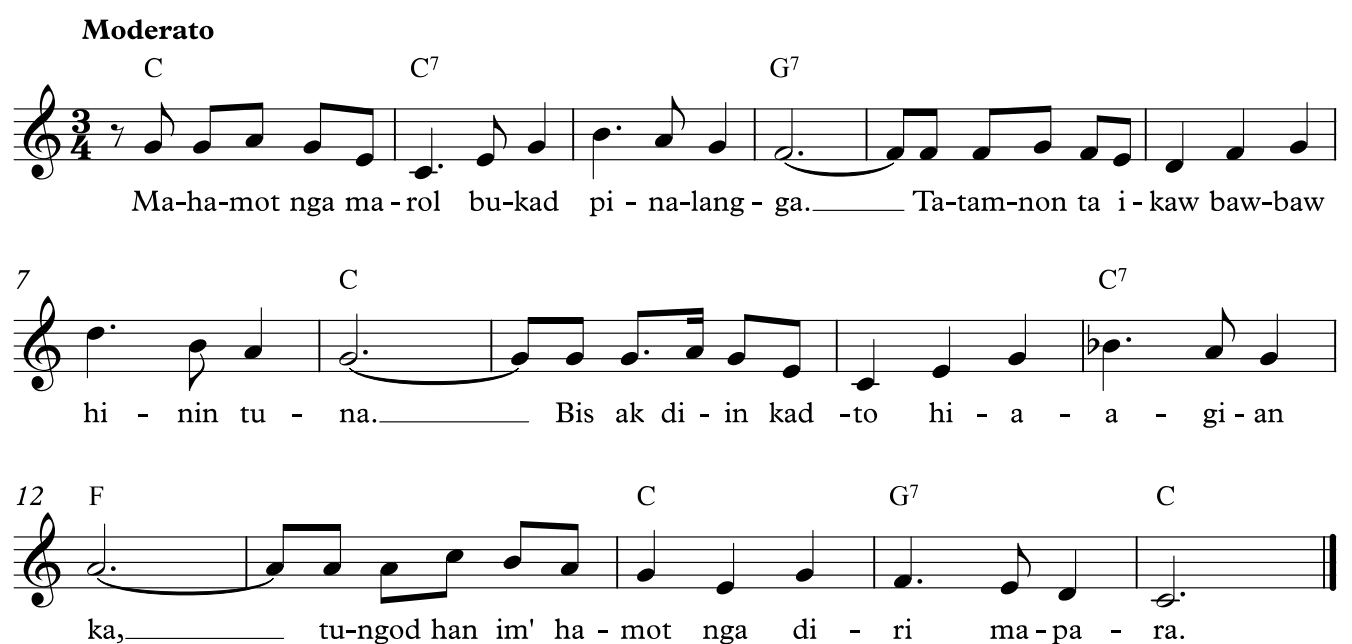

MAHAMOT NGA MAROL

Fragrant Flower

(Translation by Firie Jill T. Ramos)

Mahamot nga marol, bukad pinalangga

Fragrant flower, treasured blossom

Tatam'non ta ikaw baw-baw hinin tuna

I will plant you on this earth

Bis ak diin kadto hiaagian ka

Wherever I go, I will find my way to you

Tungod han im hamot nga diri mapara

Lead by your scent that won't ever fade 


\section{SONGS FOR GRADE III}

\section{An Kahoy Nga Lawaan}

Leyte and Samar Folk Song Sung by Soledad Tandinco of Tacloban City, Leyte

Moderato Collected by Jesusita L. Arteche (1983)

$\mathrm{Cm}$

$\mathrm{G}^{7}$

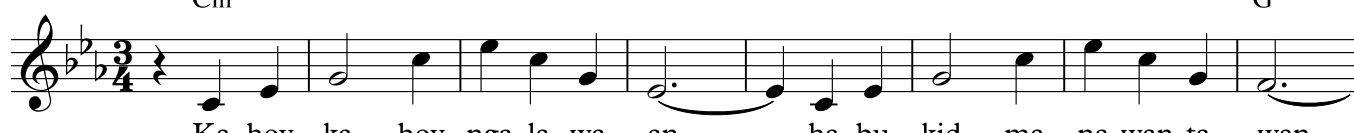

Ka-hoy, ka - hoy nga la-wa - an, ha, bu - kid

wan.

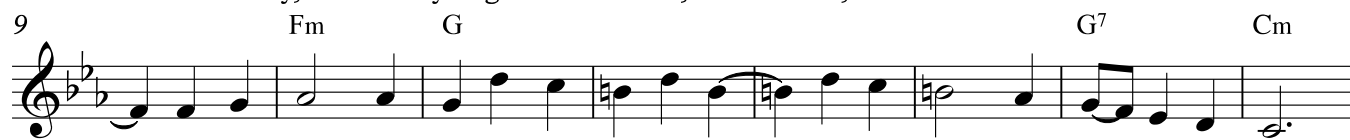

_ Kon ka - nan Dios ka pag-but-an, ay, ay__ ma-tu-pong ha u - la si man._

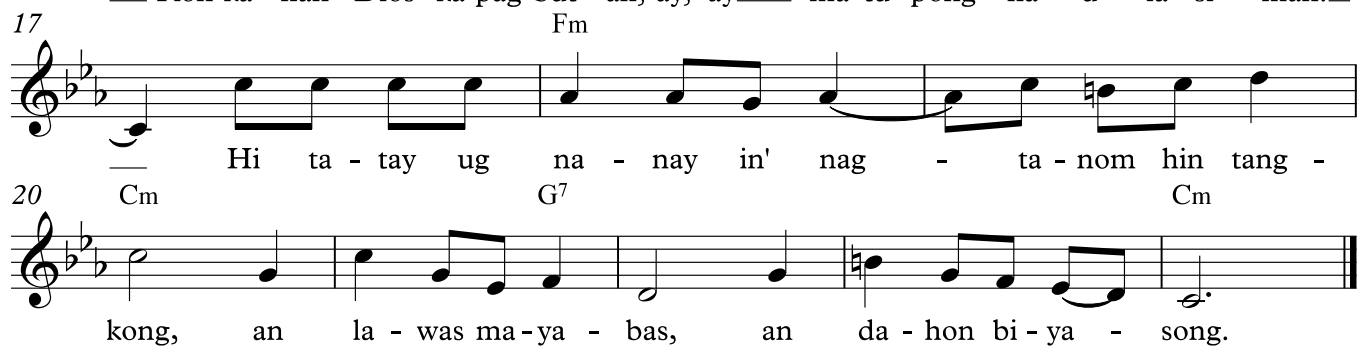

KAHOY NGA LAWAAN

The Hardwoord Lawaan

(Translation by Firie Jill T. Ramos)

Kahoy, kahoy nga Lawaan, ha bukid manawan-tawan

Oh majestic Lawaan tree, you stand mighty in the forest

Kun kanan Dyos ka pagbut'an ay, ay, matupong ha ulalasiman

But if the Lord wills it, you can be made as tall as the lowly weeds

Hi tatay ug nanay in' nagtanom hin kangkong

Father and mother planted kangkong

An lawas mayabas, an dahon biyasong

Its body is of guava, and the leaves are of lime 


\title{
An Labasero
}

Samar Folk Song

Taken from the book Samar Folk Dances by Juan C. Miel collected by Jesusita L. Arteche (1983)

\section{Moderato}

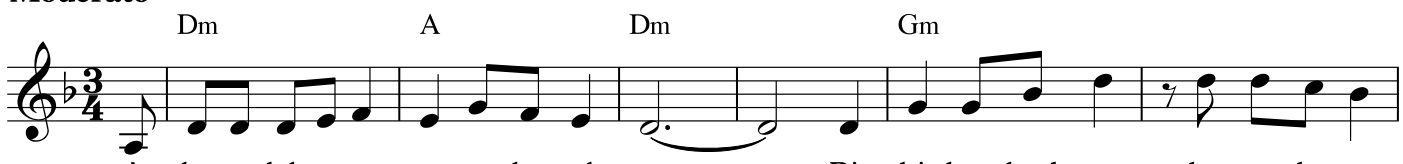

A - ko an lab-a-se - ro nga bu-rak- non.

Bit - bit han bud-yong hu-yop-hu-yo7

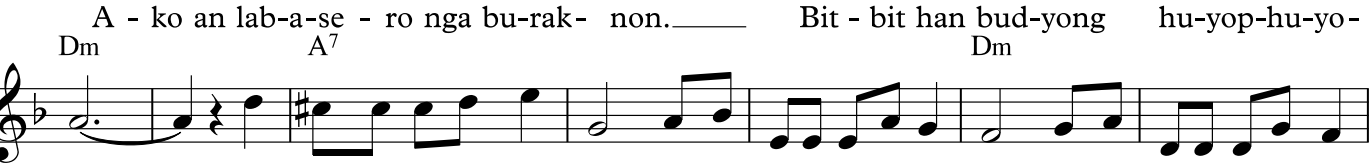

pon.__ Hu - Hop han a-kon bud yong, kay ba - si a-ko da-u - pon, kay ba - si di-re ka-but $\mathrm{Dm}$

$\mathrm{Bb}$ $\mathrm{F}$

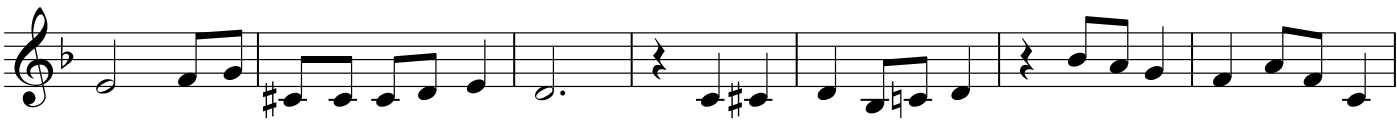

dan, han is - da nga li-ma-ba - san. C $\mathrm{Bb}$

$\mathrm{Ha}-\mathrm{la}$ F

na, ha-la na, $\mathrm{Bb}$

pa-lit a - nay hit is- da,

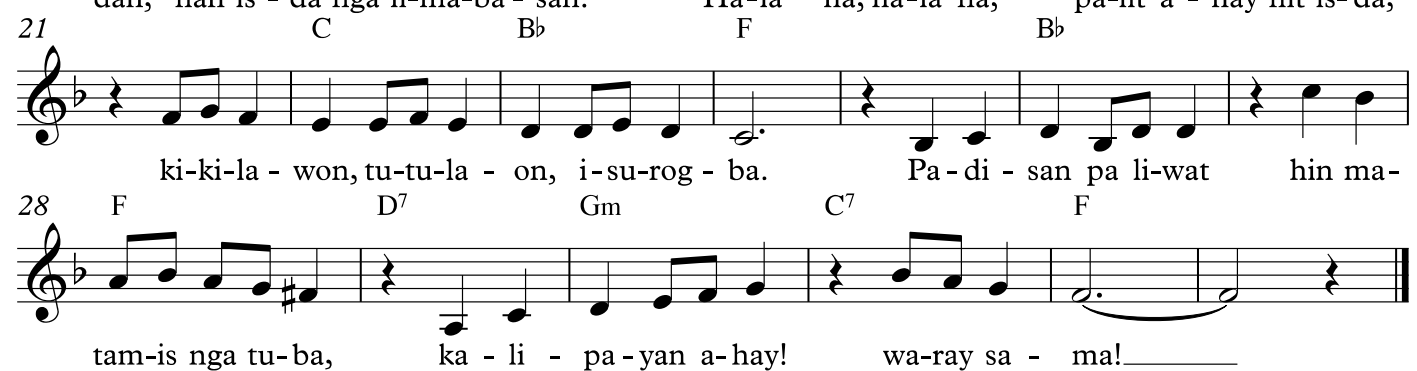

tam-is nga tu-ba,

ka - li - pa-yan a-hay!

wa-ray sa - ma

\author{
AN LABASERO \\ The Fishmonger \\ (Translation by Firie Jill T. Ramos)
}

Ako an labasero nga buraknon, bitbit an budyong, huyop-huyopon

I am the muddied fishmonger, I bring with me a conch shell, I blow on it

Huyop han akon budyong, kay basi ako daupon,

I blow to tell everyone, and call them to my fish

Kay basi diri ka butdan, han isda nga limabasa

My freshest fish I sell lest they go stale

Hala na, hala na, palit anay hin isda, kikilawon, tutulaon, isurogba

Come oh come, come and buy fish, they are best for kinilaw, soup, and for the grill

Padisan pa liwat hin matamis nga tuba, kalipayan ahay, waray sama

And down it with a glass of sweet tuba, such happiness beyond compare. 
An Lemon

Leyte and Samar Folk song

Musical score supplied by Amparo Ma. Cinco-Tizon Collected by Jesusita L. Arteche (1983)

Melodic ostinato by Gilbert William C. Salazar

Allegretto
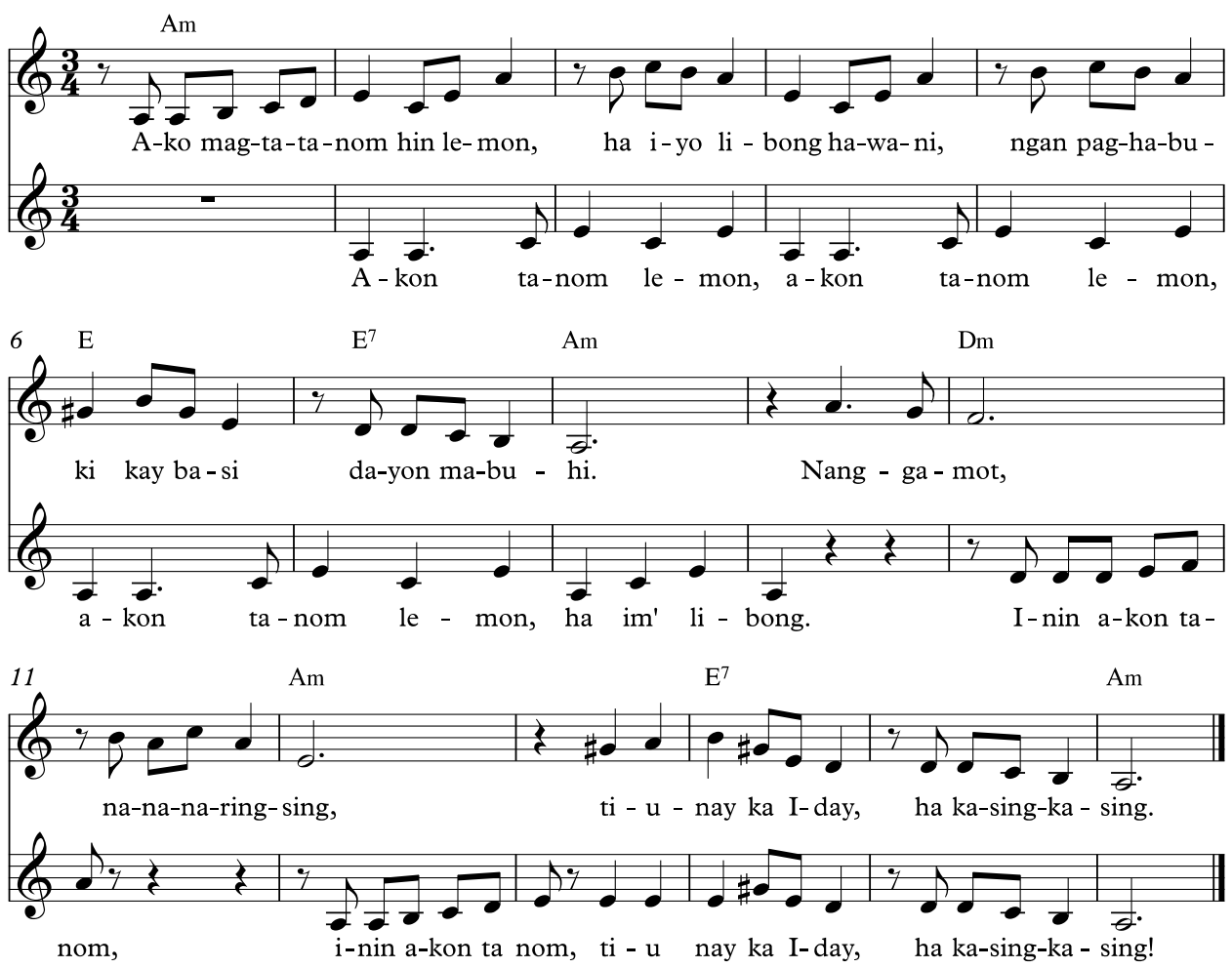

AN LEMON

The lemon

(Translation by Jesusita L. Arteche)

Ako magtatanon hin lemon, ha iyo libong hawani

I'll plant a lemon tree, there in your own yard, so you know

Ngan paghabuki kay basi dayon mabuhi

You clean the ground, soften the soil, that it may seen grow

Nanggamot, nananaringsing

Roots will sprout, then shoots will jut out

Tiupay ka iday ha kasing-kasing

You my love, is at heart, a thorn please don't doubt 
An Mananggiti
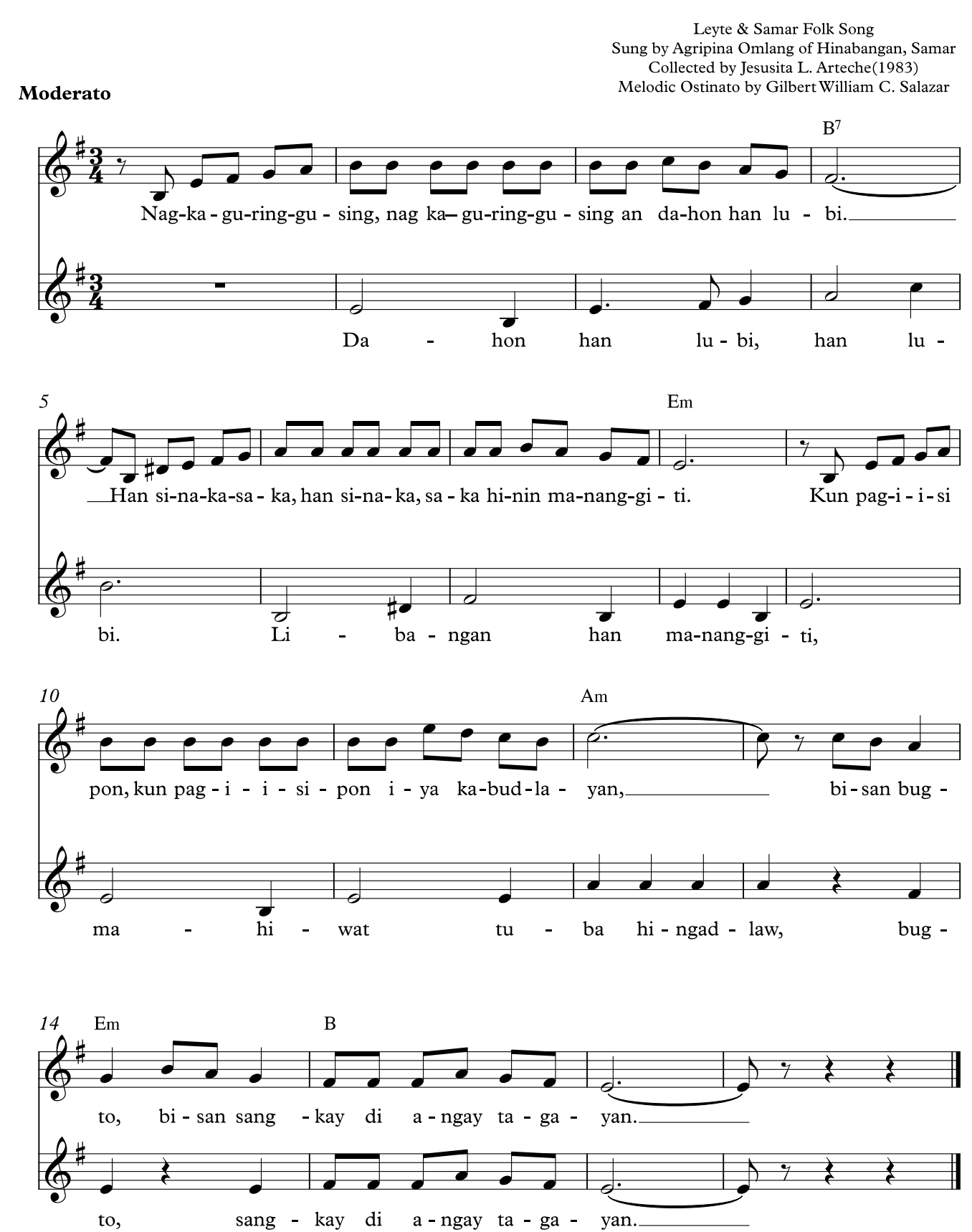
AN MANANGGITI

The Tuba-Gatherer

(Translation by Firie Jill T. Ramos)

Nagkaguring-gusing, nagkaguring-gusing an dahon han lubi

The leaves of the coconut palm are torn and frayed

Han sinakasaka, han sinaka-saka hinin mananggiti

Blame it on the tuba-gatherer, he climbs up and down this coconut palm, many a times

Kun pagdudumdumon, kun pagdudumdumon akon kabudlayan

If I should recall, if I should remember, my labors

Bisan bugto, bisan sangkay, di angay tagayan!

No kin, no friend deserves a drink!

\section{An Mga Isda}

\section{Moderato}
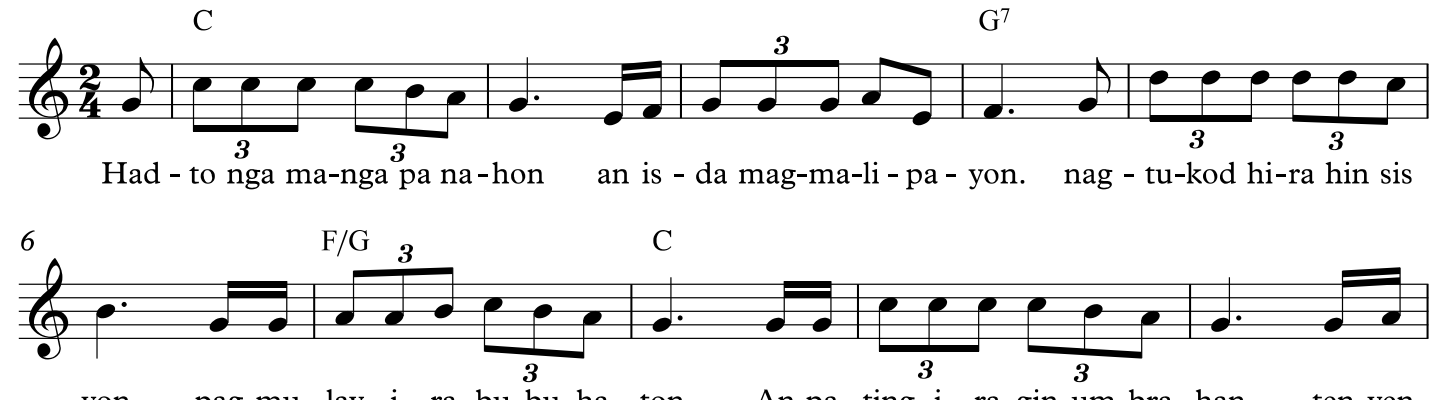

yon, pag mu-lay-i - ra bu-bu-ha-ton.

An pa-ting i - ra gin-um-bra-han, ten-yen

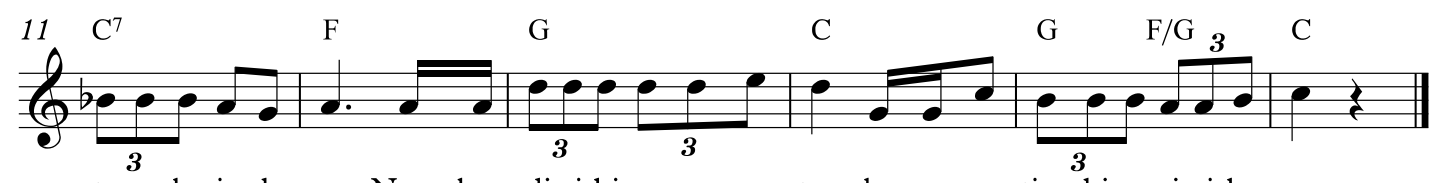

te an ka-is-da - an. Ngan kun di-ri hi-ya pag-sug-ton ka-nan pa-ting hi-ra si-si-ba-ron. 
An Mga Isda
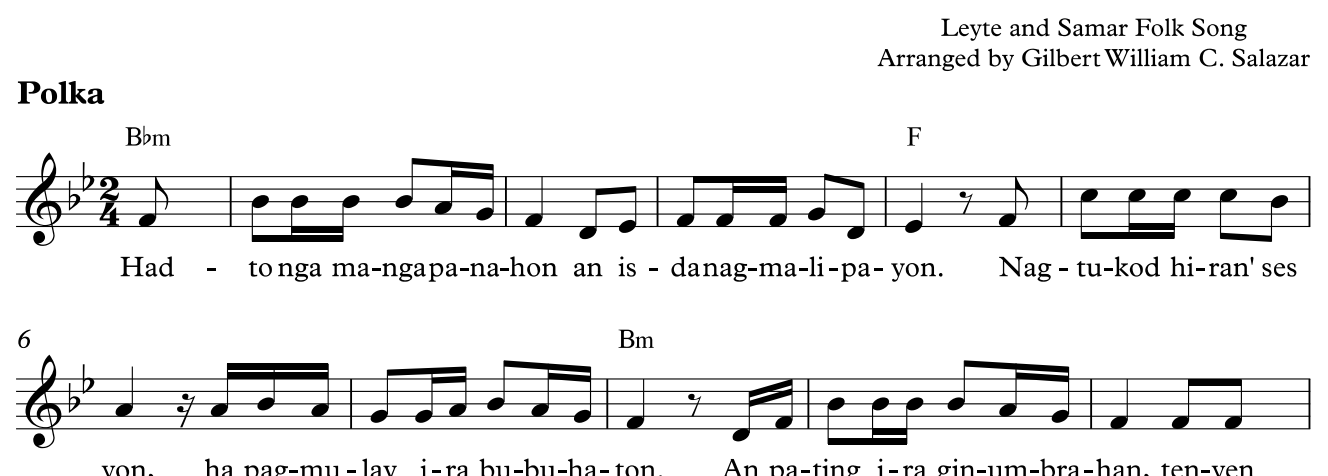

yon, ha pag-mu-lay i-ra bu-bu-ha-ton.

An pa-ting i-ra gin-um-bra-han, ten-yen

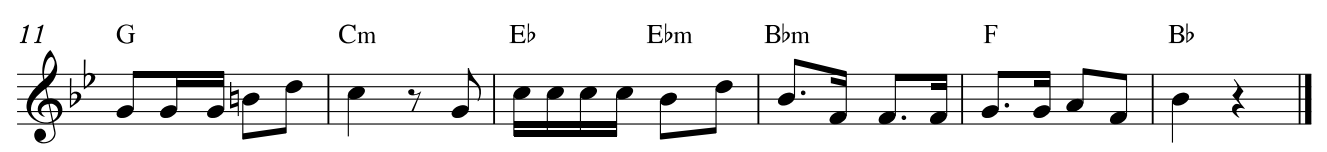

te han ka-is-da- an. Kun di-ri ni-ra pag-sun-don, ka-nan pa-ting si-si-ba-ron!

\author{
AN MGA ISDA \\ The Fishes \\ (Translation by Firie Jill T. Ramos)
}

Hadto nga mga panahon, an isda magmalipayon

In those days the fishes lived happy

Nagtugon hiran' sisyon, an pagmulay ira bubuhaton

They gathered together, and agreed to the games

An pating ira ginumbrahan, tenyente han kaisdaan

They appointed the sharks, king among fishes

Kun diri nira pagsundon kanan pating sisibaron.

Those who will not heed this pronouncement will be its prey. 


\section{Hira Nanay, Tatay}

Leyte Folk Song

Sung by Corazon Abarca of Abuyog, Leyte Collected by Jesusita L. Arteche (1983)

Moderato

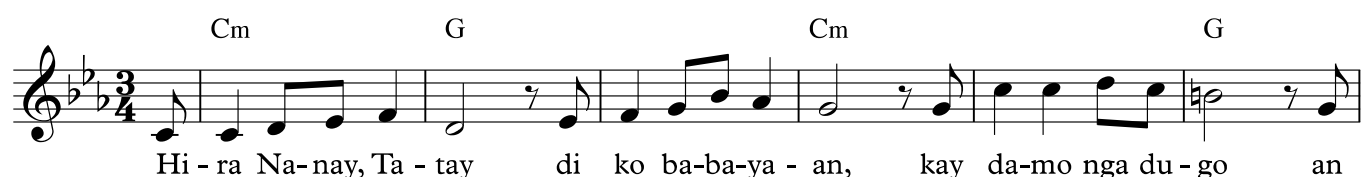

$\mathrm{Hi}$ - ra Na-nay, Ta - tay

di ko ba-ba-ya - an,

kay da-mo nga du-go

an

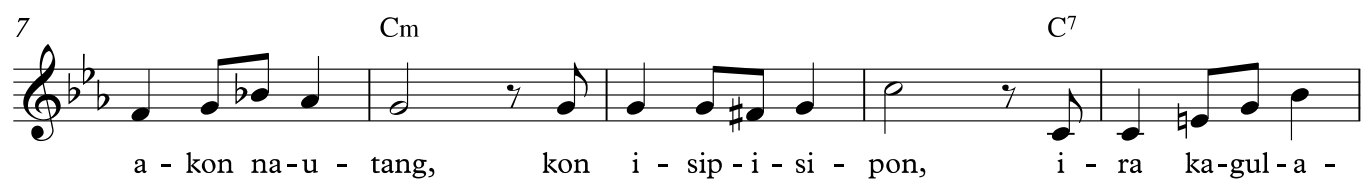

a - kon na-u - tang,

kon i $-\operatorname{sip}-\mathrm{i}-\mathrm{si}-$ pon,

$\mathrm{Cm}$

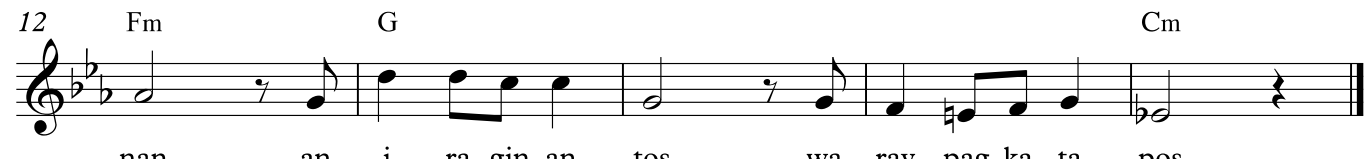

nan,

an i - ra gin-an - tos,

wa - ray pag-ka - ta - pos.

HIRA NANAY, TATAY

Father and Mother

(Translation by Firie Jill T. Ramos)

Hira nanay, tatay, di ko babayaan

I won't ever forsake Father and Mother

Kay damo nga dugo an akon nautang

For I owe them blood

Kon isip-isipon ira kagulanan

If one reflects on their labors

An ira ginantos, waray pagkatapos

The hardship they endured for me was without end 


\section{Ha Kan Inday}

Samar Folk Song

Sung by Paciencia Montances of Oras, Eastern Samar

Collected by Jesusita L. Arteche (1983)

\section{Moderato}

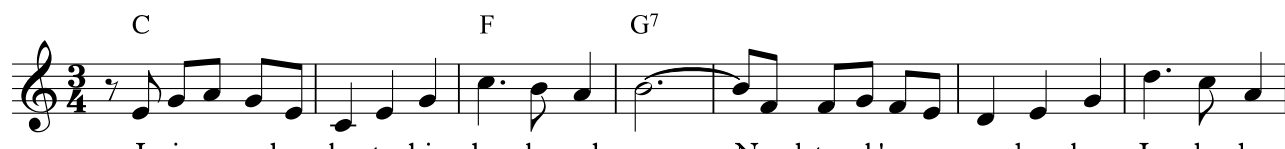

I-gin a-nod a-ko tu-big ha ka-sul- gan.__ Ngad-to ak' a nu-ran han kan In-day ha$8 \mathrm{C} \quad \mathrm{F}$

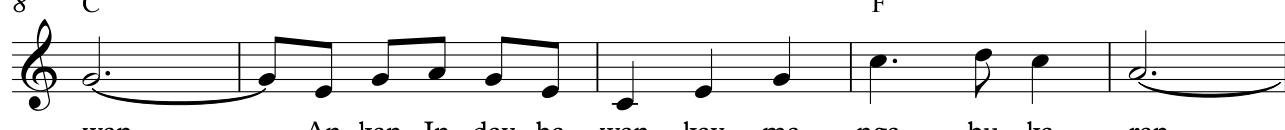

wan

An kan In-day ha - wan kay ma - nga

bu - ka - ran,

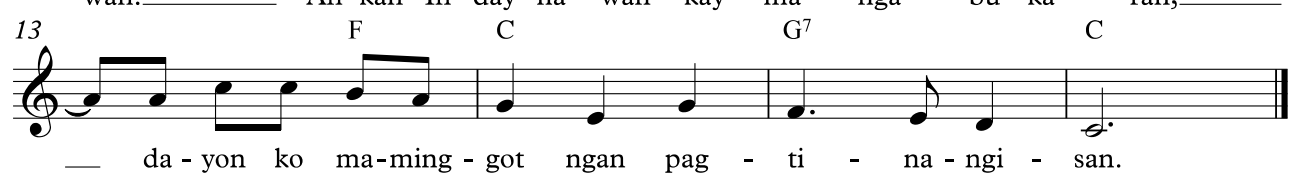

HA KAN INDAY

For you Inday

(Translation by Firie Jill T. Ramos)

Iganod ako tubig ha kasul'an,

Bring me oh river of pain

Ngadto ak anuran han kan Inday hawan

To the banks of Iday's clearing

An kan Inday hawan mga bukaran

Her garden teems with flowers

Dayon ko maminggot ngan pagtinangisan

There I will pick blossoms for me to cry on 


\section{Kamote Ragayray}

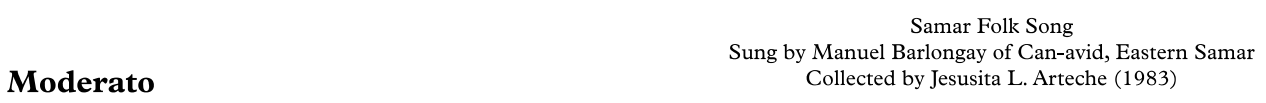

\section{Moderato}

Dm

$\mathrm{Gm}^{7}$
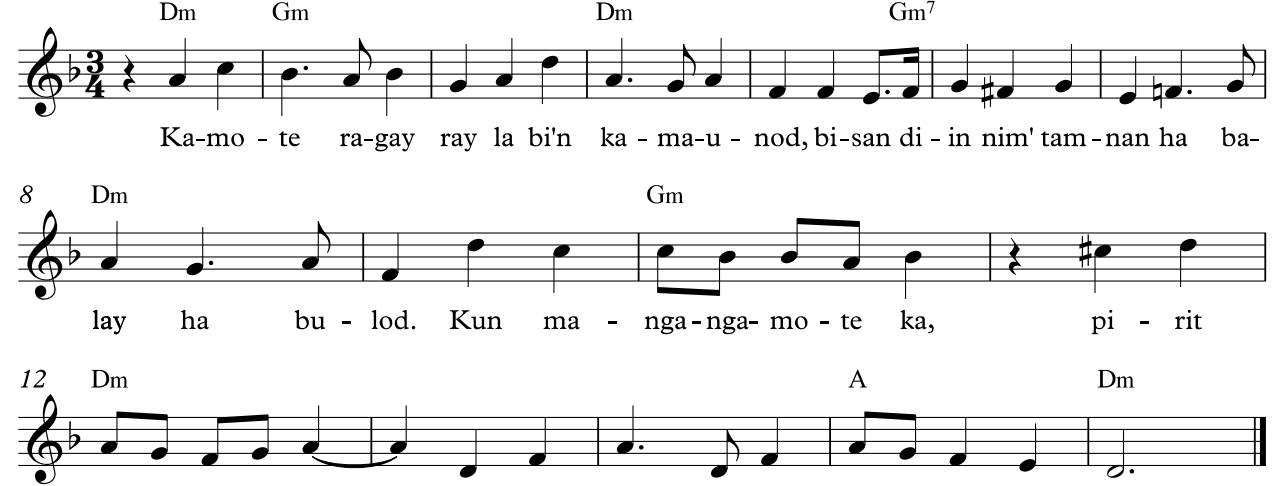

ka nga ma-lu- hod,__ pap - re - ho ka-dag - ko hit im tu - hod.

KAMOTE RAGAYRAY

Kamote, The Creeping Vine

(Translation by Firie Jill T. Ramos)

Kamote ragayray labin' kamaunod

Kamote, this creeper that yield such bounty

Bisan diin nim tamnan, ha balay, ha bulod

Wherever you're planted, be it at home or at the hillocks

Kun mangangamote ka, pirit ka nga maluhod

When they go to harvest, they have to get down on their knees

Papreho kadago hit im tuhod.

to dig you out, who is as big as their knees 


\section{Kuradang}

Samar Folk Song

Music Score taken from the book

"Samar Folk Dances" by Juan C. Miel

Moderato From the dissertation of Jesusita L. Arteche

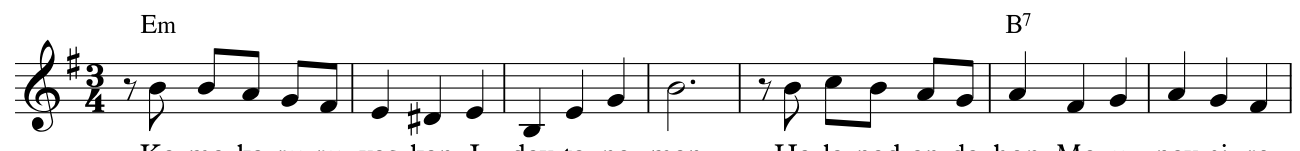

Ka-ma-ka-ru-ru-yag kan I - day ta-na-man. Ha-la-pad an da-hon. Ma-u - pay si-ro-
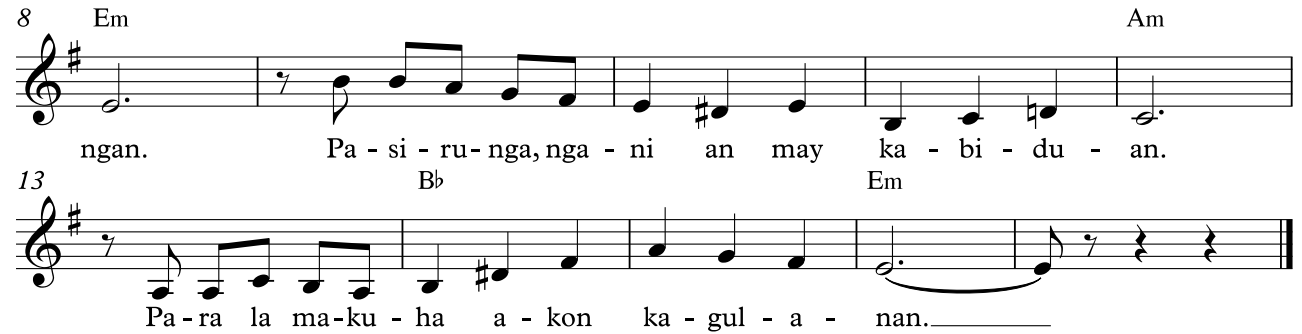

KURADANG

Kuradang, A Dance

(Translation by Firie Jill T. Ramos)

Kamakaruruyag kan Iday tanaman.

How beautiful are the plants in Iday's orchard

Halapad an dahon maupay sirongan

The leaves are so wide one can shelter

Pasironga ngani an may kabiduan

Pray, let this sad heart stand under one leaf

Para la makuha akon kagulanan

To cure this heaviness I feel 
Pinalangga ko ikaw

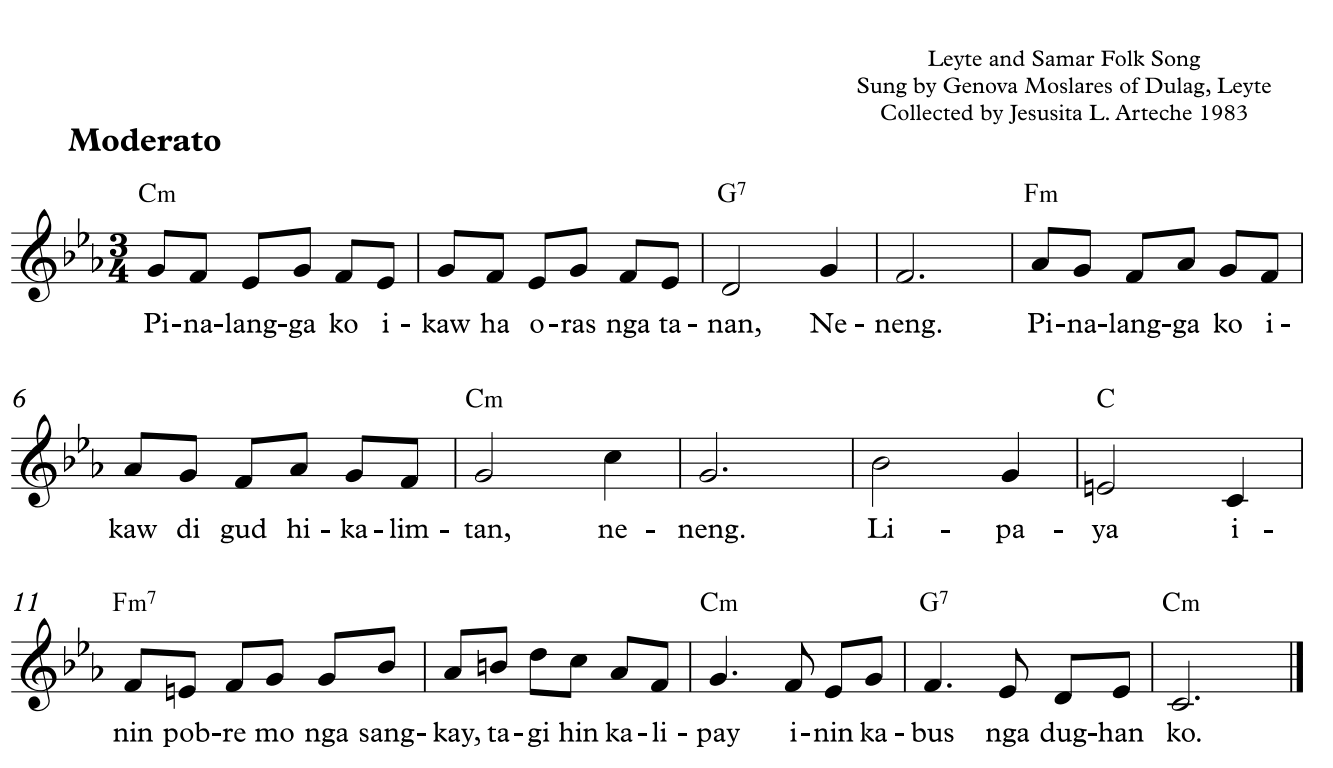

\section{PINALANGGA KO IKAW}

(Translation by Firie Jill T. Ramos)

Pinalangga ko ikaw ha oras nga tanan Neneng

I cherish you for all the days Neneng

Pinalangga ko ikaw, di gud hikalimtan Neneng

I cherish you, Neneng you won't ever be forgotten

Lipaya inin pobre mo nga sangkay

Gift me with happiness, this hapless friend of yours

Tagi hin kalipay inin kabus nga dughan ko

Drop a dose of joy, to this dry and barren heart 
Maupay Nga Pasko

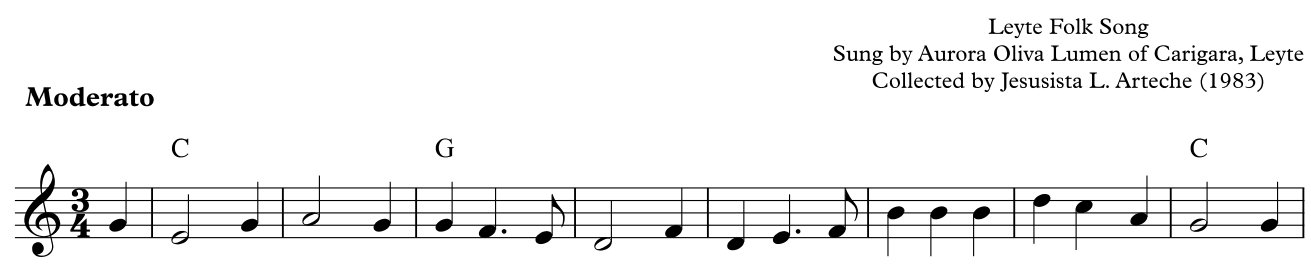

Ma- u - pay nga pas - ko tag ba-lay. Na-kan-hi ka-mi ha i - yo pag-li pay. Di-

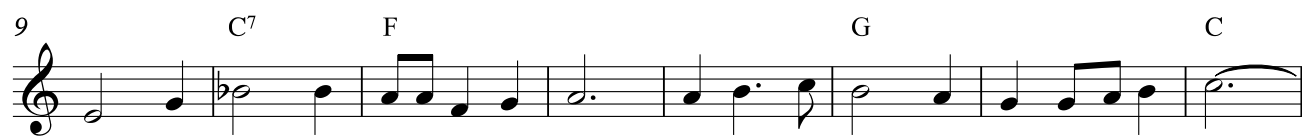

ri ni - yo ka - mi i-ka-bud-lay.

An pag - ha-pit na-mon ma-da-li - ay

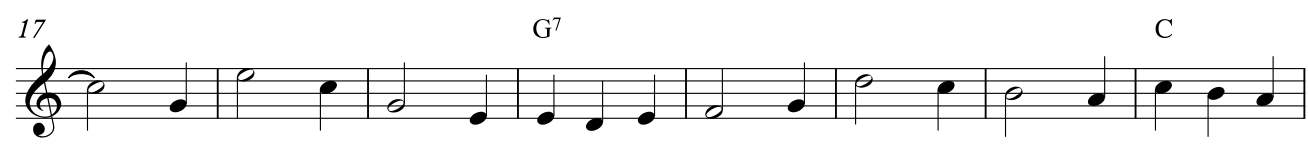

- A - mon lu - ga - ring pag-hi-num dom, had-ton tu - ig nga ma-nga u -

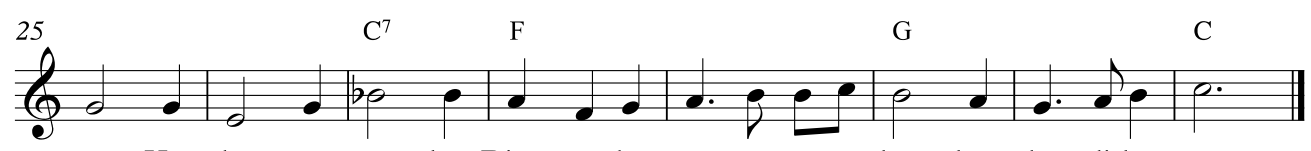

na. Han ka - ta - wo han Diyos nga ba - ta, ma-nu-nu-bos han ka - li-bu - tan.

\author{
MAUPAY NGA PASKO \\ Merry Christmas \\ (Translation by Firie Jill T. Ramos)
}

Maupay nga pasko tagbalay, nakanhi kami ha iyo paglipay

Merry Christmas dear homeowner, we come to wish you joy

Diri kami ikabudlay, an paghapit namon madaliay

I hope our brief stopover won't be such a bother

Amon lugaring paghinumdom, hadton tuig nga mga una

We only seek to rekindle that which happened eons ago

Han katawo han Dyos nga bata, manunubos han kalibutan

The birth of the Holy Child, the Savior of the world 


\section{APPENDIX E}

\section{Categorized Waray-Waray Songs for the Grades One to Three MTB-MLE Music Classes via 3ns Corpora Project Software}

Table 9. 3NS level of language appropriateness of songs for Grade One

\begin{tabular}{|l|c|}
\hline \multicolumn{1}{|c|}{ Grade One Songs } & Grade Level \\
\hline 1. Hardin & 2 \\
\hline 2. Langoy & 2 \\
\hline 3. Lubi-lubi (short ver.) & 3 \\
\hline 4. Burongkahay & 4 \\
\hline 5. Lukso & 5 \\
\hline 6. Maupay Nga Aga & 2 \\
\hline 7. Pagbakingking & 4 \\
\hline 8. Paghugas & 2 \\
\hline 9. Pagsayaw Kita & 4 \\
\hline 10. Pagtanum & 4 \\
\hline 11. Iklopon & 4 \\
\hline 12. Syomoy & 6 \\
\hline
\end{tabular}

Table 10. 3NS level of language appropriateness of songs for Grade Two

\begin{tabular}{|l|c|}
\hline \multicolumn{1}{|c|}{ Grade Two Songs } & Grade Level \\
\hline 1. An Bato & 3 \\
\hline 2. Ay Ay Alibangbang & 2 \\
\hline 3. An tungon ni nanay ngan Tatay & 3 \\
\hline 4. An Ngaran Nga nanay & 3 \\
\hline 5. An Tamsi nga tikbubulan & 4 \\
\hline 6. Hi Mano Palabyo & 3 \\
\hline 7. Dandasoy & 3 \\
\hline 8. Ayaw Pagtinangis & 3 \\
\hline 9. Hi tokmo & 5 \\
\hline 10. Ringinding 11. Inday-Inday & 3 \\
\hline 12. Mahamot nga marol & 2 \\
\hline
\end{tabular}

Table 11.3NS level of language appropriateness of songs for Grade Three

\begin{tabular}{|l|c|}
\hline \multicolumn{1}{|c|}{ Grade Three Songs } & Grade Level \\
\hline An Kahoy nga lawaan & 3 \\
\hline An Labasero & 4 \\
\hline An Lemon & 4 \\
\hline An Mananggiti & 3 \\
\hline An mga Isda & 6 \\
\hline Hira Nanay Tatay & 3 \\
\hline Ha Kan Inday & 4 \\
\hline Kamote Ragayray & 4 \\
\hline Kuradang & 4 \\
\hline Pinalangga Ko ikaw & 2 \\
\hline Lubi-lubi (with ostinato) & 5 \\
\hline Maupay nga pasko & 3 \\
\hline
\end{tabular}

